Florida International University FIU Digital Commons

\title{
Identification and Phenotypic Plasticity of Metastatic Cells in a Mouse Model of Melanoma
}

Xiaoshuang Li

liali0721@gmail.com

DOI: $10.25148 /$ etd.FIDC001923

Follow this and additional works at: https://digitalcommons.fiu.edu/etd

Part of the Biology Commons, $\underline{\text { Cancer Biology Commons, and the Skin and Connective Tissue }}$ Diseases Commons

\section{Recommended Citation}

Li, Xiaoshuang, "Identification and Phenotypic Plasticity of Metastatic Cells in a Mouse Model of Melanoma" (2017). FIU Electronic Theses and Dissertations. 3472.

https://digitalcommons.fiu.edu/etd/3472 


\title{
FLORIDA INTERNATIONAL UNIVERSITY
}

\author{
Miami, Florida
}

IDENTIFICATION AND PHENOTYPIC PLASTICITY OF METASTATIC CELLS

IN A MOUSE MODEL OF MELANOMA

A dissertation submitted in partial fulfillment of

the requirements for the degree of

DOCTOR OF PHILOSOPHY

in

BIOLOGY

by

Xiaoshuang Li 
To: Dean Michael R. Heithaus

College of Arts, Sciences and Education

This dissertation, written by Xiaoshuang $\mathrm{Li}$, and entitled Identification and Phenotypic Plasticity of Metastatic Cells in a Mouse Model of Melanoma, having been approved in respect to style and intellectual content, is referred to you for judgment.

We have read this dissertation and recommend that it be approved.

$\begin{array}{r}\hline \text { Manuel A Barbieri } \\ \hline \text { Xiaotang Wang } \\ \hline \text { Zhao-Jun Liu }\end{array}$

Fernando G Noriega

Lidia Kos, Major Professor

Date of Defense: June 16, 2017

The dissertation of Xiaoshuang Li is approved.

Dean Michael R. Heithaus

College of Arts, Sciences and Education

Andrés G. Gil

Vice President for Research and Economic Development and Dean of the University Graduate School

Florida International University, 2017 


\section{DEDICATION}

I dedicate this dissertation to my family for their support and to my advisor Dr. Lidia Kos who helped me in all things great and small. 


\section{ACKNOWLEDGMENTS}

I would like to express my heartfelt thanks to my major advisor Dr. Lidia Kos, who gave me the opportunity to join her lab as a graduate student. Thank you for always believing in me, for all the encouragement you gave me when all the unforeseen difficulties and obstacles emerged, for the ideas and freedom to pursue my own instinct to get this dissertation completed. Dr. Kos is such a great advisor not only in the academic aspect, but also in all aspects about my life. As an international student, I would not have been able to have a happy family in the United States without her support and help. Whenever I look at my lovely daughter, Jianna, I am so grateful that I had her as my advisor. I also would like to thank her for all the help she provided to my husband, Jingan. Without the time and efforts she devoted to us, I could not envision a bright future for our family. I am so fortunate to have had Dr. Kos as my mentor, especially in a country that I have never been to. Thank you!

I would also like to thank all my family for their love and support. I would like to thank my family in China, my mother, my father, my sister, who always show their trust in me believing I am the best and I can do all the things I want to. I would like to give my special thanks to my husband, Jingan Qu, for listening to me talk about my research, even though it is a total different field from what he does, for taking care of our daughter Jianna Qu when I had to work super late, for encouraging me, and for being there with me through all the difficult times. I

would also like to say thank you to my lovely daughter, Jianna Qu. She is such a 
sweet girl that she never complained about me working late. I would like to thank her for her forever smiling face especially when I was down about the research.

I would like to thank all the Kos lab members, both past and present. Thanks to Ana Paula Benaduce, Nikeisha Chin, Amy Saldana Tavares and Natasha Fernandez. I am very grateful to them for their mentorship when I first joined the lab. Each of them means a lot to me and I will treasure their friendship all my life. I would like to give my special thanks to Ana Paula and Amy, who comforted me and said everything was OK when I made a mess with the liquid nitrogen, the worst thing I have ever done in the lab. Many moments like that, all the time I spent with these ladies in the lab are the sweetest memories in my lab life. Thank you, Javier Pino and Juliano Freitas for the company during the long journey of my PhD life. My special thanks to Javier for introducing so many new things to me, the delicious food, the berry farm, the fair and all the stories about animals. I enjoyed a lot! I must extend my sincerest thanks to my undergraduate student, Raul Torres. I know working with me means lots of hardworking, but thanks for the great job you did! My project would not have progressed at the rate it did were it not for you joining me. I know you will fulfill your desire of becoming a wonderful doctor in the future, and I am sure the friendship between us will last forever. I also want to give my thanks to all the other people in the lab, Alexander Durango, Martina Cavallini, Jesus Lopez, Claudia Llorian, who all work hard. Special thanks go to Erasmo Perera, for all the generous help and always being patient and answering all the questions I had. 
I would like to thank my committee members Dr. Manuel Barbieri, Dr. Xiaotang Wang, Dr. Fernando Noriega and Dr. Zhao-Jun Liu for their generous time and valuable comments towards my project. I want to specially thank Dr. Zhao-Jun Liu, who is from University of Miami Miller School of Medicine, for all the time he spent in his car traveling back and forth in Miami's traffic and all the valuable suggestions he offered on my project.

Last but not least I would like to thank the Department of Biological Sciences for the Teaching Assistantship that allowed me to pursue my degree and the Biomedical Research Initiative (BRI) Summer Research Award (NIH/NIGMS R25 GM061347) for the financial support. I also would like to acknowledge the Department of Biological Sciences, College of Arts, Sciences and Education and Graduate \& Professional Student Committee (GPSC) for the travel funding. A special thanks to Helen Forlong for her help with TARs, room reservations, and parking decals. 
ABSTRACT OF THE DISSERTATION

IDENTIFICATION AND PHENOTYPIC PLASTICITY OF METASTATIC CELLS

IN A MOUSE MODEL OF MELANOMA

by

Xiaoshuang Li

Florida International University, 2017

Miami, Florida

Professor Lidia Kos, Major Professor

Melanoma is the deadliest form of skin cancer due to its high propensity to metastasize and resistance to current therapies. We have created a spontaneous mouse model of metastatic melanoma (Dct-Grm1/K5-Edn3) where metastasis to the lungs is $80 \%$ penetrant. The primary tumors of these mice present cellular heterogeneity with cells at varying levels of differentiation. The main goal of this study was to determine the metastatic potential of the primary tumor resident Tyrosinase positive cells and evaluate the dynamic phenotypic changes as those cells move from the primary tumors to the sites of metastasis. To accomplish this aim I crossed the Dct-Grm1/K5-Edn3 mice to CreE $R^{T 2} / m T / m G$ mice to indelibly label Tyrosinase cell populations within the primary tumor with Green Fluorescent Protein (GFP) by topical application of 4hydroxytamoxifen $(4 \mathrm{HT})$ at the tumor site. In vivo lineage tracing and characterization of GFP+ cells were performed in the metastatic lesions.

In the $4 \mathrm{HT}$ treated Dct-Grm1/ K5-Edn3/Tyr-CreER ${ }^{T 2} / m T / m G$ mice, primary tumor derived Tyrosinase positive cells or their progeny (GFP+) 
established successful metastases in the distant organs indicating the tumorigenic capacity of the differentiated cell populations. Numerous metastatic melanoma cells were identified in the vasculature of the metastatic organs and established close association with the vascular endothelium. The intravascular cells lost pigmentation and did not express melanocytic markers; however, they mimicked endothelial cell properties and gained the expression of CD31 (also known as platelet endothelial cell adhesion molecule PECAM-1) and vascular endothelial (VE)-Cadherin. In the lung metastatic foci, GFP+ cells resumed pigmentation production and lost the expression of endothelial cell markers. Evidence from other metastatic organs in the mice further supported the phenotypic plasticity of metastatic melanoma cells.

The in vivo lineage tracing system established in the melanoma mouse model revealed tumor phenotypic plasticity and will be a powerful model to evaluate and help us understand the etiology and pathogenesis of melanoma metastasis. Further characterization of those more aggressive cells in melanoma will allow for the development of new prognostic tests and novel therapeutic strategies to eliminate metastasis. 


\section{TABLE OF CONTENTS}

CHAPTER

PAGE

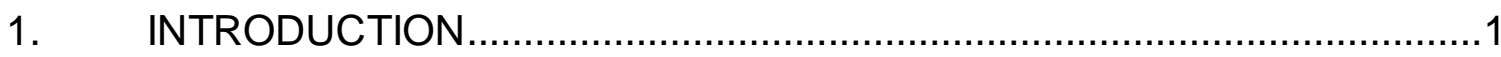

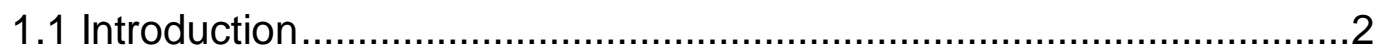

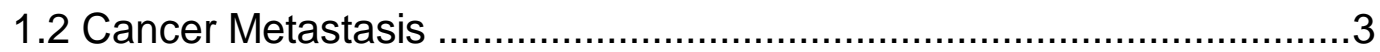

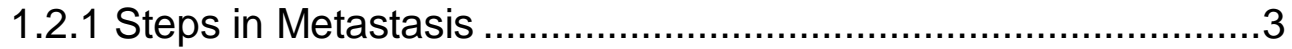

1.2.2 Mechanisms underlying Metastasis ......................................

1.2.2.1 Epithelial-mesenchymal transition ................................

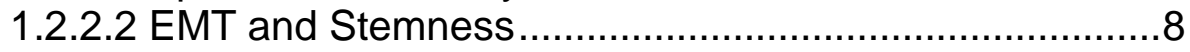

1.3 Melanoma Skin Cancer.................................................................10

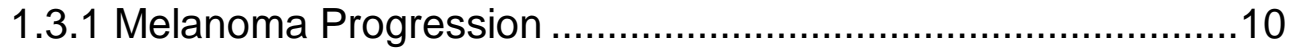

1.3.2 Melanoma Dormancy ...........................................................12

1.3.3 Melanoma and Metastasis-Initiating Cells ..............................14

1.4 Research Questions..................................................................15

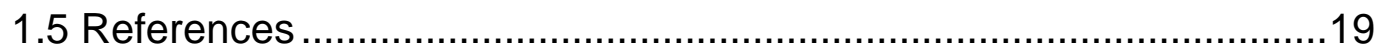

2. LINEAGE TRACING AND CHARACTERIZATION OF THE

METASTATIC CELL POPULATION IN A MOUSE MODEL OF MELANOMA.....31

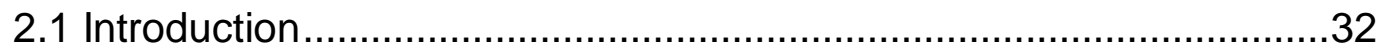

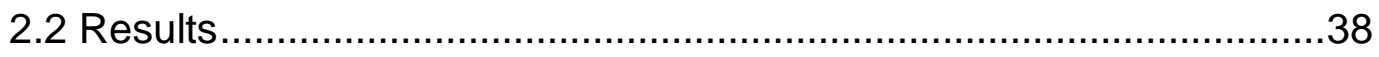

2.2.1 Tumor Heterogeneity Exists in Mouse Melanoma ....................38

2.2.2 Mouse Model and Methodology Validation .............................38

2.2.3 Labeling of the Tyr Expressing Cells in the Primary Tumors...40

2.2.4 Primary Tumor Derived Tyr Expressing Cells or Their

Progeny Can Reach the Lung and Seed Metastasis ........................41

2.2.5 Presence of Metastatic Cells inside the Lung Vasculature......43

2.2.6 Presence of Perivascular Cellular Infiltrates in Metastatic

Lungs

2.2.7 GFP + cells Lose Pigmentation upon Contact with Vascular

Endothelium.

2.2.8 Characterization of Metastatic GFP+ Cells Inside Pulmonary

Vasculature.

2.2.9 Primary Tumor Derived Tyr Expressing Cells or Their

Progeny Can Reach other organs and Seed Metastasis...

2.2.10 Metastatic Melanoma Cells Disseminate Early during

Melanomagenesis

2.3 Discussion ....

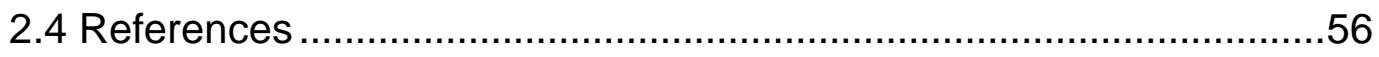

3. PHENOTYPIC PLASTICITY OF METASTATIC MELANOMA CELLS ....77

3.1 Introduction...........................................................................

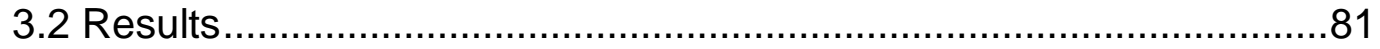

3.2.1 Vascular Endothelium Associated GFP+ Cells Express

Endothelial Cell Markers . 
3.2.2 Expression Pattern of Endothelial Cell Markers by GFP+ Cells is Dynamic

3.2.3 EndMT as a Potential Mechanism Underlying Dormant

Tumor Cell Awakening .84

3.2.4 Plasticity and Heterogeneity of Metastatic GFP+ Cells .85

3.3 Discussion .... 86

3.4 References

4. CONCLUSIONS AND FUTURE DIRECTIONS …............................109

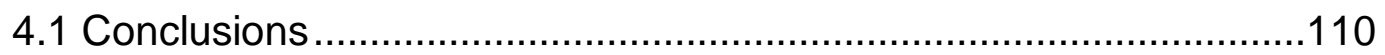

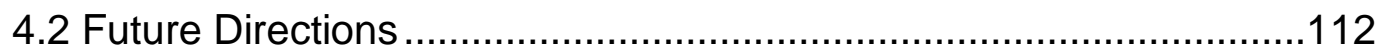

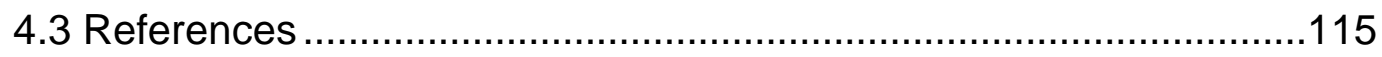

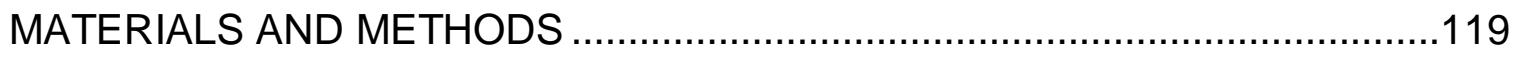

SUPPLEMENTARY FIGURES AND TABLES …..........................................127

VITA 


\section{LIST OF FIGURES}

FIGURE

PAGE

Figure 1.1 Diagram of cancer metastasis.................................................... 29

Figure 1.2 Identification of metastatic cell populations in melanoma................. 30

Figure 2.1 Heterogeneity of melanomas from different transgenic mice............ 64

Figure 2.2 Mouse model of melanoma metastasis. ........................................ 65

Figure 2.3 Mouse model of melanoma metastasis. .......................................... 67

Figure 2.4 Labeling of the Tyr expressing cells in the primary tumors............... 68

Figure 2.5 Lineage tracing of tumorigenic cells to the lung. ............................. 69

Figure 2.6 Primary tumor derived GFP+ cells proliferated in the lung................ 70

Figure 2.7 Numbers of Ki67 or Caspase3 staining of intravascular GFP+ cells

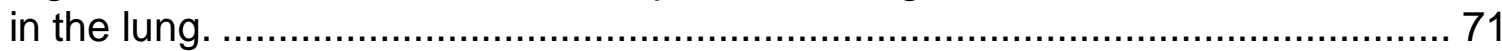

Figure 2.8 The presence of GFP+ cells in the lung was associated with perivascular infiltrates................................................................................... 72

Figure 2.9 Pigmentation level of GFP+ cells during metastasis. ...................... 73

Figure 2.10 Immunostaining of GFP+ cells in the lung vasculature of Dct-

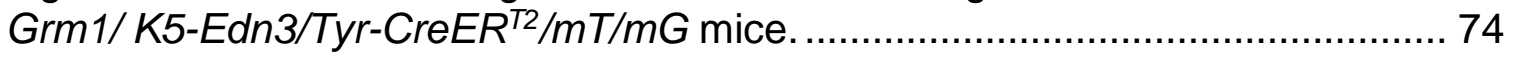

Figure 2.11 Characterization of GFP + cells in lymph nodes............................. 75

Figure 2.12 Timing of metastatic GFP+ cell dissemination............................. 76

Figure 3.1 GFP+ cells inside the pulmonary vasculature expressed endothelial

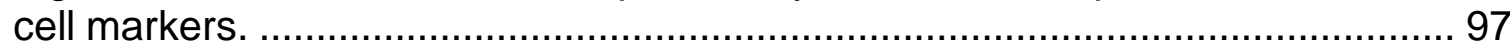

Figure 3.2 Confocal and 3D reconstruction of blood vessels. .......................... 98

Figure 3.3 Whole mount staining and 3D confocal reconstruction of arteries

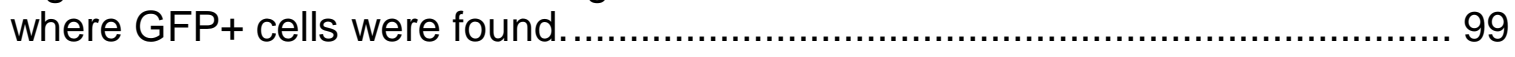

Figure 3.4 Plasticity of GFP+ cells from primary tumor sites to lung metastases. 100

Figure 3.5 Endothelial cell mimicry in lymph nodes. 101 
Figure 3.6 Immunostaining of VIMENTIN on lung cryosections.

Figure 3.7 GFP+ metastatic tumor cell acquired mesenchymal marker $\alpha$-SMA expression in the lung.

Figure $3.8 \alpha-S M A$ and CD31 immunostaining on lung sections...................... 104

Figure 3.9 3D reconstruction of GFP+ cells located in the pulmonary artery.... 105

Figure 3.10 Plasticity of GFP+ cells associated with the lung vasculature. ..... 106

Figure 3.11 Plasticity and heterogeneity of melanoma metastatic cells in other organs

Figure 4.1 Diagram of melanoma metastasis in the Dct-Grm1/K5-Edn3/TYRCreER $R^{T 2} / \mathrm{mT} / \mathrm{mG}$ mice.

Figure S 1. GFP+ cells in the tail tumors after $4 \mathrm{HT}$ induction.

Figure S 2.Primary tumor derived GFP+ green cells were found in different organs.

Figure S 3. Cleaved Caspase 3 staining on the lung..................................... 132

Figure S 4. Ki67 staining on lung perivascular infiltrates. .............................. 133

Figure S 5. Metastatic tumors on the skin. ....................................................... 134

Figure S 6. GFP+ cells inside the alveolar capillaries were CD31 positive...... 135 


\section{ABBREVIATIONS AND ACCRONYMS}

$3 \mathrm{D}$ Three-dimensional

$4 \mathrm{HT}$ 4-hydroxytamoxifen a-SMA a-smooth muscle actin

AAD $\alpha 1$ and $\alpha 2$ domains of HLA-A2 linked to the $\alpha 3$ domain of H2-Dd ABCB5 ATP binding cassette subfamily B member 5 bHLH Basic helix-loop-helix Bmi1 .B lymphoma Mo-MLV insertion region 1 homolog BMP Bone morphogenetic protein BSA Bovine serum albumin CD31 or PECAM-1 Platelet endothelial cell adhesion molecule CSCs. Cancer stem cells CTCs Circulating tumor cells

Cx43 Connexin43

Dct. Dopachrome tautomerase DMSO Dimethyl sulfoxide $E$ Glutamic acid ECM Extracellular matrix Edn3 Endothelin 3 Ednrb Endothelin Receptor B EET Epithelial-to-endothelial transition EMT. ..Epithelial-mesenchymal transition 
FDA Food and Drug Administration Forkhead Box O3

FSP1 Fibroblast-specific protein 1 FZD7 Frizzled class receptor 7

G Gauge GBM Glioblastoma GFP Green fluorescent protein GLIZ Glucocorticoid-induced Leucine Zipper Grm1 Glutamate Metabotropic Receptor 1 $H \& E$. Hematoxylin and eosin stain $\mathrm{H}_{2} \mathrm{O}_{2}$ Hydrogen peroxide HER-2 Human epidermal growth factor receptor 2 HGF. Hepatocyte growth factor $\mathrm{IHC}$ Immunohistochemistry K5 Keratin 5

LAMC2 Laminin 5 y2-chain Lgr5 Leucine-rich repeat-containing G-protein coupled receptor 5 LLCcm. Lewis lung carcinoma cells LYVE-1 Lymphatic vessel endothelial hyaluronan receptor 1 MCCs Mesenchymal cancer stem cells 
$m G$ Green fluorescent protein $\mathrm{mg}$ Microgram MICs Melanoma-initiating cells MITF Microphthalmia-associated transcription factor miPS mouse induced pluripotent stem cells

$\mathrm{ml}$ Microliter $\mathrm{mm}$ milimeter $\mathrm{mm}$ Micrometer MRF Melanoma Research Foundation $\mathrm{mT}$ tdTomato $\mathrm{n}$ Number NOD-SCID ...................... Nonobese diabetic/severe combined immunodeficiency OCT. Optimal cutting temperature OCT4 Octamer-binding transcription factor 4 PAX3 Paired box 3 PBS Phosphate buffer solution PCR. Polymerase chain reaction PFA. Paraformaldehyde PyMT Polyoma middle T RET Rearranged during transfection' proto oncogene RGP Radial growth phase RT-PCR Real time-polymerase chain reaction SF. scatter factor 
Shh Sonic hedhehog

Snail1 Snail family zinc finger 1

Snail2 Snail family zinc finger 2

SNP Single-nucleotide polymorphism

Sox10 Sex determining region $Y$ (SRY)-box 10 SOX2 Sex determining region $\mathrm{Y}$ box 2 $\operatorname{Tg}$ Thansgene TGF-b Transforming growth factor-beta TGF-b Transforming growth factor-beta TRP1 Tyrosinase-related protein 1 TRP2 Tyrosinase-related protein 2 tTA Tetracycline-sensitive transcriptional activator

Twist Twist Family BHLH Transcription Factor Twist1 Twist Family BHLH Transcription Factor 1 Tyr or TYR Tyrosinase TRP1 tyrosinase related protein 1 UV Ultraviolet V Valine VE Vascular endothelial VEGF Vascular endothelial growth factor VGP. Vertical growth phase VM Vasculogenic mimicry Vs Versus 
vWF Von Willebrand factor WNT Wingless-type MMTV integration site family ZEB1 Zinc Finger E-box-binding homeobox 1 ZEB2 Zinc Finger E-box-binding homeobox 2

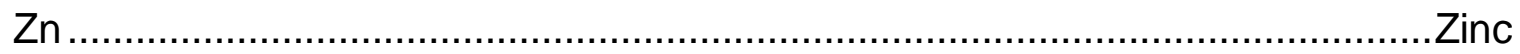




\section{CHAPTER}

1. INTRODUCTION 


\subsection{Introduction}

Most cancer patients die of metastasis [1]. Cancer metastasis is the spread of a cancer from one organ or part of the body to another organ or part of the body that is not directly connected. The process of metastasis consists of a series of interconnected, sequential or parallel steps that must be completed by tumor cells if a metastasis is to develop, although the exact steps for individual tumors are widely context-dependent. The vasculature plays essential roles during cancer metastasis. In addition to the authentic endothelial cell-lined vasculature, new models of vasculature, such as vasculogenic mimicry, vessel co-option and cancer cell-derived endothelial cells, have been reported [2]. Mechanisms underlying tumor metastasis are still under investigation, among which epithelial-mesenchymal transition (EMT) is receiving increasing attention $[3,4]$.

Melanoma is the type of skin cancer that causes the most deaths because of its high metastatic potential. Progression of normal melanocytes to metastatic melanoma was thought to be linear, but recent evidence has suggested it is more complex and less linear in nature [5]. Clinical cases of late recurrence after the initial primary melanoma resection [6] not only implicated the early dissemination of tumor cells, but also suggested melanoma dormancy. Although a number of studies have proposed an important role for cancer stem cells (CSCs) in melanoma, their existence and relevance remain a controversial issue [7]. The role of circulating tumor cells (CTCs) in metastatic colonization is also extensively discussed $[8,9]$. In this chapter, steps of cancer metastasis are summarized and 
the putative roles of EMT in metastasis are reviewed. In addition, descriptions of melanoma progression and dormancy are introduced as well as the current available evidence for metastasis-initiating cells focusing on CTCs.

\subsection{Cancer Metastasis}

\subsubsection{Steps in Metastasis}

Cancer metastasis involves several steps; metastatic cancer cells leave the primary tumor, travel to distant organs through various mechanisms and eventually seed metastases in the secondary organs. Blood/lymphatic vasculature plays essential roles in cancer metastasis by providing a route for the travel of cancer cells from primary sites to secondary sites. As malignant cancer cells start to proliferate out of control, a solid mass will appear as the primary tumor. Further growth of the primary tumor was originally believed to be angiogenesis-dependent and neovascularization was needed for tumor invasion and metastasis [10]. The promise of this hypothesis has been subjected to clinical evaluations and anti-angiogenesis agents have been used as standardof-care therapies for various types of cancers [11]. Later, this classic concept was challenged by studies showing that micro-tumors may initiate tumor growth by hijacking the pre-existing host vessels, a process known as vessel co-option (also known as vascular co-option), without inducing angiogenesis in a vascularized tissue [12-15]. Vessel co-option is also responsible for tumor progression after anti-angiogenesis therapies [16-19]. Other than the endothelial cell-lined vasculature in tumors, aggressive tumor cells can form blood-perfused tubular channels, termed as vasculogenic mimicry (VM), linking directly to normal 
vessels for the blood supply of the tumor growth [20]. Although aggressive uveal melanoma cells engaged in the formation of VM in 3D Matrigel downregulated invasiveness related genes [21], VM is strongly associated with clinical deaths of metastasis in uveal and cutaneous melanoma patients [22, 23]. The plasticity of tumor cells to gain an endothelial-like phenotype is depicted in another form of vasculature in cancer, the mosaic vessels. Tumor cells can mimic endothelial cells by participating in the formation of blood vessels. Mosaic vessels are marked by discontinued endothelial cell marker CD31 expression and the replacement of some endothelial cells with tumor cells in the vessels [24]. It is reasonable to propose that the presence of cancer cells within the mosaic vessels in contact with the blood lumen indicate tumor dissemination and metastasis [25]. Recent observations in glioma adds another layer to the role played by the tumor vasculature in that glioma cells can transdifferentiate into endothelial cells and express endothelial cell markers [26-31].

Several interactions or phenomena between cancer cells and the vasculature have been suggested or observed. The well-studied interaction between cancer cells and blood vessels is transendothelial migration. Tumor cells can migrate through the vascular endothelium to reach the blood (intravasation) and after transport in the blood stream, some cells can get out of the vasculature (extravasation) to seed metastases. Tumor cells within the blood stream are called circulating tumor cells (CTCs). Metastatic tumor cells can enter circulation as single cells or as cell clusters [32]. Circulating tumor cells have been successfully isolated from human blood in several cancers [33-36]. During 
hematogenous dissemination, intravascular rolling behavior of metastatic cancer cells has been reported [37-41]. In contrast to intravascular dissemination or migration, Lugassy and Barnhill suggested "angiotropism" in melanoma as a new mechanism of tumor spread. They termed this phenomenon as 'extravascular migratory metastasis' (EVMM), emphasizing the pericytic mimicry of tumor cells. Extravascular migratory metastasis describes the continuous migration of tumor cells along the abluminal vascular surfaces to nearby or more distant sites [4244]. The similarity of vessel co-option and angiotropism and the significance of these mechanisms during the metastatic process have been further discussed in a brain melanoma mouse model [15].

At the metastatic sites, tumor cells reach the metastatic organs by whichever migration mechanism (extravasation, vessel co-option, EMVV) and start to proliferate and seed successful metastases. Intravascular proliferation of tumor cells has been suggested as an alternative origin of early metastasis in the lung $[40,45]$. Instead of angiogenesis switch for further growth of metastatic tumors, vessel co-option is common in vasculature-rich tissues [18]. The overall process of cancer metastasis is summarized in Figure. 1.1.

\subsubsection{Mechanisms underlying Metastasis}

\subsubsection{Epithelial-mesenchymal transition}

Epithelial-mesenchymal transition was originally defined in developmental biology as a conversion from embryonic epithelia to individual mesenchymal cells that can invade and migrate through the extracellular matrix (ECM) [46]. During normal development, epithelial cells provide cell-cell adhesion essential to 
establish a barrier to the external environment for the development of embryos. In contrast, mesenchymal cells are free to rearrange or move around in three dimensions thus adding more plasticity for body patterning and morphogenesis [47]. Epithelial-mesenchymal transition involves not only morphological changes but also gene expression switch, in particular, the downregulation of E-cadherin and upregulation of $\mathrm{N}$-cadherin. It took a long time for EMT to be recognized as a potential mechanism underlying carcinoma progression. Since local invasion is the first step for cancer metastasis, it is essential for tumor cells to lose cell-cell adhesion and acquire invasive or migratory behaviors. The similarities between the tumor malignancy switch and the developmental signature have solidified the notion that EMT is a major contributor to the escape of tumor cells from the primary tumors [48].

Although clinically carcinomas (tumors of epithelial origin) and sarcomas (tumors of mesenchymal origin) are generally not thought to interconvert, various carcinoma cell lines undergo EMT during specific culturing conditions in vitro [49]. The first evidence of EMT in cancer was noted by studies demonstrating that invasiveness and adoption of a fibroblast morphology can be achieved by down regulation of E-cadherin expression in various epithelial cancer cell lines $[50,51]$. In addition, re-expression of E-cadherin can reverse the invasive property of cancer cells $[50,52,53]$. Transforming growth factor-beta (TGF- $\beta$ ) was shown to be a main inducer in the cancer EMT process. Transformed mammary epithelial cells exhibited fibroblastoid properties in the presence of TGF- $\beta$, the converted cells themselves produced high levels of TGF- $\beta 1$ and maintained a highly 
invasive phenotype both in vitro and in vivo. Neutralization of TGF- $\beta$ reverted the epithelial phenotype of the fibroblastoid cells [54]. Blockage of TGF- $\beta$ receptor abolished metastasis formation in highly metastatic mesenchymal mouse colon carcinoma cells [55]. However, because of the numerous biological interactions TGF- $\beta$ is involved in, the interpretation that EMT occurs in response to TGF- $\beta$ is complex [56]. The understanding of EMT in cancer advanced when specific transcriptional modulators of E-cadherin gene promoter were identified. In 2000, two groups showed strong evidence that Snail1 binds directly to the promoter of E-cadherin and represses the transcription of this gene in invasive mouse and human carcinoma cell lines $[57,58]$. Other $\mathrm{Zn}$ (zinc)-finger transcription factors, including Snail2 [59], ZEB1 [60], ZEB2 [61], were also shown to directly bind to the E-boxes of the E-cadherin promoter to repress its transcription. In addition to these Zn-finger transcription factors, ectopic expression of bHLH family transcription factor Twist1 resulted in the loss of E-cadherin mediated cell-cell adhesion, expression of mesenchymal markers and induction of cell motility, hallmarks of EMT in normal mammalian cells. Suppression of Twist in highly metastatic mammary carcinoma cells inhibited their metastatic capacity from the mammary gland to the lung in a murine breast tumor model [62]. Correlations between Twist1 and Snail2 during EMT in cancer metastasis were also discussed [63]. Other signaling pathways underlying EMT include bone morphogenetic protein (BMP), Wnt- $\beta$-catenin, Notch signaling, Hedgehog signaling, and receptor tyrosine kinases. In addition, environmental factors such as hypoxia and ECM also contribute to EMT process $[64,65]$. 
Nonetheless, the abundant stromal fibroblasts and the dynamics of EMT challenge our interpretation of EMT in human tumors [4]. Although numerous clinical studies correlate EMT with poor clinical outcomes, direct evidence is better demonstrated from the studies of CTCs. By lineage tracing, epithelialorigin CTCs acquiring EMT phenotype were identified in a mouse model of pancreatic cancer [66]. Another study, using a spontaneous squamous cell carcinoma mouse model, showed that activation of EMT by Twist1 induction increased CTCs over 2-fold compared with the control group, most important, these CTCs exhibited mesenchymal marker expression [67]. In a human breast cancer xenograft mouse model, Bonnomet et al. showed that EMT in the primary tumor was associated with an enhanced number of CTCs that expressed mesenchymal markers Snail, Slug and Vimentin [68]. Circulating tumor cells with an EMT feature have also been reported in human patients, including breast cancer, lung, colorectal, prostate, bladder, ovarian, and endometrial cancers [6971].

\subsubsection{EMT and Stemness}

Cancer stem cells (CSCs), also known as cancer-initiating cells, are those cells that have the ability to perpetuate themselves through self-renewal and to generate mature cells of a particular tissue through differentiation [72]. Cancer stem cells share similar stemness as regular stem cells in developmental processes. Recent studies have correlated EMT with stemness or CSCs. Mani and colleagues showed immortalized human mammary epithelial cells acquired the expression of stem-cell markers after EMT induction, and those transformed 
cells exhibited stem-cell properties by a higher efficiency in mammosphere and tumor formation [73]. In the context of cancer metastasis, the relationship between EMT and tumor-initiating capacity is better identified by studies on CTCs. Circulating tumor cells isolated from breast cancer patients showed EMT and stem cell characteristics, and inclusion of EMT markers to optimize CTCs detection was suggested [74-76]. In another study, a cell subpopulation with both tumor-initiating feature $\left(\mathrm{CD} 44^{+} / \mathrm{CD} 24^{-/ l o w}\right)$ and in vitro mammosphere-forming potential was identified in conventional therapy treated breast cancer samples. The increased expression of mesenchymal markers in this cell subpopulation has related EMT with tumor-initiating cells [77]. In a study of epithelial lineage tracing in a mouse model of pancreatic cancer, the authors showed that epithelialderived CTCs expressed mesenchymal markers, and further characterized the tumor initiating properties of those cells by transplantation [66]. However, not all cells that have undergone EMT possess stem cell-like properties, as is shown by the study in a spontaneous model of EMT using a primary prostate cancer derived cell line [78]. The cross talk between EMT and stemness is far more complex than expected. Different research groups have demonstrated that EMT can suppress the tumor-initiating capacities of human epithelial cells [79]. Epithelial-mesenchymal transition and stemness may be coupled, antagonistic or independent processes in cancer metastasis [80]. 


\subsection{Melanoma Skin Cancer}

\subsubsection{Melanoma Progression}

Cutaneous melanoma has been one of the fastest rising cancers over the past several decades. According to the American Cancer Society, about 87,110 new melanomas will be diagnosed and 9,730 people are expected to die of melanoma in 2017. Melanoma is notorious for its tendency to metastasize and for its poor response to current therapeutic regimens.

Melanoma results from the malignant proliferation of melanocytes, the pigment producing cells in the skin. The classic paradigm describing the progression of normal melanocytes to metastatic melanoma is linear [81, 82]. Melanoma starts from the melanocytic nevus, a benign precursor lesion, followed by the dysplastic nevus. The first malignant stage of melanoma is called the radial growth phase (RGP). At RGP, transformed melanocytes start to spread laterally, but remain close to the epidermis and still under the control of the growth factors from the keratinocytes. The continuing invasion of melanocytes from basement membrane to the upper epidermis and lower dermis leads to the next stage, vertical growth phase (VGP). At VGP, melanocytes completely escape from the keratinocyte signals and new interactions between surrounding stroma cells are established. Melanocytes at VGP have the potential to disseminate and seed distant metastases in other organs [81-83].

However, the progression of melanoma may not be sequential or linear; emerging evidence both in mouse models and clinical observations suggest a much more elaborate view of melanoma metastasis [5]. In contrast to the 
traditional notion that metastasis is a late event in tumor progression and it only occurs after the completion of all the required stages, early dissemination of abnormal cells was detected in both murine models and human samples. Husemann performed a comprehensive study about the early dissemination of breast cancer cells in both HER-2 and PyMT transgenic mice. In these breast cancer mouse models, transformed epithelial cells disseminated early from the atypical hyperplastic areas and those early disseminating cells can grow into metastases. Another finding of this study is that the dissemination of tumor cells was not associated with tumor size both in the mouse model and ductal carcinomas in situ in women [84]. A similar study using PyMT mice identified the stem cell property of some early disseminating cells. The disseminating and tumorigenic potential of the disseminating cells was further assessed by transplantation assay using GFP PyMT mice [85]. In a study by Podsypanina et al., untransformed mouse mammary cells in circulation were able to acquire malignant growth upon oncogene activation. They demonstrated this by introducing the premalignant mammary cells into circulation directly without going through the transformation within the primary tumors. Although they could not show the timing of the dissemination, they argued the possibility that untransformed cells that disseminated early could account for the later metastases [86]. Early dissemination before tumor formation was also reported in a pancreatic tumor mouse model, in which cells disseminated at premalignant stage reached the liver as single cells albeit no micro- or macro-metastases were observed [66]. In the spontaneous melanoma mouse model RET.AAD, early 
dissemination of melanoma cells before primary tumor formation was identified through a series of assays, including SNP genetic analysis, IHC, RT-PCR and H\&E staining. The authors also noted the dormancy of disseminating tumor cells in the lung [87]. Clinically, numerous cases of patients with metastatic melanoma free of detectable primary tumors have been reported [88-93].

\subsubsection{Melanoma Dormancy}

Malignant melanoma is one of the two malignancies with the highest donor tumor transmission rates $(74 \%$ transmission rate with $58 \%$ mortality) in human transplantations [94]. Organs from donors with melanoma history but free of disease for more than 10 years after initial surgery can present with recurrent metastasis in organ recipients. Late recurrence of melanoma after the initial primary tumor resection is reported [6]. Although various adjuvant therapies are designed to prevent the development of local recurrences or metastasis by targeting "residual" disease, the results have not necessarily been successful. Why is it that the "residual" tumor cells are so persistent? The answer may lie in the fact that the biology of some "residual" cells, that may disseminate into other organs before the removal of primary tumors, seem to be highly divergent from that of the primary tumor and/or overt metastasis [95]. All clinical observations listed previously point to an increasing concern surrounding melanomametastatic dormancy, which may be the underlying cause for the incomplete cure of melanoma.

Although a handful of reviews on melanoma dormancy are available [9698], the number of studies specifically focusing on this phenomenon in 
melanoma is very limited compared with that for breast and prostate cancers. Despite the well documented clinical observations, evidence of melanoma dormancy in mouse models, which could serve as a useful tool to reveal the mechanisms underlying human disease, is scarce. An early study by Cameron et al. showed dormancy of solitary melanoma cells in lung using B16F10 cell injection. They concluded that solitary cell dormancy is a post-extravasation event contributing to metastasis inefficiency [99]. A similar study, where human melanoma cells were injected into the tail vein of immunodeficient mice, demonstrated that single or clusters of $<10$ cells in the lung failed to proliferate in vivo up to 60 days but retained tumor initiating capacity after in vitro culture [100]. Another study employing in vivo imaging showed that uveal melanoma cells can persist in the liver for 6 weeks in a dormant state [101]. Nonetheless, these studies did not provide or propose the underlying mechanisms for how these cells kept dormant and were able to escape immune attack in the metastatic organs. Without a mechanistic understanding, the evidence of melanoma dormancy in humans or mice is of little use in reducing recurrence or increasing survival of patients. A very recent study by Touil et al. may offer more clues on melanoma dormancy. In their study, they obtained a mouse model of melanoma dormancy through melanoma-based immunotherapy and ascertained the in vivo existence of immune-resistant dormant melanoma cells in different organs by qRT-PCR one year after the immunotherapy challenge. Unfortunately, no spatial information of those dormant cells was reported and the following characterization of the dormant cells was done through in vitro study of the 
dormant cell-derived cell lines. Although they provided evidence that the dormant cells presented stem-like properties and that the GILZ/FOXO3A pathway was involved in the quiescence of those cells, these in vitro results are not as convincing as in vivo characterization [102].

\subsubsection{Melanoma and Metastasis-Initiating Cells}

Melanoma is less common, but more serious than other types of skin cancers because of its high metastatic potential. The cellular composition of tumors is heterogeneous; there are many subpopulations of cells within the same tumor. Some cells are more differentiated, some are less differentiated showing a stem cell-like phenotype. Recent evidence suggested that the less differentiated cell population (i.e.,CSCs) may be responsible for tumor initiation and resistance to therapies [72]. Although several melanoma stem cell markers have been described [103-107], the robustness of these markers is questionable considering the limitations of the xenotransplantation assay that is widely used in cancer stem cell studies. In addition, the tumor initiating capacity of CSCs in melanoma was mainly discussed in the context of primary tumor formation and little is known about metastasis-initiating capacities. The differentiation levels of melanocytes with respect to their ability to metastasize was discussed by Damsky et al. Microphthalmia-associated transcription factor (MITF) and WNT/ $\beta$ catenin signaling are the known players controlling melanocyte differentiation, but their effects on melanoma metastasis seem to be context-dependent. Two hypotheses have been proposed to explain the controversial effects of the two 
players on metastasis: the proper balance in the degree of differentiation, and the phenotypic plasticity of melanoma cells [5].

If during metastasis, the dissemination of tumor-initiating cells is required, presence of circulating tumor-initiating cells should be associated with worse patient outcome. A study demonstrated that CD133 and Nestin were expressed on CTCs, and those CTCs showed a similar expression profile with the matched metastatic lesions [108]. Another corroborating study demonstrated that Nestin was expressed in a proportion of melanoma cells enriched from peripheral blood of melanoma patients, and the expression level of Nestin was higher in stage IV patients compared with stage III/IV patients [109]. Clonal dominance of CD133 in primary tumors of patients with recurrence or metastatic lesions was found, suggesting that CD133 subpopulation may be a determinant of tumor metastasis/tumor relapse [105]. Another study using experimental metastasis models, showed that the WNT receptor, FZD7, was required for the initiation and proliferation of metastatic melanoma growth [110]. In addition, Frank's group has identified a subpopulation of tumor-initiating cells in melanoma by ABCB5 expression [111]. Later they showed that human melanoma CTCs contain tumorigenic cell subpopulations capable of causing metastases, most interestingly, $\mathrm{ABCB} 5$-positive tumor cells were highly enriched among melanoma CTCs compared to either primary tumors or pulmonary metastases [112].

\subsection{Research Questions}

Although efforts to identify melanoma-initiating cells (MICs) or CSCs are increasing and strong evidence is emerging, connections between MICs and 
metastasis still remain an open question. This is partly because of the complexity of tumor progression in that both external and internal factors may account for tumor metastasis. Another reason is the lack of good melanoma metastasis models. For obvious reasons, it is impossible to follow a specific cell population in human melanoma patients from the primary tumor to the metastatic sites to check their metastasis-initiating capacity. Proper mouse melanoma metastasis models are very limited and in vivo tracing of cells requires numerous optimized conditions, such as timing of metastasis formation and visualization of interested melanoma cells. The effort to fully characterize melanoma metastasis-initiating cells is worthwhile because it will not only enhance our understanding of melanoma metastasis, but also provide insights for the development of metastasis-targeted therapies.

Phenotypic plasticity of cancer cells is a well-recognized phenomenon; we know that tumor cells can switch gene expression profiles as necessary to best adapt to the environment. However, to what extent and how these changes are related to the spatial or temporal dimensions of tumor progression have not been sufficiently investigated. Histological and morphological dynamics may be observable through real-time in vivo imaging on zebrafish models or mouse models for a short period, while genetic changes are hard to be characterized in those setups. A detailed lineage tracing study in melanoma has not been pursued. As such, the establishment of an in vivo lineage tracing system of the tumorigenic cell subpopulations in a spontaneous mouse model of melanoma metastasis is essential. This system will not only delineate the tumor-initiating 
capacity of specific cell subpopulations in the context of metastasis but also indicate the phenotypic plasticity of the metastatic cells (Figure 1.2). My overall hypothesis is that the primary tumor derived cell subpopulation with a more differentiated state possesses metastasis-initiating capacities and exhibit phenotypic plasticity during the metastatic process. To test this hypothesis, I addressed the following questions:

Question 1: Can primary tumor derived cell subpopulations with a more differentiated state reach the secondary organs and seed successful metastases?

I created a spontaneous melanoma metastasis mouse Tg (Grm1) Epv / K5-tTA-Edn3 (referred to as Dct-Grm1/ K5-Edn3) where metastasis to the lungs is $80 \%$ penetrant. Using the Cre/loxp system, I genetically labeled Tyr expressing cell subpopulations within the primary tumors with GFP in these mice and performed lineage tracing of the labeled cells. I hypothesized that the primary tumor derived Tyr expressing cells or their progeny can reach the lung and successfully seed metastases indicating the tumor-initiating capacities of the differentiated melanoma cell subpopulation.

Question 2: When do the metastatic melanoma cells start to disseminate into the circulation system?

My aim was to identify the metastasis-initiating capacities of the primary tumor derived Tyr expressing cells. Experimental mice were monitored for several months after primary tumor formation. Given the variability in the timing of primary tumor and lung metastasis formation, I could not establish the exact 
time of arrival of metastatic cells in the lung. Instead, I focused on the timing of metastatic cell intravasation. I labeled Tyr expressing cells in the mice at three different stages during tumor progression: pre-nevus stage, nevus stage and mature tumor stage. I hypothesized that Tyr expressing cells can invade blood vessels even before the appearance of any noticeable nevus.

\section{Question 3: What are the phenotypic changes that cells undergo during the process of metastasis?}

The GFP+ metastatic cells are derived from Tyr expressing cells inside the primary tumors. As the cells leave the primary tumors and enter the circulatory system, I hypothesized that the gene expression profile and pigmentation levels of those cells may undergo a reversible switch to facilitate metastasis. I used immunofluorescence staining with various markers to characterize the phenotype of metastatic cells associated with the pulmonary vasculature.

\section{Question 4: What are the putative mechanisms underlying melanoma metastasis?}

The GFP+ cells found in the lung were mostly associated with the vascular endothelium with an elongated shape. The mechanism and functional significance underlying the association between metastatic melanoma cells and vascular endothelial cells is not clear. I performed immunofluorescence staining of intravascular metastatic melanoma cells with endothelial cell specific markers and hypothesized that melanoma-endothelial transition in the primary tumors and endothelial-mesenchymal transition (EndMT) in the metastatic site are mechanisms underlying melanoma metastasis in the Dct-Grm1/K5-Edn3 mice. 


\subsection{References}

1. Mehlen, P. and A. Puisieux, Metastasis: a question of life or death. Nat Rev Cancer, 2006. 6(6): p. 449-58.

2. Krishna Priya, S., et al., Tumour angiogenesis-Origin of blood vessels. Int J Cancer, 2016. 139(4): p. 729-35.

3. Ribatti, D., Epithelial-mesenchymal transition in morphogenesis, cancer progression and angiogenesis. Exp Cell Res, 2017. 353(1): p. 1-5.

4. Yeung, K.T. and J. Yang, Epithelial-mesenchymal transition in tumor metastasis. Mol Oncol, 2017. 11(1): p. 28-39.

5. Damsky, W.E., N. Theodosakis, and M. Bosenberg, Melanoma metastasis: new concepts and evolving paradigms. Oncogene, 2014. 33(19): p. 241322.

6. Tsao, H., A.B. Cosimi, and A.J. Sober, Ultra-late recurrence (15 years or longer) of cutaneous melanoma. Cancer, 1997. 79(12): p. 2361-70.

7. Shakhova, O. and L. Sommer, Testing the cancer stem cell hypothesis in melanoma: the clinics will tell. Cancer Lett, 2013. 338(1): p. 74-81.

8. Massague, J. and A.C. Obenauf, Metastatic colonization by circulating tumour cells. Nature, 2016. 529(7586): p. 298-306.

9. Dasgupta, A., A.R. Lim, and C.M. Ghajar, Circulating and disseminated tumor cells: harbingers or initiators of metastasis? Mol Oncol, 2017. 11(1): p. $40-61$.

10. Folkman, J., Tumor angiogenesis: therapeutic implications. N Engl J Med, 1971. 285(21): p. 1182-6.

11. Ye, W., The Complexity of Translating Anti-angiogenesis Therapy from Basic Science to the Clinic. Dev Cell, 2016. 37(2): p. 114-25.

12. Dome, B., et al., Vascularization of cutaneous melanoma involves vessel co-option and has clinical significance. J Pathol, 2002. 197(3): p. 355-62.

13. Leenders, W.P., B. Kusters, and R.M. de Waal, Vessel co-option: how tumors obtain blood supply in the absence of sprouting angiogenesis. Endothelium, 2002. 9(2): p. 83-7.

14. Zhao, C., et al., Distinct contributions of angiogenesis and vascular cooption during the initiation of primary microtumors and micrometastases. Carcinogenesis, 2011. 32(8): p. 1143-50. 
15. Bentolila, L.A., et al., Imaging of Angiotropism/Vascular Co-Option in a Murine Model of Brain Melanoma: Implications for Melanoma Progression along Extravascular Pathways. Sci Rep, 2016. 6: p. 23834.

16. Leenders, W.P., et al., Antiangiogenic therapy of cerebral melanoma metastases results in sustained tumor progression via vessel co-option. Clin Cancer Res, 2004. 10(18 Pt 1): p. 6222-30.

17. Mandelcorn, E.D., et al., Vascular co-option in lung cancer metastatic to the eye after treatment with bevacizumab. J Ophthalmic Inflamm Infect, 2010. 1(1): p. 35-8.

18. Donnem, T., et al., Vessel co-option in primary human tumors and metastases: an obstacle to effective anti-angiogenic treatment? Cancer Med, 2013. 2(4): p. 427-36.

19. Valiente, M., et al., Serpins promote cancer cell survival and vascular cooption in brain metastasis. Cell, 2014. 156(5): p. 1002-16.

20. Folberg, R., M.J. Hendrix, and A.J. Maniotis, Vasculogenic mimicry and tumor angiogenesis. Am J Pathol, 2000. 156(2): p. 361-81.

21. Folberg, R., et al., Tumor cell plasticity in uveal melanoma: microenvironment directed dampening of the invasive and metastatic genotype and phenotype accompanies the generation of vasculogenic mimicry patterns. Am J Pathol, 2006. 169(4): p. 1376-89.

22. Warso, M.A., et al., Prognostic significance of periodic acid-Schiff-positive patterns in primary cutaneous melanoma. Clin Cancer Res, 2001. 7(3): $p$. 473-7.

23. Makitie, T., et al., Microvascular density in predicting survival of patients with choroidal and ciliary body melanoma. Invest Ophthalmol Vis Sci, 1999. 40(11): p. 2471-80.

24. Chang, Y.S., et al., Mosaic blood vessels in tumors: frequency of cancer cells in contact with flowing blood. Proc Natl Acad Sci U S A, 2000. 97(26): p. 14608-13.

25. di Tomaso, E., et al., Mosaic tumor vessels: cellular basis and ultrastructure of focal regions lacking endothelial cell markers. Cancer Res, 2005. 65(13): p. 5740-9.

26. Ricci-Vitiani, L., et al., Tumour vascularization via endothelial differentiation of glioblastoma stem-like cells. Nature, 2010. 468(7325): p. 824-8. 
27. Shaifer, C.A., J. Huang, and P.C. Lin, Glioblastoma cells incorporate into tumor vasculature and contribute to vascular radioresistance. Int $\mathrm{J}$ Cancer, 2010. 127(9): p. 2063-75.

28. Wang, R., et al., Glioblastoma stem-like cells give rise to tumour endothelium. Nature, 2010. 468(7325): p. 829-33.

29. Zhao, Y., et al., Endothelial cell transdifferentiation of human glioma stem progenitor cells in vitro. Brain Res Bull, 2010. 82(5-6): p. 308-12.

30. Soda, Y., et al., Transdifferentiation of glioblastoma cells into vascular endothelial cells. Proc Natl Acad Sci U S A, 2011. 108(11): p. 4274-80.

31. Chen, X., et al., A new mosaic pattern in glioma vascularization: exogenous endothelial progenitor cells integrating into the vessels containing tumor-derived endothelial cells. Oncotarget, 2014. 5(7): p. 1955-68.

32. Aceto, N., et al., Circulating tumor cell clusters are oligoclonal precursors of breast cancer metastasis. Cell, 2014. 158(5): p. 1110-22.

33. Steen, S., et al., Circulating tumor cells in melanoma: a review of the literature and description of a novel technique. Proc (Bayl Univ Med Cent), 2008. 21(2): p. 127-32.

34. Cheng, M., et al., Circulating tumor cells are associated with bone metastasis of lung cancer. Asian Pac J Cancer Prev, 2014. 15(15): p. 6369-74.

35. Chudasama, D., et al., Detection of Circulating Tumour Cells and Survival of Patients with Non-small Cell Lung Cancer. Anticancer Res, 2017. 37(1): p. $169-173$.

36. Qi, Y. and W. Wang, Clinical significance of circulating tumor cells in squamous cell lung cancer patients. Cancer Biomark, 2017. 18(2): p. 161167.

37. Glinsky, V.V., et al., Intravascular metastatic cancer cell homotypic aggregation at the sites of primary attachment to the endothelium. Cancer Res, 2003. 63(13): p. 3805-11.

38. Glinskii, O.V., et al., Continuous real time ex vivo epifluorescent video microscopy for the study of metastatic cancer cell interactions with microvascular endothelium. Clin Exp Metastasis, 2003. 20(5): p. 451-8.

39. Khaldoyanidi, S.K., et al., MDA-MB-435 human breast carcinoma cell homo- and heterotypic adhesion under flow conditions is mediated in part 
by Thomsen-Friedenreich antigen-galectin-3 interactions. J Biol Chem, 2003. 278(6): p. 4127-34.

40. Al-Mehdi, A.B., et al., Intravascular origin of metastasis from the proliferation of endothelium-attached tumor cells: a new model for metastasis. Nat Med, 2000. 6(1): p. 100-2.

41. Dimitroff, C.J., et al., Rolling of human bone-metastatic prostate tumor cells on human bone marrow endothelium under shear flow is mediated by E-selectin. Cancer Res, 2004. 64(15): p. 5261-9.

42. Lugassy, C., et al., Pericytic-like angiotropism of glioma and melanoma cells. Am J Dermatopathol, 2002. 24(6): p. 473-8.

43. Lugassy, C., et al., Angiotropism of human melanoma: studies involving in transit and other cutaneous metastases and the chicken chorioallantoic membrane: implications for extravascular melanoma invasion and metastasis. Am J Dermatopathol, 2006. 28(3): p. 187-93.

44. Barnhill, R.L., P.J. Benson, and C. Lugassy, Conspicuous angiotropism of malignant melanoma involving the brain: implications for extravascular migratory metastasis. Am J Dermatopathol, 2009. 31(2): p. 205-8.

45. Wong, C.W., et al., Intravascular location of breast cancer cells after spontaneous metastasis to the lung. Am J Pathol, 2002. 161(3): p. 749-53.

46. Hay, E.D., An overview of epithelio-mesenchymal transformation. Acta Anat (Basel), 1995. 154(1): p. 8-20.

47. Shook, D. and R. Keller, Mechanisms, mechanics and function of epithelial-mesenchymal transitions in early development. Mech Dev, 2003. 120(11): p. 1351-83.

48. Micalizzi, D.S., S.M. Farabaugh, and H.L. Ford, Epithelial-mesenchymal transition in cancer: parallels between normal development and tumor progression. J Mammary Gland Biol Neoplasia, 2010. 15(2): p. 117-34.

49. Thiery, J.P., Epithelial-mesenchymal transitions in tumour progression. Nat Rev Cancer, 2002. 2(6): p. 442-54.

50. Vleminckx, K., et al., Genetic manipulation of E-cadherin expression by epithelial tumor cells reveals an invasion suppressor role. Cell, 1991. 66(1): p. 107-19.

51. Frixen, U.H., et al., E-cadherin-mediated cell-cell adhesion prevents invasiveness of human carcinoma cells. J Cell Biol, 1991. 113(1): p. 17385. 
52. Frixen, U.H. and Y. Nagamine, Stimulation of urokinase-type plasminogen activator expression by blockage of E-cadherin-dependent cell-cell adhesion. Cancer Res, 1993. 53(15): p. 3618-23.

53. Perl, A.K., et al., A causal role for E-cadherin in the transition from adenoma to carcinoma. Nature, 1998. 392(6672): p. 190-3.

54. Oft, M., et al., TGF-beta1 and Ha-Ras collaborate in modulating the phenotypic plasticity and invasiveness of epithelial tumor cells. Genes Dev, 1996. 10(19): p. 2462-77.

55. Oft, M., K.H. Heider, and H. Beug, TGFbeta signaling is necessary for carcinoma cell invasiveness and metastasis. Curr Biol, 1998. 8(23): p. 1243-52.

56. Ahmed, S. and A. Nawshad, Complexity in interpretation of embryonic epithelial-mesenchymal transition in response to transforming growth factor-beta signaling. Cells Tissues Organs, 2007. 185(1-3): p. 131-45.

57. Cano, A., et al., The transcription factor snail controls epithelialmesenchymal transitions by repressing E-cadherin expression. Nat Cell Biol, 2000. 2(2): p. 76-83.

58. Batlle, E., et al., The transcription factor snail is a repressor of E-cadherin gene expression in epithelial tumour cells. Nat Cell Biol, 2000. 2(2): p. 849.

59. Hajra, K.M., D.Y. Chen, and E.R. Fearon, The SLUG zinc-finger protein represses E-cadherin in breast cancer. Cancer Res, 2002. 62(6): p. 16138.

60. Eger, A., et al., DeltaEF1 is a transcriptional repressor of E-cadherin and regulates epithelial plasticity in breast cancer cells. Oncogene, 2005. 24(14): p. 2375-85.

61. Comijn, J., et al., The two-handed $E$ box binding zinc finger protein SIP1 downregulates E-cadherin and induces invasion. Mol Cell, 2001. 7(6): p. 1267-78.

62. Yang, J., et al., Twist, a master regulator of morphogenesis, plays an essential role in tumor metastasis. Cell, 2004. 117(7): p. 927-39.

63. Casas, E., et al., Snail2 is an essential mediator of Twist1-induced epithelial mesenchymal transition and metastasis. Cancer Res, 2011. 71(1): p. 245-54. 
64. Gonzalez, D.M. and D. Medici, Signaling mechanisms of the epithelialmesenchymal transition. Sci Signal, 2014. 7(344): p. re8.

65. Jung, H.Y., L. Fattet, and J. Yang, Molecular pathways: linking tumor microenvironment to epithelial-mesenchymal transition in metastasis. Clin Cancer Res, 2015. 21(5): p. 962-8.

66. Rhim, A.D., et al., EMT and dissemination precede pancreatic tumor formation. Cell, 2012. 148(1-2): p. 349-61.

67. Tsai, J.H., et al., Spatiotemporal regulation of epithelial-mesenchymal transition is essential for squamous cell carcinoma metastasis. Cancer Cell, 2012. 22(6): p. 725-36.

68. Bonnomet, A., et al., A dynamic in vivo model of epithelial-tomesenchymal transitions in circulating tumor cells and metastases of breast cancer. Oncogene, 2012. 31(33): p. 3741-53.

69. Alix-Panabieres, C., S. Mader, and K. Pantel, Epithelial-mesenchymal plasticity in circulating tumor cells. J Mol Med (Berl), 2017. 95(2): p. 133142.

70. Francart, M.E., et al., Epithelial-Mesenchymal Plasticity and Circulating Tumor Cells: Travel Companions to Metastases. Dev Dyn, 2017.

71. Chebouti, I., et al., EMT-like circulating tumor cells in ovarian cancer patients are enriched by platinum-based chemotherapy. Oncotarget, 2017.

72. Reya, T., et al., Stem cells, cancer, and cancer stem cells. Nature, 2001. 414(6859): p. 105-111.

73. Mani, S.A., et al., The epithelial-mesenchymal transition generates cells with properties of stem cells. Cell, 2008. 133(4): p. 704-15.

74. Raimondi, C., et al., Epithelial-mesenchymal transition and stemness features in circulating tumor cells from breast cancer patients. Breast Cancer Res Treat, 2011. 130(2): p. 449-55.

75. Aktas, B., et al., Stem cell and epithelial-mesenchymal transition markers are frequently overexpressed in circulating tumor cells of metastatic breast cancer patients. Breast Cancer Res, 2009. 11(4): p. R46.

76. Hennessy, B.T., et al., Characterization of a naturally occurring breast cancer subset enriched in epithelial-to-mesenchymal transition and stem cell characteristics. Cancer Res, 2009. 69(10): p. 4116-24. 
77. Abell, A.N. and G.L. Johnson, Implications of Mesenchymal Cells in Cancer Stem Cell Populations: Relevance to EMT. Curr Pathobiol Rep, 2014. 2(1): p. 21-26.

78. Harner-Foreman, N., et al., A novel spontaneous model of epithelialmesenchymal transition (EMT) using a primary prostate cancer derived cell line demonstrating distinct stem-like characteristics. Sci Rep, 2017. 7: p. 40633.

79. Celia-Terrassa, T., et al., Epithelial-mesenchymal transition can suppress major attributes of human epithelial tumor-initiating cells. J Clin Invest, 2012. 122(5): p. 1849-68.

80. Fabregat, I., A. Malfettone, and J. Soukupova, New Insights into the Crossroads between EMT and Stemness in the Context of Cancer. J Clin Med, 2016. 5(3).

81. Hsu, M.Y., F. Meier, and M. Herlyn, Melanoma development and progression: a conspiracy between tumor and host. Differentiation, 2002. 70(9-10): p. 522-36.

82. Gaggioli, C. and E. Sahai, Melanoma invasion - current knowledge and future directions. Pigment Cell Res, 2007. 20(3): p. 161-72.

83. Chin, L., The genetics of malignant melanoma: lessons from mouse and man. Nat Rev Cancer, 2003. 3(8): p. 559-70.

84. Husemann, Y., et al., Systemic spread is an early step in breast cancer. Cancer Cell, 2008. 13(1): p. 58-68.

85. Weng, D., et al., Metastasis is an early event in mouse mammary carcinomas and is associated with cells bearing stem cell markers. Breast Cancer Res, 2012. 14(1): p. R18.

86. Podsypanina, K., et al., Seeding and propagation of untransformed mouse mammary cells in the lung. Science, 2008. 321(5897): p. 1841-4.

87. Eyles, J., et al., Tumor cells disseminate early, but immunosurveillance limits metastatic outgrowth, in a mouse model of melanoma. J Clin Invest, 2010. 120(6): p. 2030-9.

88. Dasgupta, T. and R. Brasfield, METASTATIC MELANOMA. A CLINICOPATHOLOGICAL STUDY. Cancer, 1964. 17: p. 1323-39.

89. Giuliano, A.E., H.S. Moseley, and D.L. Morton, Clinical aspects of unknown primary melanoma. Ann Surg, 1980. 191(1): p. 98-104. 
90. Panagopoulos, E. and D. Murray, Metastatic malignant melanoma of unknown primary origin: a study of 30 cases. J Surg Oncol, 1983. 23(1): $p$. 8-10.

91. Reintgen, D.S., et al., Metastatic malignant melanoma with an unknown primary. Surg Gynecol Obstet, 1983. 156(3): p. 335-40.

92. Reddy, P., C. Walker, and B. Afonso, A rare case of metastatic malignant melanoma to the colon from an unknown primary. Case Rep Gastrointest Med, 2014. 2014: p. 312902.

93. Shenoy, A.S., et al., Metastatic malignant melanoma in a young adult with unknown primary. Indian J Cancer, 2015. 52(3): p. 446-7.

94. Buell, J.F., et al., Donor transmitted malignancies. Ann Transplant, 2004. 9(1): p. 53-6.

95. Klein, C.A., Selection and adaptation during metastatic cancer progression. Nature, 2013. 501(7467): p. 365-72.

96. Ossowski, L. and J.A. Aguirre-Ghiso, Dormancy of metastatic melanoma. Pigment Cell Melanoma Res, 2010. 23(1): p. 41-56.

97. Pierard, G.E., et al., Smouldering malignant melanoma and metastatic dormancy: an update and review. Dermatol Res Pract, 2012. 2012: p. 461278.

98. Tseng, W.W., N. Fadaki, and S.P. Leong, Metastatic tumor dormancy in cutaneous melanoma: does surgery induce escape? Cancers (Basel), 2011. 3(1): p. 730-46.

99. Cameron, M.D., et al., Temporal progression of metastasis in lung: cell survival, dormancy, and location dependence of metastatic inefficiency. Cancer Res, 2000. 60(9): p. 2541-6.

100. Goldberg, S.F., et al., Metastasis-suppressed C8161 melanoma cells arrest in lung but fail to proliferate. Clin Exp Metastasis, 1999. 17(7): $p$. 601-7.

101. Logan, P.T., et al., Single-cell tumor dormancy model of uveal melanoma. Clin Exp Metastasis, 2008. 25(5): p. 509-16.

102. Touil, Y., et al., Melanoma dormancy in a mouse model is linked to GILZ/FOXO3A-dependent quiescence of disseminated stem-like cells. Sci Rep, 2016. 6: p. 30405. 
103. Brychtova, S., et al., Nestin expression in cutaneous melanomas and melanocytic nevi. Journal of Cutaneous Pathology, 2007. 34(5): p. 370-5.

104. Monzani, E., et al., Melanoma contains CD133 and ABCG2 positive cells with enhanced tumourigenic potential. European journal of cancer, 2007. 43(5): p. 935-46.

105. Sharma, B.K., et al., Clonal dominance of CD133+ subset population as risk factor in tumor progression and disease recurrence of human cutaneous melanoma. Int J Oncol, 2012.

106. Boiko, A.D., et al., Human melanoma-initiating cells express neural crest nerve growth factor receptor CD271. Nature, 2010. 466(7302): p. 133-7.

107. Civenni, G., et al., Human CD271-positive melanoma stem cells associated with metastasis establish tumor heterogeneity and long-term growth. Cancer Research, 2011. 71(8): p. 3098-109.

108. Fusi, A., et al., Expression of the stem cell markers nestin and CD133 on circulating melanoma cells. J Invest Dermatol, 2011. 131(2): p. 487-94.

109. Fusi, A., et al., Expression of the stem cell marker nestin in peripheral blood of patients with melanoma. Br J Dermatol, 2010. 163(1): p. 107-14.

110. Tiwary, S. and L. Xu, FRIZZLED7 Is Required for Tumor Inititation and Metastatic Growth of Melanoma Cells. PLoS One, 2016. 11(1): p. e0147638.

111. Schatton, T., et al., Identification of cells initiating human melanomas. Nature, 2008. 451(7176): p. 345-9.

112. Ma, J., et al., Isolation of tumorigenic circulating melanoma cells. Biochem Biophys Res Commun, 2010. 402(4): p. 711-7. 


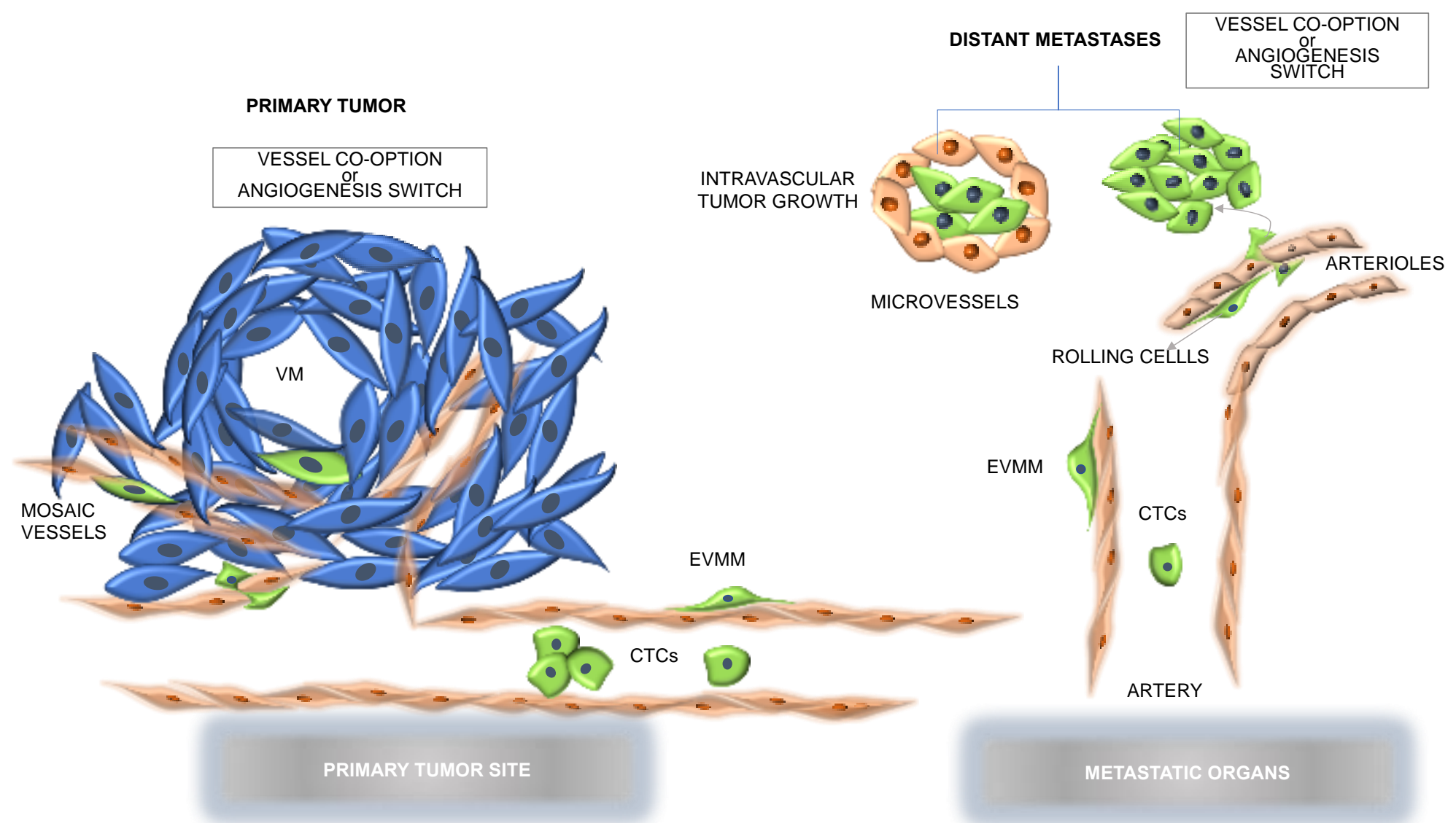


Figure 1.1 Diagram of cancer metastasis.

In primary tumors, angiogenesis, vessel co-option, VM and mosaic vessels are potential mechanisms underlying tumor vasculature. The vasculature in primary tumors not only provides oxygen and nutrients for tumor growth, but also provides a potential route for tumor dissemination. Metastatic tumor cells enter the circulation system as single CTCs or clusters through intravasation or other dissemination pathways or migrate along the abluminal vascular surfaces to nearby or distant sites as EVMM. CTCs arrest at the vascular endothelium in the metastatic organs and establish interactions with endothelial cells, roll along the endothelium to find the best sites for extravasation. Extravasated tumor cells proliferate and grow using angiogenesis or vessel co-option. EVMM is another potential source for metastases formation. Intravascular growth of metastatic cells in the microvessels with subsequent extravasation when intravascular micro-metastatic foci outgrow the vessels they are in can be another source. 


\section{PRIMARY TUMORS}

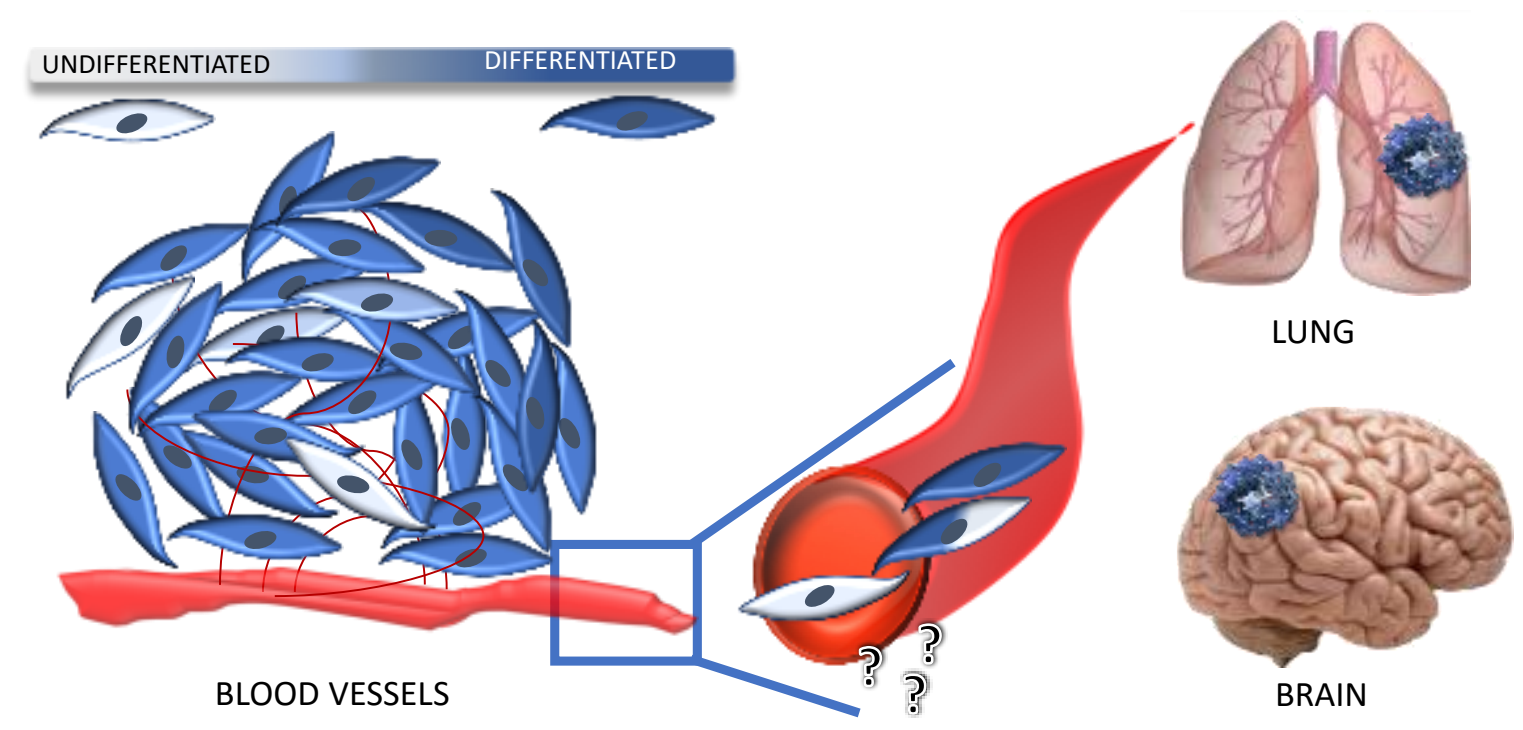

Figure 1.2 Identification of metastatic cell populations in melanoma.

Cells with varying differentiation levels are indicated by different colors in melanoma primary tumors. Certain melanoma cells can leave the primary tumor, enter the circulation system and reach the distal organs to seed metastases. The cell subpopulations that initiate melanoma distant metastases are still unclear and the phenotypic plasticity of the metastatic cell populations will be under investigation. 


\section{CHAPTER}

2. LINEAGE TRACING AND CHARACTERIZATION OF THE METASTATIC CELL POPULATION IN A MOUSE MODEL OF MELANOMA 


\subsection{Introduction}

Tumors are heterogeneous, involving not only the differences between various solid tumors but also between cell subpopulations within the same tumor. One of the important aspects of tumor heterogeneity that has recently gained increasing acceptance is the cancer stem cell model [1-3]. When it was first introduced in studies of human myeloid leukemia, it proposed that tumors are comprised of phenotypically diverse populations of cells, with only a rare, phenotypically distinct subset of cells having the capacity to significantly proliferate and form new tumors, while the bulk of cells within the tumor lose the tumorigenic capacity [4]. The cancer stem cell hypothesis has been extended to a great array of solid tumors. Using a model in which human breast cancer cells were grown in immunocompromised mice, Al-Hajj et al. showed that only a minority of breast cancer cells possessed the ability to form new tumors. Using the cell surface markers CD44+CD24-/low expression, they were able to distinguish the tumorigenic from the non-tumorigenic cancer cells within the breast cancer bulk [5]. Later, Singh et al. demonstrated that only the CD133+ brain tumor fraction contained cells capable of tumor initiation in NOD-SCID mouse brains and injection of as few as 100 CD133+ cells produced a tumor that could be serially transplanted and re-establish the heterogeneity of the parental tumor, whereas injection of $10^{5}$ CD133- cells did not produce a tumor [6]. A similar study was carried out on prostate cancer. On the basis of the high surface expression of integrin $\alpha 2 \beta 1$ and CD133, the authors reported the identification and characterization of a subset of cells from primary and metastatic prostate 
tumors that had cancer stem cell characteristics, which was also able to regenerate the phenotypically mixed populations of nonclonogenic cells [7]. In a study of human colorectal cancer, O'Brien et al. identified a human coloninitiating cell subpopulation that was able to maintain themselves as well as differentiate and reestablish tumor heterogeneity upon serial transplantation using CD133 expression [8]. Subsequently, Dalerba et al. provided a more extensive surface marker profile, which better supported the tumor heterogeneity hypothesis, highlighting the epithelial cell adhesion molecule (EpCAM), also known as epithelial-specific antigen (ESA), and CD44 as more robust markers for colorectal cancer stem cells when compared to the previously reported marker CD133 [9]. Another study using a xenograft model identified a highly tumorigenic subpopulation of pancreatic cancer cells expressing the cell surface markers CD44, CD24, and ESA [10]. Using a similar approach as that for studies on breast cancer, Prince et al. identified a subpopulation of cells with cancer stem cell properties in head and neck squamous cell carcinoma (HNSSC), which were CD44+ and typically comprised $<10 \%$ of the cells in a HNSCC tumor [11].

The cancer stem cell model has also been proposed for melanoma [12] and several melanoma stem cell markers such as Nestin [13], CD133 [14, 15], CD271(also p75NTR) $[16,17]$, and JARID1B $[18,19]$ were demonstrated to select a subpopulation of melanoma cells with a higher tumor initiating capacity. However, the cancer stem cell model remains controversial in the melanoma field and several questions are still unanswered. For example, are the cancer stem cells a constant cell population within the hierarchically organized tumor? Or 
does reversible phenotypic plasticity exist among these markers? Quintana et al. [20] pointed out that the frequency of tumorigenic melanoma cells that can be detected after xenotransplantation was highly assay-dependent. By making a series of changes in assay conditions, they increased the detectable frequency of tumorigenic melanoma cells after xenotransplantation into NOD/SCID IL2Rgnull (NSG) mice, proving that both CD133+ and CD133- fractions formed tumors that exhibited similar heterogeneity in CD133 expression. In a subsequent study [21] by the same group, neither ABCB5 nor CD271 expression defined a subpopulation of cells that had enriched tumorigenic potential since all injections formed tumors that were phenotypically similar to the parent tumors irrespective of whether the cells injected were marker positive or negative. Additionally, both CD271 + and CD271- cells formed tumors capable of metastasis. Combined, the results of Quintana et al. led them to the conclusion that tumorigenic cells appeared to undergo reversible changes in the expression of many markers in vivo. This conclusion is further supported by the study of Roesch et al. [19] demonstrating that the JARID1B phenotype was dynamic, in that JARID1Bnegative cells also gave rise to a heterogeneous progeny containing JARID1Bpositive cells, which suggested a new understanding of melanoma heterogeneity with tumor maintenance as a dynamic process mediated by a temporarily distinct subpopulation.

Overall, the two key components in the cancer stem cell scenario, the rarity and tumor initiating capacity, are still being questioned [22-24]. Xenotransplantation experiments were the basis to enrich tumorigenic cells from 
non-tumorigenic cells in most of the cancer stem cell studies. Though widely used, as human tumor cells are being processed and transplanted, they are subjected to new environmental conditions that may alter their phenotype and consequently their tumor initiating capabilities [25]. Any of the conditions, such as the enzymatic dissociation conditions for human cells, mouse injection sites, the use of immunocompromised mice, as well as the patient's stage of disease can contribute to conflicting results. Civenni et al. [16] developed a protocol to avoid trypsin during melanoma cell fraction preparation and the results obtained were compatible with those of some earlier studies. Their study provided some more convincing data given that the injected cells most likely did not lose surface marker expression because of interactions with digestive enzymes. Roesch et al. [19] compared the different effects of cell culture conditions and found that human embryonic stem cell medium better supported the survival of cells with inherent self-renewal potential when compared with conventional culture conditions. The optimized xenotransplantation assay with a more highly immunocompromised NOD/SCID IL2Rynull mice increased the detection of tumorigenic melanoma cells, demonstrating that tumorigenic cells are common in some human cancers [20]. Furthermore, certain cancer cell subpopulations were shown to have reversible drug-tolerance capacity and lose their stem cell markers during this process [26]. It is thus reasonable to speculate that the injection of cells obtained from patients that have undergone particular medical treatments may result in the generation of stem cell marker negative cells with tumorigenic capacity. 
Because of the complexity of the metastatic process and the conflicting results obtained from injection and xenotransplantation studies, I propose that the direct in vivo lineage tracing of tumorigenic cells in a spontaneous mouse model of melanoma is a more robust and powerful tool to understand how specific subpopulations of cells within a tumor acquire highly invasive properties and is responsible for the seeding of distant lesions. My study will provide significant value to the understanding of melanoma metastasis and offer new venues for therapy development of melanoma patients.

The use of lineage tracing in the cancer field has become more popular in recent years emphasizing the tracing of all progeny of one single cell. The basic foundations of lineage tracing and how data obtained from lineage tracing can be interpreted is reviewed by Blanpain and Simons with the focus on epithelial tissues [27]. Lineage tracing by genetic labeling is widely used for cell fate determination of stem and progenitor cells in the field of developmental biology, tissue maintenance and repair, and dynamics of tumor initiating capability of cancer cells. Shin and colleagues did fate mapping of Sonic hedhehog (Shh) expressing basal cells of the urothelium by lineage tracing and showed that Shh expressing cells can function as stem cells capable of generating all cell types to help maintain the epithelial integrity upon bacterial infection or chemical injury [28]. Another epithelial stem cell lineage tracing study performed in the murine small intestine showed that B lymphoma Mo-MLV insertion region 1 homolog (Bmi1)-expressing cells act as an alternative stem cell pool after the ablation of Leucine-rich repeat-containing G-protein coupled receptor 5 (Lgr5) expressing 
stem cells [29]. In vivo lineage tracing and retracing by multicolor reporter mice gave the first strong evidence that Lgr5 expressing cells are stem cells in unperturbed primary tumors on a mouse model of intestinal adenomas [30]. A more recent clonal analysis using multicolor lineage tracing system on intestinal tumors further demonstrated the cancer stem cell role of Bmi1 and Lgr5 expressing cells during tumor propagation [31]. Another good example for lineage tracing was carried out by Zhu and colleagues on high grade brain tumors [32]. This study gave direct evidence that TIx is a brain tumor stem cell marker in a mouse model using RCAS/tv-a system [33] for tumor induction and Cre/loxp system for in vivo lineage tracing. Although lineage tracing has been widely used in different fields and certain kinds of tumors, there is a substantial gap in the field of melanoma biology and little is known about the cellular origin of melanoma, especially in identification of the precursor cells of metastasis. This is most likely the result of the lack of a good metastatic melanoma mouse model that can be used together with Cre/loxp system. In contrast, lineage tracing of stromal or endothelial cells during melanoma formation is easier since melanoma tumors can be obtained through tumor engraftment and transgenic mice with stromal or endothelial cells labeled are available. A recent quantitative clonal analysis using multicolor lineage tracing by Corey et.al [34] showed that in an elaborate tumor microenvironment created by the injection of the murine melanoma cell line B16F10, blood vessels followed a pattern of dynamic clonal evolution accompanied by the loss of lymphocyte adhesion molecules favoring the immune escape of cancer cells. The establishment of an in vivo lineage 
tracing system to provide a detailed characterization of the cellular origin of melanoma metastasis is needed and will be of great significance both to the field of basic cancer research as well as to future clinical applications.

\subsection{Results}

\subsubsection{Tumor Heterogeneity Exists in Mouse Melanoma}

To demonstrate cellular tumor heterogeneity in mouse melanoma, I studied the composition of tumors from Hepatocyte Growth Factor/Scatter Factor (HGF/SF) mice [35], Dct-Grm1/ K5-Edn3 mice and Dct-Grm1/K5-Edn3/Dct-Ednrb mice with spontaneously developed or UV induced lesions. Nestin [13], CD 271 (also known as p75) $[16,17]$ were chosen as the stem cell markers and tyrosinase (TYR) or tyrosinase related protein 1 (TRP1) were used as differentiation cell markers. All the three melanoma tumors showed cellular heterogeneity with non-overlapping cell subpopulations positive for various markers (Figure 2.1).

\subsubsection{Mouse Model and Methodology Validation}

The Dct-Grm1/ K5-Edn3 mice were created in our laboratory [36, 37]. Depending on the aberrant expression of glutamate metabotropic receptor 1 in melanocytes and environmental Endothelin 3 (Edn3) expressed by keratinocytes, these mice not only spontaneously develop melanoma tumors on the ear, tail and dorsal skin, but also show metastases in the lung (Figure 2.2). Chin et al. previously showed that Edn3 signaling promotes melanoma progression in DctGrm1/ K5-Edn3 mice resulting in 80\% penetrant lung metastases compared with the Dct-Grm1 controls that have limited metastatic capability [38]. On the basis of 
the tumor heterogeneity scenario, this spontaneous mouse model of melanoma metastasis will be an ideal system to identify the intrinsic tumor initiating capacity of certain cell subpopulations within an unperturbed tumor environment. Given that the Nestin positive melanoma stem cells are rare in these tumors (Figure 2.1), the differentiated Tyr expressing cells which constitute the majority of the tumor is a better option for lineage tracing. Tyrosinase is a copper-containing enzyme that catalyzes the production of melanin and the substrates give the color of skin, hair and eyes. Tyr is expressed specifically in melanocytes, the pigment producing cells, and majority of melanoma cells.

Lineage tracing was performed using the Cre/loxp system with TYRCreER $R^{T 2} / m T / m G$ mice. Briefly, in the TYR-CreER $R^{T 2} / m T / m G$ mice, prior to Cre recombination, cell membrane-localized tdTomato $(\mathrm{mT})$ fluorescence is expressed in every single cell. After tamoxifen/4HT induction, Tyr positive Cre recombinase expressing cells (and future cell lineages derived from these cells) show cell membrane-localized GFP (mG) fluorescence expression replacing the red fluorescence (Figure 2.3A). In vivo lineage tracing of Tyr expressing cells in the primary tumors can be performed on Dct-Grm1/ K5-Edn3/ TYR-CreER ${ }^{T 2}$ / $m T / m G$ mice by topical $4 \mathrm{HT}$ application using a small painting brush on the primary tumor sites (Figure 2.3B).

The Dct-Grm1/ K5-Edn3/ TYR-CreER ${ }^{T 2 / m T / m G ~ m i c e ~ o b t a i n e d ~ f r o m ~ t h e ~}$ mating of Dct-Grm1/ K5-Edn3 melanoma mice and TYR-CreR ${ }^{T 2} / \mathrm{mT} / \mathrm{mG}$ mice spontaneously develop primary and metastatic melanomas, and Cre inducible Tyr positive cells that can be labeled with GFP making them distinguishable from 
the other red fluorescent labeled cells in the body. Because these mice were obtained through breeding of several transgenic mice, the copy numbers of transgenes essential for tumor development were dramatically diluted resulting in a considerable delay in tumor appearance when compared to what was initially reported in Chin, 2015 [38]. In Dct-Grm1/ K5-Edn3/TYR-CreERT2/ mT/mG mice, the first primary tumors appeared at an average of 7.5 month $(n=25)$, which is 2.5 month longer than previously reported for the Dct-Grm1/ K5-Edn3 mice.

To validate the topical application methodology, dorsal skin of the TYRCreER $R^{T 2} / \mathrm{mT} / \mathrm{mG}$ mice was topically painted and successful GFP labeling of melanocytes in the hair follicles was observed, while other cells in the skin retained the tdTomato red fluorescence color (Figure 2.3C). The same induction method was applied to K5-Edn3/ TYR-CreERT2/ mT/mG mice, in which accumulation of melanocytes outside the hair follicles at the dermal-epidermal junction was expected [36]. Indeed, GFP+ green cells were found outside the hair follicles (Figure 2.3D). To establish if the TYR promoter can also drive Tyr expression in melanoma tumors in Dct-Grm1/ K5-Edn3/ TYR-CreER ${ }^{T 2} / \mathrm{mT} / \mathrm{mG}$ mice, topical painting of $4 \mathrm{HT}$ was performed on the tail tumors of Dct-Grm1/ K5Edn3/ TYR-CreERT2/ mT/mG mice. A mutually exclusive pattern of GFP and tdTomato colors was found inside the tumors (Figure 2.3E).

\subsubsection{Labeling of the Tyr Expressing Cells in the Primary Tumors}

At an average of 7.5 month of age when the lesion first appeared as a nevus ( $<1 \mathrm{~mm}$ in height) on the Dct-Grm1/ K5-Edn3/TYR-CreER ${ }^{T 2} / \mathrm{mT} / \mathrm{mG}$ mice, I started $4 \mathrm{HT}$ topical administration. $4 \mathrm{HT}$ induction exclusively at an early stage 
was not sufficient to label the majority of Tyr expressing cells in the primary tumors (Figure S1). To ensure the labeling of most Tyr expressing cells in the primary tumors, $4 \mathrm{HT}$ topical administration was repeated for $3 \sim 4$ weeks during tumor growth until euthanasia. Numerous GFP+ cells were detected in cryosections of primary tumors and lung metastases (Figure 2.4). To establish if the GFP+ cells in the primary tumors expressed Tyr protein, cryosections of the tumor were prepared soon after $4 \mathrm{HT}$ application and labeled with Tyr antibody. GFP + cells were found to be positive for Tyr immunoreactivity (data not shown).

\subsubsection{Primary Tumor Derived Tyr Expressing Cells or Their Progeny Can}

\section{Reach the Lung and Seed Metastasis}

The appearance of metastases in distant organs was established 2 weeks to 7 months after the first $4 \mathrm{HT}$ painting of primary tumors. Micro-metastases, characterized as clusters of less than 10 cells, were detected in $86 \%$ of lungs examined $(n=15)$. Each lung was sectioned and at least 20 cryosections per lung were examined for the presence of primary tumor derived GFP+ cells. In $50 \%$ of 4HT painted Dct-Grm1/ K5-Edn3/TYR-CreER ${ }^{T 2} / m T / m G$ mice, GFP+ cells were identified in various areas of the lung and other organs (Table S1). The number of GFP+ cells found in the lung varied considerably, from 2 to 20 or more cells per section. In most mice, the numbers were low, except for one mouse that presented with pepper like micro-metastases and another one with macrometastases. No GFP+ cells were found in lungs of control mice (Dct-Grm1/ K5Edn3/ $m T / m G)$ that had tumors painted with $4 \mathrm{HT}(\mathrm{n}=10)$. Additionally, no GFP+ cells were detected in the lungs of mice that did not bear tumors (Dct-Grm1/K5- 
Edn3/ TYR-CreER $\left.R^{T 2} / m T / m G\right)$ and had their dorsum painted with $4 \mathrm{HT}(\mathrm{n}=3)$. The location of the primary tumor affected the penetrance of GFP+ cells in the lung of 4HT painted Dct-Grm1/ K5-Edn3/ TYR-CreERT/ mT/mG mice (Table S1). Only one out of seven mice $(1 / 7,14 \%)$ that had only tail tumors painted, in contrast to three out of four $(3 / 4,75 \%)$ mice that had only dorsal tumor painted, presented with GFP+ cells in the lung. The only mouse with a dorsal tumor that did not have GFP + cells in the lung was painted only once at the nevus stage and no obvious tumor growth was observed upon euthanasia.

The GFP+ cells were distributed into three categories depending on their location in the lungs. The first category termed "inside the vessels" includes intravascular solitary cells with an elongated and spindle shape found in close association with the endothelial layer of the lung vasculature (Figure 2.5A). Cells in this category were detected consistently, even on metastasis-free lungs, providing support to the hematogenous dissemination of metastatic cells. The second category termed "outside the vessels" consists of clusters of GFP+ cells overlapping with the pigmented metastases (Figure 2.5B) with the possibility that some may be still inside the alveolar capillaries. The rarest third category consisted of solitary or tiny clusters $(2 \sim 5)$ of cells outside the vasculature displaying no pigmentation. Immunostaining showed that the GFP+ cell populated metastatic lesions in the lung were positive for melanoma markers TYR and TRP1 (Figure 2.5C, D), indicating the tumor initiating capacity of the differentiated Tyr expressing cells or their progeny in the Dct-Grm1/ K5-Edn3/ $T Y R-C r e E R^{T 2} / m T / m G$ mice. Of note, not all metastatic lesions in the lung 
contained GFP+ cells. This finding was not unexpected given that the efficiency of the topical $4 \mathrm{HT}$ induction is not $100 \%$, and that, primary tumor resident Tyr negative cells might also metastasize.

\subsubsection{Presence of Metastatic Cells inside the Lung Vasculature}

Melanoma metastasis has been suggested as an inefficient process, during which only a small number of cells can go through all the steps for a clinically significant metastasis $[39,40]$. It has been generally thought that most metastatic cells are eliminated in the circulation [41]. In a small number of animals $(n=4)$ that were not subjected to cardiac PBS perfusion, lungs were snap frozen immediately after euthanasia. In sections of these lungs, the blood vessels were filled with blood but very few circulating GFP+ cells were found inside the lumen of the vasculature (Figure S2E). Instead, we observed large numbers of metastatic GFP+ cells associated with the pulmonary vascular endothelium or invading the lung tissue. The number of GFP+ cells "inside the vessels" far exceeded the micro- or macro-metastatic lesions "outside the vessels". To find out if GFP+ cells were proliferating, we performed Ki67 staining on the lung sections where GFP+ cells were found. Double labeled GFP and Ki67 cells were mostly confined to cell clusters "outside the vessels" (Figure 2.6E-H). In contrast, the solitary GFP+ cells "inside the vessels" were mostly Ki67 negative, although some Ki67+ cells were identified (Figure 2.6A-D). In the lungs of Dct-Grm1/ K5Edn3/TYR-CreER ${ }^{T 2} / m T / m G$ mice $(\mathrm{n}=3)$, the percentage of Ki67+ intravascular GFP+ cells was less than 1\% (Figure 2.7A). Disseminated cancer cells within the circulation are exposed to the mechanical sheer stress, as well as immune 
surveillance, which may lead to rapid cell death $[40,42]$. Most of the GFP+ cells were found inside the vasculature including the big pulmonary arteries. To determine if GFP+ cells had undergone apoptosis, we performed immunostaining with an antibody against Cleaved Caspase 3 . We were only able to detect a small number of double labeled GFP + and Cleaved Caspase $3+$ cells "inside the vessels" (Figure S3). In the lungs of Dct-Grm1/ K5-Edn3/ TYR-CreERT2/ $m T / m G$ mice $(\mathrm{n}=3)$, the percentage of Caspase $3+$ intravascular GFP + cells was less than 3\% (Figure 2.7B).

\subsubsection{Presence of Perivascular Cellular Infiltrates in Metastatic Lungs}

The detailed examination of lung cryosections of Dct-Grm1/ K5-Edn3/ $T Y R-C r e E R^{T 2} / m T / m G$ mice where GFP+ cells were found, indicated the presence of perivascular infiltrates in close proximity to the GFP+ cells. Notably, the infiltrates were more obvious in lungs with micro-metastases $(n=5)$ compared with that with macro-metastases $(n=2)$. Hematoxylin-eosin (H\&E) staining showed abnormal aggregates of cells surrounding the pulmonary vasculature, among which brown pigmented macrophages were noticed (Figure 2.8A, B). Small to no infiltrates were observed in GFP+ cell-free lungs. Fluorescence immunostaining of the lung cryosections showed that the infiltrates were mostly composed of CD45+ lymphocytes (Figure 2.8C), including CD3 positive T cells (Figure 2.8D). Most cells within the infiltrates showed high levels of proliferation as demonstrated by Ki67 immunoreactivity (Figure S4), suggesting the activation of an immune response to the arrival of GFP+ metastatic cancer cells inside the vasculature. These abnormal perivascular infiltrates found in lungs containing 
foreign GFP+ cells may add another explanation for the dormancy of intravascular cancer cells.

\subsubsection{GFP+ cells Lose Pigmentation upon Contact with Vascular Endothelium}

In order to detect any changes in the differentiation status of metastatic cells, the pigmentation level of GFP+ cells was monitored as cells traveled from the primary tumor to the lungs. At the primary tumor site, tissues deep underneath the skin tumors containing blood vessels were collected and sectioned. GFP+ cells were identified both inside and outside the vasculature and interestingly, GFP+ cells inside the vasculature were not pigmented (Figure 2.9A, D, arrowhead) while GFP+ cells outside the vasculature were pigmented (Figure 2.9A, D, arrow). This same dynamic pattern of pigmentation levels was observed in the lung. Intravascular GFP+ cells in the lung vasculature were not pigmented (Figure 2.9B, E, arrowhead), but resumed pigmentation production while populating the lung metastases (Figure 2.9C, F, arrow).

\subsubsection{Characterization of Metastatic GFP+ Cells Inside Pulmonary Vasculature}

Given the loss of pigmentation by GFP+ cells as they entered the vasculature, further characterization was necessary to establish their level of differentiation. Immunostaining was performed on the lung cryosections with the neural crest specific marker SOX10 (Figure 2.10A-D) and differentiated melanocyte markers TYR and TRP1 (Figure 2. 10E-L). The GFP+ cells were negative for all of them. The testing of other melanocytic lineage markers such as 
MITF and TRP2 also yielded negative results (data not shown). Based on the stem cell model, it is possible that the differentiated Tyr expressing cells or their progeny de-differentiated and transiently acquired stem cell properties. In previous studies, P75 and Nestin were shown to selectively label melanoma tumor initiating cells $[13,16,17]$. As such, we performed immunostaining with P75 and Nestin on the lung cryosections where GFP+ cells were found, and the results were also negative (Figure $2.10 \mathrm{M}-\mathrm{T}$ ). All fluorescence immunostaining was done with a positive control to validate the indicated antibodies used, and the staining results are representative of at least five mice.

\subsubsection{Primary Tumor Derived Tyr Expressing Cells or Their Progeny Can Reach other organs and Seed Metastasis}

Regional lymph node metastasis is regarded as an indicator of metastasis for many malignancies, including melanoma [43]. Although organ preferences of melanoma metastasis are observed, they can spread widely in the body. Most Dct-Grm1/ K5-Edn3/ TYR-CreER ${ }^{T 2} / \mathrm{mT} / \mathrm{mG}$ mice with tumors showed enlarged and hyperpigmented lymph nodes. Cervical lymph nodes were collected from $4 \mathrm{HT}$ painted mice and examined for GFP+ cells. Fifty eight percent (7/12) of the mice with the presence of GFP+ cells in the lung also presented with GFP+ cells in the lymph nodes (Table S1 and Figure 2.11). The enlarged lymph nodes of Dct-Grm1/ K5-Edn3/ TYR-CreER ${ }^{T 2 / ~} \mathrm{mT} / \mathrm{mG}$ mice were rich with vessels (blood/lymphatic). The staining pattern of TYR in lymph nodes occupied by GFP+ cells was different from that in the lung. The GFP+ cells in lymph nodes were more heterogeneous, both TYR+ (Figure 2.11, arrowhead) and TYR- (Figure 
2.11, arrow) GFP+ cells were found. Additionally, TYR+ cells that were not GFP+ were also observed (Figure 2.11, star) indicating either the insufficiency of $4 \mathrm{HT}$ topical induction or the presence of non-Tyr expressing cell subpopulations.

The most common sites of visceral metastases in the Dct-Grm1/ K5-Edn3/ TYR-CreERT2/ mT/mG mice were lungs, with only one mouse (1/15) showing evident kidney and spleen metastases. The GFP+ cells were found inside the metastatic foci of the kidney and spleen (Figure S2F-I), further demonstrating the tumor initiating potential of the primary tumor derived Tyr expressing cells or their progeny.

The Dct-Grm1/ K5-Edn3/ TYR-CreER T2/ $m T / m G$ mice spontaneously develop multiple melanocytic tumors on the skin, all of which were presumed as primary tumors. However, it is plausible that cells from the first dorsal/tail tumor spread and seeded the secondary dorsal/tail tumor at different sites of the dorsum/tail. In three Dct-Grm1/K5-Edn3/TYR-CreER $R^{T 2} / m T / m G$ mice, the dorsal tumors and only one tail tumor were subjected to topical $4 \mathrm{HT}$ painting. One tumor per mouse that appeared later and was not painted was checked for the presence of GFP+ cells. Interestingly, non-painted tumors from the three mice were mainly constituted by GFP+ cells (Figure S5). To exclude the inappropriate spread of $4 \mathrm{HT}$ from grooming behavior, the non-painted tumors examined were chosen as far as possible from the painted ones, for example, a non-painted tail tumor proximal to the body vs. a painted tail tumor distal to the body; a nonpainted dorsal tumor on top of right hind leg vs. a painted dorsal tumor on left flank. Although we could not establish whether the tumorigenic GFP+ cells giving 
rise to the non-painted tumor were dorsal tumor-derived or tail tumor-derived, the result presented here further proved the tumor initiating capacity of Tyr expressing melanoma cells or their progeny.

\subsubsection{Metastatic Melanoma Cells Disseminate Early during}

\section{Melanomagenesis}

Late recurrence is fatal and has been shown clinically in melanoma patients who have gone through primary tumor resection at early diagnosis. Although greater than $85 \%$ cutaneous melanoma patients can be cured after the removal of the primary tumors, a small number of patients may show recurrence as late as $15-20$ years [44]. This not only indicates the existence of metastasis dormancy but also suggests that metastatic melanoma cells may disseminate into the circulation system much earlier than previously expected. To test this, we grouped the Dct-Grm1/K5-Edn3/TYR-CreER $R^{T 2} \mathrm{mT} / \mathrm{mG}$ mice into three stages, before nevus stage ( $n=3$, no noticeable nevus or tumor was observed), nevus stage $(n=3,<1 \mathrm{~mm}$ in height) and tumor stage $(n=3)$. We painted $4 \mathrm{HT}$ on the nevus or tumor as described previously. For the before nevus stage group, painting of $4 \mathrm{HT}$ was performed $3-4 \mathrm{~cm}$ from the end of the tail. The tails with the painted area were collected and sections containing blood vessels were analyzed for the presence of GFP+ cells. The GFP+ cells were found inside the tail vasculature at all three stages (Figure 2.12). The results indicate that tumorigenic cells acquire and maintain the ability to enter the circulation at all times during the process of tumorigenesis, even prior to the formation of a sizable tumor. 


\subsection{Discussion}

Melanoma, the deadliest type of skin cancer, still imposes a great challenge for therapy because of its highly aggressive nature to metastasize to distant organs. As an important step of preclinical research, some melanoma murine models have been developed, including xenograft, syngeneic, and genetically engineered models, to help understand the mechanisms of melanoma progression or develop promising therapies to melanoma patients. It is generally believed that genetically engineered models are better options compared with xenograft or syngeneic models in regard to anticancer drug assessment [45]. Among the genetically engineered melanoma mouse models that have been developed, some require extra carcinogens to induce melanoma, such as UV exposure, which adds to the cost and labor-intensive interbreeding of multiple mouse strains. More important, few of the genetically engineered melanoma mouse models were reported to develop visceral metastases, which limits the study of melanoma metastasis. Of the several melanoma mouse models that show distant metastasis, some of them already employed Cre/loxp to induce tumors, preventing us from using the Cre/loxp system for lineage tracing [46, 47].

The Dct-Grm1/ K5-Edn3 mice, to our knowledge, is the first spontaneous melanoma metastasis mouse model that is free of oncogenes and dependent exclusively on the presence of signaling pathways. The tumor metastasis process of these mice closely resembles that in human melanoma patients given

the variability in time to tumor and appearance of metastasis. Although the DctGrm1/ K5-Edn3 mice provide us with an optimum system for lineage tracing of 
metastatic cells within an unperturbed tumor environment, the number of samples that can be obtained within a reasonable amount of time is limited. In the Dct-Grm1/K5-Edn3/TYR-CreER $R^{T 2} / \mathrm{mT} / \mathrm{mG}$ mice where lung metastases are identified, the terminal fate of those labeled cells in the secondary organ can be determined and perhaps more interesting, the dynamic changes in genotype and phenotype during the metastatic process can also be investigated.

To spatially restrict Cre induction within the primary tumors, we topically applied 4HT on the tumors instead of systemic administration. 4hydroxytamoxifen topical application has been successfully used in other studies for site specific Cre induction [48-50]. The fact that GFP+ cells were absent in some lungs with pigmented metastases attests to the spatial restriction of Cre induction, given that all melanocytic lesions should be labeled with GFP if systemic administration of $4 \mathrm{HT}$ through blood happened. In addition, the absence of GFP + cells in some pigmented lesions, but not others, in the same lung further excluded the possibility of $4 \mathrm{HT}$ systemic administration. In other words, GFP+ cells found in the lung can only be derived from the dorsal/tail tumor that were 4HT painted. Although labeling of Tyr expressing cells may not be $100 \%$ efficient, this should not constitute a problem for this study considering the abundance of differentiated cells in the melanoma lesions. It is important to bear in mind that cancer is complex and dynamic. As tumors grow, they may recruit more melanocytes located in the dermal-epidermal junction, and it is also possible that stroma cells transdifferentiate into Tyr expressing melanocytes as it was shown 
that a combination of three factors, MITF, SOX10 and PAX3, were sufficient to convert mouse and human fibroblasts to functional melanocytes in vitro [51].

The heterogeneity of tumors including melanoma has been recognized for decades pointing to the varied tumor initiating capacities of cell subpopulations within the solid tumors [52]. While some studies have confirmed that cells that express melanoma stem cell markers have tumor initiating capacity, they have mostly focused on primary tumor formation not metastasis. The robustness of the stem cell markers used in these studies is also controversial based on the use of xenotransplantion assays [13-17]. Here, using Cre/loxp system, we genetically labeled Tyr expressing cells within the primary tumors in the Dct-Grm1/K5-Edn3/ $T Y R-C r e E R^{T 2} / m T / m G$ mice and tracked the fate of the labeled cells by lineage tracing. We demonstrated that the more differentiated Tyr expressing cells can also be the progenitors of tumor initiating cells and seed distant metastases in various organs successfully in mice. However, what we have shown does not refute entirely the stem cell scenario in that gene expression profiles are dynamic, and it is possible that GFP+ cells de-differentiated to a more stem cell-like state after the labeling. This is also supported by the fact that GFP+ cells lost their pigmentation, as well as melanocytic lineage markers while in contact with the vascular endothelium, but, regained those features after seeding metastases. The fact that tumor cells are plastic increases the complexity of the melanomagenesis process, suggesting that the tumor initiating potential of melanoma cells may be underestimated and the spatial and timing elements 
should be considered when a melanoma stem cell marker is defined or characterized.

Metastasis disease is the primary cause of death in cancer patients. Although prolonged survival occurs as a result of the development of newr therapies and better understanding of the metastatic mechanism, the early diagnosis of cancer metastases has always been a challenge. In general, human tumor metastasis consists of a series of biological processes including: metastatic cells leave the primary tumor, invade into surrounding tissues and enter the blood or lymphatic vessels, travel through the circulatory system, arrest at the distant organs and finally seed successful metastases [53, 54]. Most studies on melanoma metastasis were either focused on the first stage (primary tumors) or the last stage (metastatic tumors). Gene microarray data from different stages of melanoma progression were analyzed and shed light on the mechanism of metastasis [55-58]. Metastatic tumor cells in circulation have been long recognized, and CTCs in the blood stream have been successfully isolated from human blood [59-61]. An FDA approved detection system, Cellsearch, is available for the isolation of CTCs and has been successfully used for monitoring patients with metastatic breast, prostate and colon cancers [62]. Nonetheless, no consensus has been reached regarding melanoma CTCs because of sample scarcity, cohort heterogeneity, and the application of Cellsearch on melanoma patients seems not sensitive enough and needs further investigations [63]. The development of real-time imaging techniques, such as non-invasive methods or intravital microscopy, make it possible to study the dynamic process of cancer 
metastasis [64-66], including melanoma [67, 68]. However, real time imaging cannot investigate the genetic diversity of the metastatic tumor cells, and most in vivo real time imaging has been based on cell injection, xenograft or syngeneic transplantations, bypassing the complexity of endogenous tumor-host interactions. In our study the use of a spontaneous melanoma mouse model depending on GRM1 and Edn3 signaling pathways allowed us to characterize the dynamic gene expression profiles of metastatic cells in relationship to their spatial distribution during the journey from primary tumor sites to secondary organs and represents a tremendous advantage in understanding mechanisms associated with melanoma metastasis.

It is noteworthy that the better studied CTCs are not necessarily the contributors of metastases or recurrence, instead, disseminating cells that survive after infiltrating distant organs, may be more dangerous since they can be dormant anywhere as invisible, undetectable solitary or cluster of cells. Studies about metastatic dormancy on a variety of cancers have been increasing [62, 64, 69], but little attention has been paid to metastatic dormancy of melanoma. During the discussion between members of the Melanoma Research Foundation (MRF) Scientific Advisory Council and Breakthrough Consortium in 2015, Merlino et al. highlighted melanoma dormancy as one of the four thematic areas and raised the issue that study of melanoma dormancy lagged significantly behind that of breast and prostate cancers and research about this area was required [70]. 
Although it has been proposed that metastatic dormancy of melanoma can be established directly at the target organ [70], in vivo evidence is missing. The best studied location of metastatic dormancy in cancers is the bone marrow [7173], as has been shown in the only melanoma dormancy study with the Ret transgenic mouse model [74]. The data presented in this study suggested that the vascular endothelium in the target organ can act as a potential reservoir for metastatic melanoma cell dormancy. We found that the primary tumor derived metastatic melanoma cells associated with the pulmonary vascular endothelium did not proliferate or undergo apoptosis, recapitulating the state of metastatic dormancy. As a consequence of the limitation of our model, identification of the fate of each individual cell is impossible, as such, we cannot conclude that the dormant melanoma cells inside the pulmonary vasculature are the ones that exit and seed the overt metastases after reactivation. The CTCs may also be possible contributors [75].

Late recurrence of melanoma has been reported, and the recurrence site is commonly the lungs [76]. If the presence of putative dormant metastatic cells in the vasculature of the lung also occurs in human patients, stopping therapies in patients who are thought to be disease free may have dire consequences. The mechanism used by disseminated tumor cells to survive in immunocompetent individuals for an extended period of time is one of the biggest conundrums in tumor immunology. A possible explanation is what has been called tumor immunoediting: genetically and epigenetically unstable tumor cells can adapt to immune attack by either down regulating tumor associated antigens or shutting 
down death signaling pathways [77]. The loss of the melanocytic/melanoma markers by the GFP+ cells may represent this concept of immunoediting. Although viable, the outgrowth of the dormant tumor cells is restrained by the adaptive immunity. Koebel et al. called this process "equilibrium" and they provided evidence that tumor cells in equilibrium were highly immunogenic whereas the outgrowing tumor cells were not [78]. This is in line with the results obtained with the Ret transgenic mouse model where it was shown that bone marrow melanoma-specific memory $\mathrm{T}$ Cells were detectable and functionally active in tumor free mice [74] and that CD8+ T cells could delay the visceral metastases in the mice $[79,80]$. Stronger evidence of the tumor-immune "equilibrium" can be obtained from clinical reports of donor derived melanoma through transplantation surgeries [81-84]. In our study, the fact that lymphocytes in the perivascular infiltrates were found in the lungs where dormant melanoma cells were identified but not obvious in lungs with full-blown metastases can be explained by the immune equilibrium. Yet, further investigation is needed to elucidate the mechanisms underlying the interplay between immune cells and dormant metastatic cells.

Early dissemination of abnormal cells has been detected in murine models of various cancers [85-89]. Numerous cases of patients with metastatic melanoma free of detectable primary tumors have been reported clinically [90-95]. The presence of GFP+ cells inside the vasculature at all stages during the process of tumorigenesis, even prior to the formation of a sizable tumor indicated the early dissemination of melanocytes. Although there is a high chance that 
these intravascular GFP+ cells disseminating early into tail vasculature are just dormant and not fully malignant, this still constitutes strong evidence that prospective metastatic melanoma cells may enter the circulation system before the formation of primary tumors. The study showing untransformed mouse mammary cells in the circulation could acquire malignant growth upon oncogene activation further argued the possibility that untransformed cells that disseminated early could account for the later metastases [87].

\subsection{References}

1. Reya, T., et al., Stem cells, cancer, and cancer stem cells. Nature, 2001. 414(6859): p. 105-11.

2. Shackleton, M., et al., Heterogeneity in cancer: cancer stem cells versus clonal evolution. Cell, 2009. 138(5): p. 822-9.

3. Dalerba, P., R.W. Cho, and M.F. Clarke, Cancer stem cells: models and concepts. Annu Rev Med, 2007. 58: p. 267-84.

4. Hope, K.J., L. Jin, and J.E. Dick, Acute myeloid leukemia originates from a hierarchy of leukemic stem cell classes that differ in self-renewal capacity. Nat Immunol, 2004. 5(7): p. 738-43.

5. Al-Hajj, M., From the Cover: Prospective identification of tumorigenic breast cancer cells. Proceedings of the National Academy of Sciences, 2003. 100(7): p. 3983-3988.

6. Singh, S.K., et al., Identification of a cancer stem cell in human brain tumors. Cancer Res, 2003. 63(18): p. 5821-8.

7. Collins, A.T., et al., Prospective identification of tumorigenic prostate cancer stem cells. Cancer Research, 2005. 65(23): p. 10946-51.

8. O'Brien, C.A., et al., A human colon cancer cell capable of initiating tumour growth in immunodeficient mice. Nature, 2006. 445(7123): p. 106110.

9. Dalerba, P., et al., Phenotypic characterization of human colorectal cancer stem cells. Proceedings of the National Academy of Sciences, 2007. 104(24): p. 10158-10163. 
10. Li, C., et al., Identification of pancreatic cancer stem cells. Cancer Research, 2007. 67(3): p. 1030-7.

11. Prince, M.E., et al., Identification of a subpopulation of cells with cancer stem cell properties in head and neck squamous cell carcinoma. Proceedings of the National Academy of Sciences, 2007. 104(3): p. 973978.

12. Regenbrecht, C., et al., Cancer stem cells in melanoma. Ecancermedicalscience, 2008. 2: p. 114.

13. Brychtova, S., et al., Nestin expression in cutaneous melanomas and melanocytic nevi. Journal of Cutaneous Pathology, 2007. 34(5): p. 370-5.

14. Monzani, E., et al., Melanoma contains CD133 and ABCG2 positive cells with enhanced tumourigenic potential. European journal of cancer, 2007. 43(5): p. 935-46.

15. Sharma, B.K., et al., Clonal dominance of CD133+ subset population as risk factor in tumor progression and disease recurrence of human cutaneous melanoma. Int J Oncol, 2012.

16. Civenni, G., et al., Human CD271-positive melanoma stem cells associated with metastasis establish tumor heterogeneity and long-term growth. Cancer Research, 2011. 71(8): p. 3098-109.

17. Boiko, A.D., et al., Human melanoma-initiating cells express neural crest nerve growth factor receptor CD271. Nature, 2010. 466(7302): p. 133-7.

18. Radberger, P., et al., JARID1B protein expression and prognostic implications in uveal melanoma. Invest Ophthalmol Vis Sci, 2012. 53(8): $p$. $4442-9$.

19. Roesch, A., et al., A temporarily distinct subpopulation of slow-cycling melanoma cells is required for continuous tumor growth. Cell, 2010. 141(4): p. 583-94.

20. Quintana, E., et al., Efficient tumour formation by single human melanoma cells. Nature, 2008. 456(7222): p. 593-598.

21. Quintana, E., et al., Phenotypic Heterogeneity among Tumorigenic Melanoma Cells from Patients that Is Reversible and Not Hierarchically Organized. Cancer Cell, 2010. 18(5): p. 510-523.

22. Adams, J.M. and A. Strasser, Is tumor growth sustained by rare cancer stem cells or dominant clones? Cancer Res, 2008. 68(11): p. 4018-21. 
23. Kelly, P.N., et al., Tumor growth need not be driven by rare cancer stem cells. Science, 2007. 317(5836): p. 337.

24. Zhong, Y., et al., Cancer stem cells sustaining the growth of mouse melanoma are not rare. Cancer Lett, 2010. 292(1): p. 17-23.

25. Baker, M., Melanoma in mice casts doubt on scarcity of cancer stem cells. Nature, 2008. 456(7222): p. 553.

26. Sharma, S.V., et al., A chromatin-mediated reversible drug-tolerant state in cancer cell subpopulations. Cell, 2010. 141(1): p. 69-80.

27. Blanpain, C. and B.D. Simons, Unravelling stem cell dynamics by lineage tracing. Nat Rev Mol Cell Biol, 2013. 14(8): p. 489-502.

28. Shin, K., et al., Hedgehog/Wnt feedback supports regenerative proliferation of epithelial stem cells in bladder. Nature, 2011. 472(7341): $p$. 110-4.

29. Tian, $\mathrm{H}$., et al., A reserve stem cell population in small intestine renders Lgr5-positive cells dispensable. Nature, 2011. 478(7368): p. 255-9.

30. Schepers, A.G., et al., Lineage tracing reveals Lgr5+ stem cell activity in mouse intestinal adenomas. Science, 2012. 337(6095): p. 730-5.

31. Yanai, H., et al., Intestinal cancer stem cells marked by Bmi1 or Lgr5 expression contribute to tumor propagation via clonal expansion. Sci Rep, 2017. 7: p. 41838.

32. Zhu, Z., et al., Targeting self-renewal in high-grade brain tumors leads to loss of brain tumor stem cells and prolonged survival. Cell Stem Cell, 2014. 15(2): p. 185-98.

33. Federspiel, M.J., et al., A system for tissue-specific gene targeting: transgenic mice susceptible to subgroup $A$ avian leukosis virus-based retroviral vectors. Proc Natl Acad Sci U S A, 1994. 91(23): p. 11241-5.

34. Corey, D.M., Y. Rinkevich, and I.L. Weissman, Dynamic Patterns of Clonal Evolution in Tumor Vasculature Underlie Alterations in LymphocyteEndothelial Recognition to Foster Tumor Immune Escape. Cancer Res, 2016. 76(6): p. 1348-53.

35. Noonan, F.P., et al., Animal models of melanoma: an HGF/SF transgenic mouse model may facilitate experimental access to UV initiating events. Pigment Cell Res, 2003. 16(1): p. 16-25. 
36. Garcia, R.J., et al., Endothelin 3 induces skin pigmentation in a keratindriven inducible mouse model. J Invest Dermatol, 2008. 128(1): p. 131-42.

37. Pollock, P.M., et al., Melanoma mouse model implicates metabotropic glutamate signaling in melanocytic neoplasia. Nat Genet, 2003. 34(1): p. 108-12.

38. Chin, N., The Role of Endothelin 3 in Melanoma Progression and Metastasis. FIU Electronic Theses and Dissertations, 2015. 2286.

39. Cameron, M.D., et al., Temporal progression of metastasis in lung: cell survival, dormancy, and location dependence of metastatic inefficiency. Cancer Res, 2000. 60(9): p. 2541-6.

40. Luzzi, K.J., et al., Multistep nature of metastatic inefficiency: dormancy of solitary cells after successful extravasation and limited survival of early micrometastases. Am J Pathol, 1998. 153(3): p. 865-73.

41. Fidler, I.J., Metastasis: quantitative analysis of distribution and fate of tumor emboli labeled with 125 I-5-iodo-2'-deoxyuridine. J Natl Cancer Inst, 1970. 45(4): p. 773-82.

42. Sosa, M.S., P. Bragado, and J.A. Aguirre-Ghiso, Mechanisms of disseminated cancer cell dormancy: an awakening field. Nat Rev Cancer, 2014. 14(9): p. 611-22.

43. Thompson, J.F., et al., Sentinel lymph node status as an indicator of the presence of metastatic melanoma in regional lymph nodes. Melanoma Res, 1995. 5(4): p. 255-60.

44. Ossowski, L. and J.A. Aguirre-Ghiso, Dormancy of metastatic melanoma. Pigment Cell Melanoma Res, 2010. 23(1): p. 41-56.

45. Combest, A.J., et al., Genetically engineered cancer models, but not xenografts, faithfully predict anticancer drug exposure in melanoma tumors. Oncologist, 2012. 17(10): p. 1303-16.

46. Kuzu, O.F., et al., Current State of Animal (Mouse) Modeling in Melanoma Research. Cancer Growth Metastasis, 2015. 8(Suppl 1): p. 81-94.

47. Walker, G.J., et al., Modelling melanoma in mice. Pigment Cell Melanoma Res, 2011. 24(6): p. 1158-76.

48. Dankort, D., et al., Braf(V600E) cooperates with Pten loss to induce metastatic melanoma. Nat Genet, 2009. 41(5): p. 544-52. 
49. Marsh Durban, V., et al., Differential AKT dependency displayed by mouse models of BRAFV600E-initiated melanoma. J Clin Invest, 2013. 123(12): p. 5104-18.

50. Scortegagna, M., et al., Genetic inactivation or pharmacological inhibition of Pdk1 delays development and inhibits metastasis of Braf(V600E)::Pten(-/-) melanoma. Oncogene, 2014. 33(34): p. 4330-9.

51. Yang, R., et al., Direct conversion of mouse and human fibroblasts to functional melanocytes by defined factors. Nat Commun, 2014. 5: p. 5807.

52. Reya, T., et al., Stem cells, cancer, and cancer stem cells. Nature, 2001. 414(6859): p. 105-111.

53. Steeg, P.S., Tumor metastasis: mechanistic insights and clinical challenges. Nat Med, 2006. 12(8): p. 895-904.

54. Talmadge, J.E. and I.J. Fidler, AACR centennial series: the biology of cancer metastasis: historical perspective. Cancer Res, 2010. 70(14): p. 5649-69.

55. Scott, K.L., et al., Proinvasion metastasis drivers in early-stage melanoma are oncogenes. Cancer Cell, 2011. 20(1): p. 92-103.

56. $\mathrm{Xu}, \mathrm{L}$. , et al., Gene expression changes in an animal melanoma model correlate with aggressiveness of human melanoma metastases. Mol Cancer Res, 2008. 6(5): p. 760-9.

57. Smith, A.P., K. Hoek, and D. Becker, Whole-genome expression profiling of the melanoma progression pathway reveals marked molecular differences between nevi/melanoma in situ and advanced-stage melanomas. Cancer Biol Ther, 2005. 4(9): p. 1018-29.

58. Hoek, K., et al., Expression profiling reveals novel pathways in the transformation of melanocytes to melanomas. Cancer Res, 2004. 64(15): p. $5270-82$.

59. Chudasama, D., et al., Detection of Circulating Tumour Cells and Survival of Patients with Non-small Cell Lung Cancer. Anticancer Res, 2017. 37(1): p. $169-173$.

60. Qi, Y. and W. Wang, Clinical significance of circulating tumor cells in squamous cell lung cancer patients. Cancer Biomark, 2017. 18(2): p. 161167. 
61. Cheng, M., et al., Circulating tumor cells are associated with bone metastasis of lung cancer. Asian Pac J Cancer Prev, 2014. 15(15): p. 6369-74.

62. van der Toom, E.E., J.E. Verdone, and K.J. Pienta, Disseminated tumor cells and dormancy in prostate cancer metastasis. Curr Opin Biotechnol, 2016. 40: p. 9-15.

63. Steen, S., et al., Circulating tumor cells in melanoma: a review of the literature and description of a novel technique. Proc (Bayl Univ Med Cent), 2008. 21(2): p. 127-32.

64. Kienast, Y., et al., Real-time imaging reveals the single steps of brain metastasis formation. Nat Med, 2010. 16(1): p. 116-22.

65. Christensen, J., D. Vonwil, and V.P. Shastri, Non-Invasive In Vivo Imaging and Quantification of Tumor Growth and Metastasis in Rats Using Cells Expressing Far-Red Fluorescence Protein. PLoS One, 2015. 10(7): p. e0132725.

66. Ellenbroek, S.I. and J. van Rheenen, Imaging hallmarks of cancer in living mice. Nat Rev Cancer, 2014. 14(6): p. 406-18.

67. Tang, Q., et al., Imaging tumour cell heterogeneity following cell transplantation into optically clear immune-deficient zebrafish. Nat Commun, 2016. 7: p. 10358.

68. Headley, M.B., et al., Visualization of immediate immune responses to pioneer metastatic cells in the lung. Nature, 2016. 531(7595): p. 513-7.

69. Ghajar, C.M., et al., The perivascular niche regulates breast tumour dormancy. Nat Cell Biol, 2013. 15(7): p. 807-17.

70. Merlino, G., et al., The state of melanoma: challenges and opportunities. Pigment Cell Melanoma Res, 2016. 29(4): p. 404-16.

71. Payne, R.E., et al., The presence of disseminated tumour cells in the bone marrow is inversely related to circulating free DNA in plasma in breast cancer dormancy. Br J Cancer, 2012. 106(2): p. 375-82.

72. Rameshwar, P., Breast cancer cell dormancy in bone marrow: potential therapeutic targets within the marrow microenvironment. Expert Rev Anticancer Ther, 2010. 10(2): p. 129-32.

73. Walker, N.D., et al., The bone marrow niche in support of breast cancer dormancy. Cancer Lett, 2016. 380(1): p. 263-71. 
74. Umansky, V., et al., Melanoma-specific memory $T$ cells are functionally active in Ret transgenic mice without macroscopic tumors. Cancer Res, 2008. 68(22): p. 9451-8.

75. Massague, J. and A.C. Obenauf, Metastatic colonization by circulating tumour cells. Nature, 2016. 529(7586): p. 298-306.

76. Tsao, H., A.B. Cosimi, and A.J. Sober, Ultra-late recurrence (15 years or longer) of cutaneous melanoma. Cancer, 1997. 79(12): p. 2361-70.

77. Smyth, M.J., G.P. Dunn, and R.D. Schreiber, Cancer immunosurveillance and immunoediting: the roles of immunity in suppressing tumor development and shaping tumor immunogenicity. Adv Immunol, 2006. 90: p. 1-50.

78. Koebel, C.M., et al., Adaptive immunity maintains occult cancer in an equilibrium state. Nature, 2007. 450(7171): p. 903-7.

79. Lengagne, R., et al., Spontaneous vitiligo in an animal model for human melanoma: role of tumor-specific CD8+ T cells. Cancer Res, 2004. 64(4): p. $1496-501$.

80. Lengagne, R., et al., Distinct role for CD8 T cells toward cutaneous tumors and visceral metastases. J Immunol, 2008. 180(1): p. 130-7.

81. Penn, I., Malignant melanoma in organ allograft recipients. Transplantation, 1996. 61(2): p. 274-8.

82. Elder, G.J., P. Hersey, and P. Branley, Remission of transplanted melanoma--clinical course and tumour cell characterisation. Clin Transplant, 1997. 11(6): p. 565-8.

83. Suranyi, M.G., et al., Advanced donor-origin melanoma in a renal transplant recipient: immunotherapy, cure, and retransplantation. Transplantation, 1998. 66(5): p. 655-61.

84. MacKie, R.M., R. Reid, and B. Junor, Fatal melanoma transferred in a donated kidney 16 years after melanoma surgery. N Engl J Med, 2003. 348(6): p. 567-8.

85. Husemann, Y., et al., Systemic spread is an early step in breast cancer. Cancer Cell, 2008. 13(1): p. 58-68.

86. Weng, D., et al., Metastasis is an early event in mouse mammary carcinomas and is associated with cells bearing stem cell markers. Breast Cancer Res, 2012. 14(1): p. R18. 
87. Podsypanina, K., et al., Seeding and propagation of untransformed mouse mammary cells in the lung. Science, 2008. 321(5897): p. 1841-4.

88. Eyles, J., et al., Tumor cells disseminate early, but immunosurveillance limits metastatic outgrowth, in a mouse model of melanoma. J Clin Invest, 2010. 120(6): p. 2030-9.

89. Rhim, A.D., et al., EMT and dissemination precede pancreatic tumor formation. Cell, 2012. 148(1-2): p. 349-61.

90. Dasgupta, T. and R. Brasfield, METASTATIC MELANOMA. A CLINICOPATHOLOGICAL STUDY. Cancer, 1964. 17: p. 1323-39.

91. Giuliano, A.E., H.S. Moseley, and D.L. Morton, Clinical aspects of unknown primary melanoma. Ann Surg, 1980. 191(1): p. 98-104.

92. Panagopoulos, E. and D. Murray, Metastatic malignant melanoma of unknown primary origin: a study of 30 cases. J Surg Oncol, 1983. 23(1): $p$. 8-10.

93. Reintgen, D.S., et al., Metastatic malignant melanoma with an unknown primary. Surg Gynecol Obstet, 1983. 156(3): p. 335-40.

94. Reddy, P., C. Walker, and B. Afonso, A rare case of metastatic malignant melanoma to the colon from an unknown primary. Case Rep Gastrointest Med, 2014. 2014: p. 312902.

95. Shenoy, A.S., et al., Metastatic malignant melanoma in a young adult with unknown primary. Indian J Cancer, 2015. 52(3): p. 446-7. 


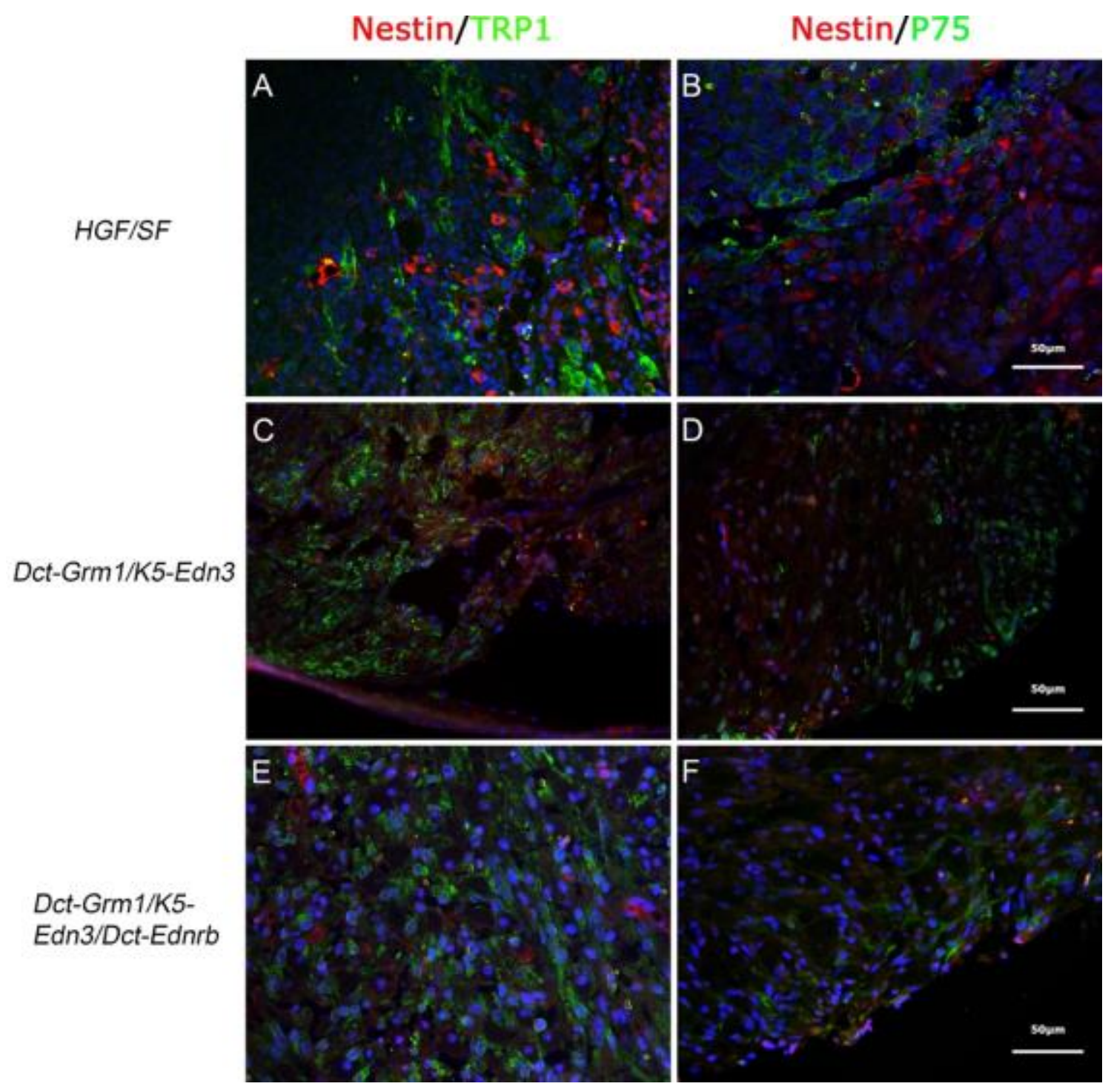

Figure 2.1 Heterogeneity of melanomas from different transgenic mice.

A and B, HGF/SF mouse; $\mathrm{C}$ and D, Dct-Grm1/K5-Edn3 mouse; E and F, DctGrm1/K5-Edn3/Dct-Ednrb mouse. A, C and E indicate Nestin and TRP1 immunostaining of paraffin-sections. B, D and F indicate Nestin and P75 immunostaining of paraffin-sections. Note the distinct cell subpopulations in the same solid tumor. 


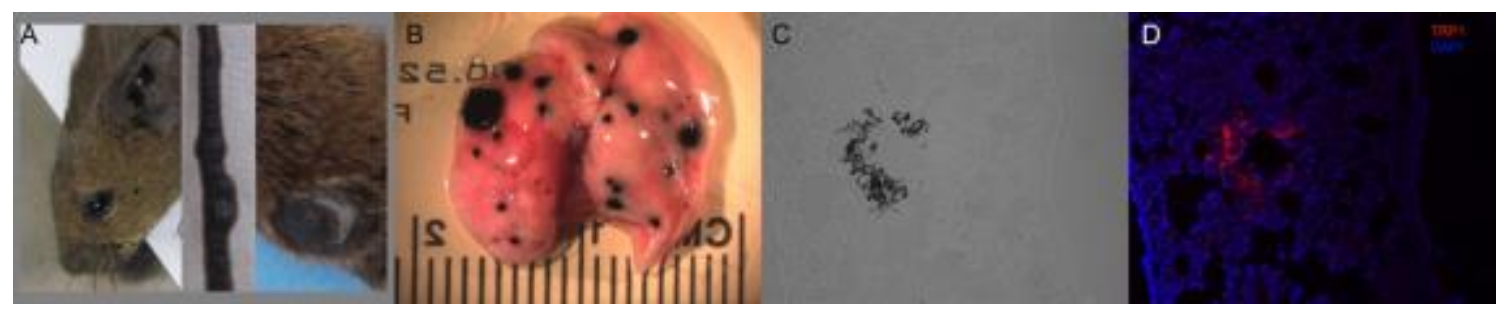

Figure 2.2 Mouse model of melanoma metastasis.

Dct-Grm1/ K5-Edn3 mice spontaneously develop melanocytic lesions on the ear, tail and dorsal skin (A) and metastases in the lung (B). The pigmented lesion in the lung is positive for melanoma marker TRP1 ( $C$ is the bright field of $D$ ). 


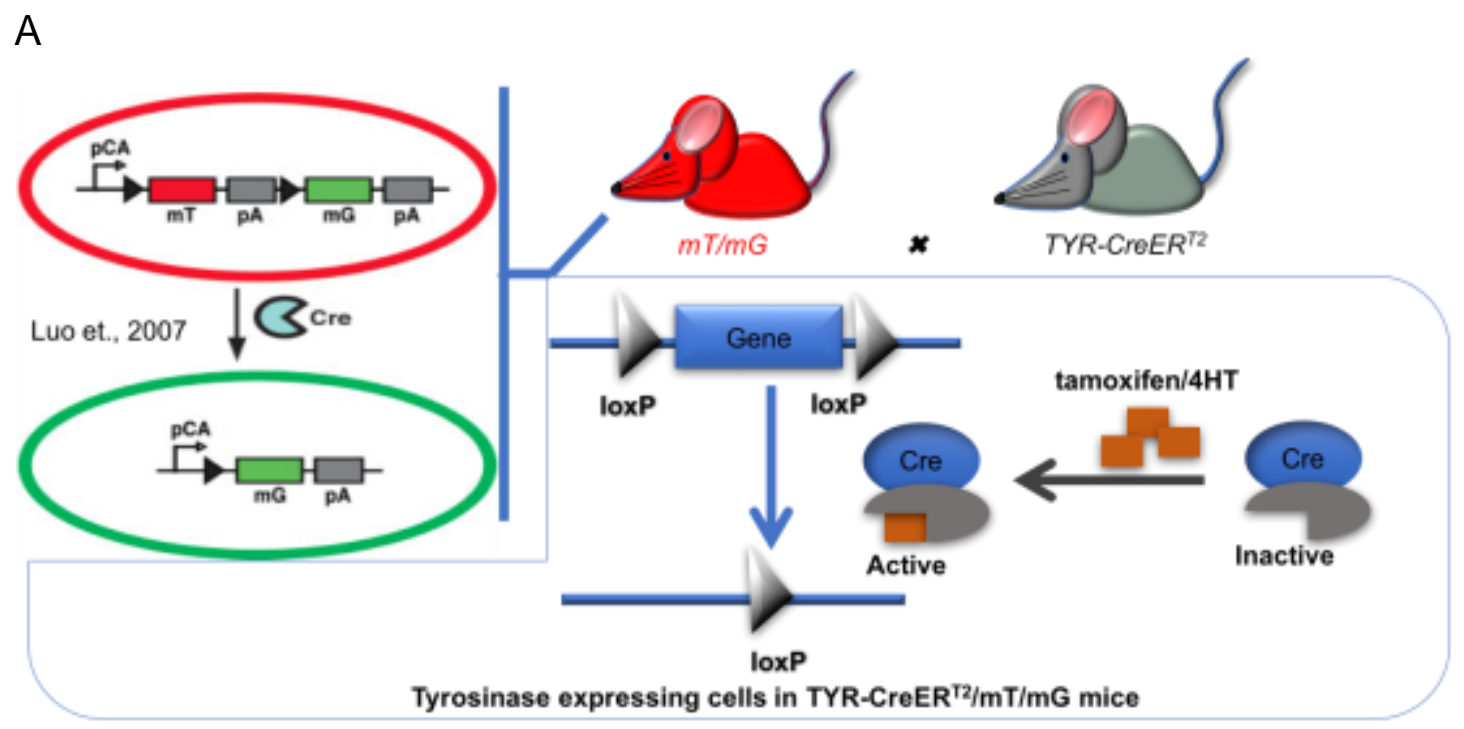

B
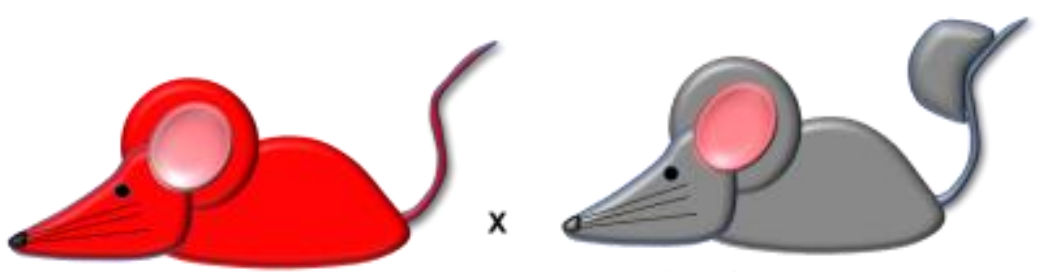

TYR-CreERT2/mT/mG

Dct-Gm1/K5-Edn3

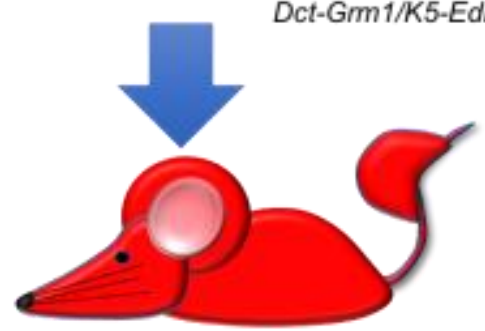

Dct-Gm1/ K5-Edn3/TYR-CreER ${ }^{T 2} / m T / m G$

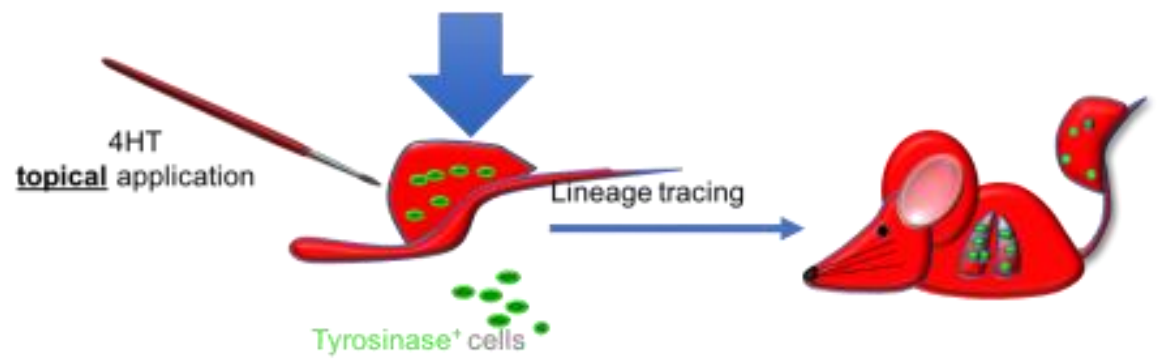

PRIMARY TUMORS (tail/dorsal/ear tumors) 

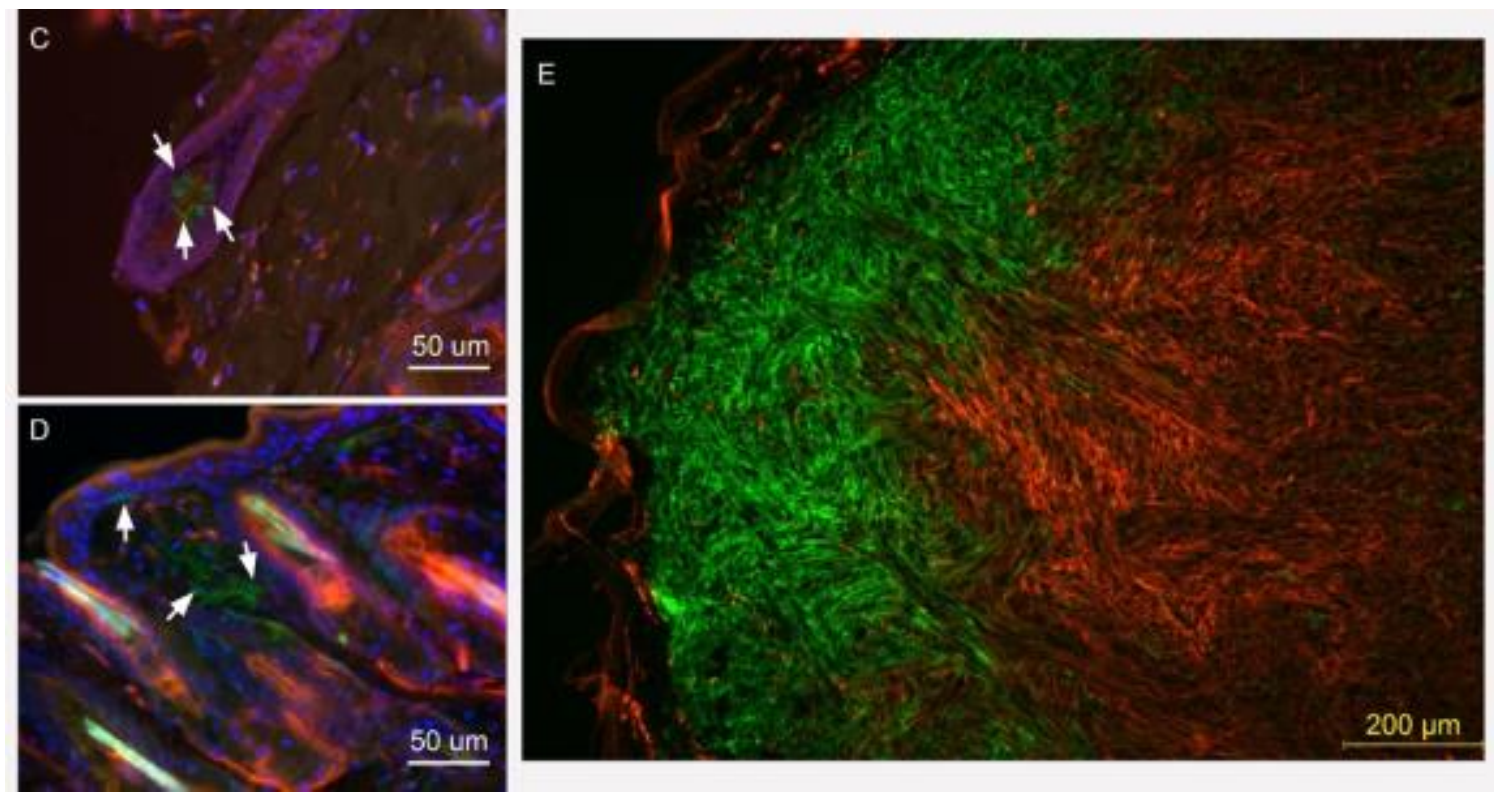

Figure 2.3 Mouse model of melanoma metastasis.

Diagram shows how Cre/loxp system was used with $m T / m G$ loxp reporter mice and TYR promoter/enhancer controlled Cre expression in TYR-CreER $R^{T 2}$ mice (A). An in vivo lineage tracing system can be established on the progeny mice carrying all the transgenes from TYR-CreER $R^{T 2} / \mathrm{mT} / \mathrm{mG}$ and Dct-Grm1/K5-Edn3 mating. Instead of systemic administration, $4 \mathrm{HT}$ was topically applied to the primary tumor sites to exclusively label Tyr expressing cells inside the tumor, not the other sites. Lineage tracing of the GFP+ cells during melanoma metastasis is achievable (B). 4HT topical application was validated on both TYR-CreERT2/ $\mathrm{mT} / \mathrm{mG}$ mice, where melanocytes are located inside hair follicles (C, arrow), and $\mathrm{K} 5$-Edn3/ TYR-CreER ${ }^{T 2} / \mathrm{mT} / \mathrm{mG}$ mice, where melanocytes outside the hair follicles are also expected due to the abundant Edn 3 in the environment (D, arrow). This methodology was also valid in the melanoma mouse model DctGrm1/K5-Edn3/TYR-CreER $R^{T 2} / \mathrm{mT} / \mathrm{mG}$. 4HT painted tail tumor cryosections were directly visualized under fluorescent microscope. Numerous green cells were found inside the tumor, consistent with the abundance of Tyr expressing differentiated cells in melanoma (E). Green, GFP+ melanocytes; Red, tdTomato, expressed in all non-recombined cells; Blue, nuclei counterstained with DAPI. 

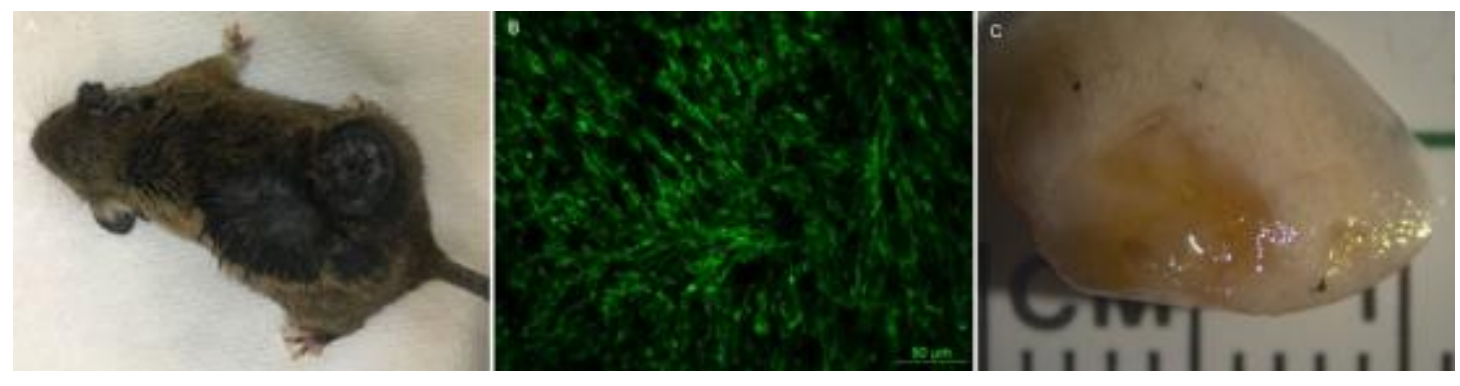

Figure 2.4 Labeling of the Tyr expressing cells in the primary tumors.

4HT was topically painted on the dorsal (A) or tail tumors of Dct-Grm1/K5-Edn3/ $T Y R-C r e E R^{T 2} / \mathrm{mT} / \mathrm{mG}$ mice, lung metastases with pigmentation were found after the mice were euthanized(C). Cryosections of the dorsal tumor were directly visualized under the fluorescence microscope and numerous GFP+ cells were found (B). 


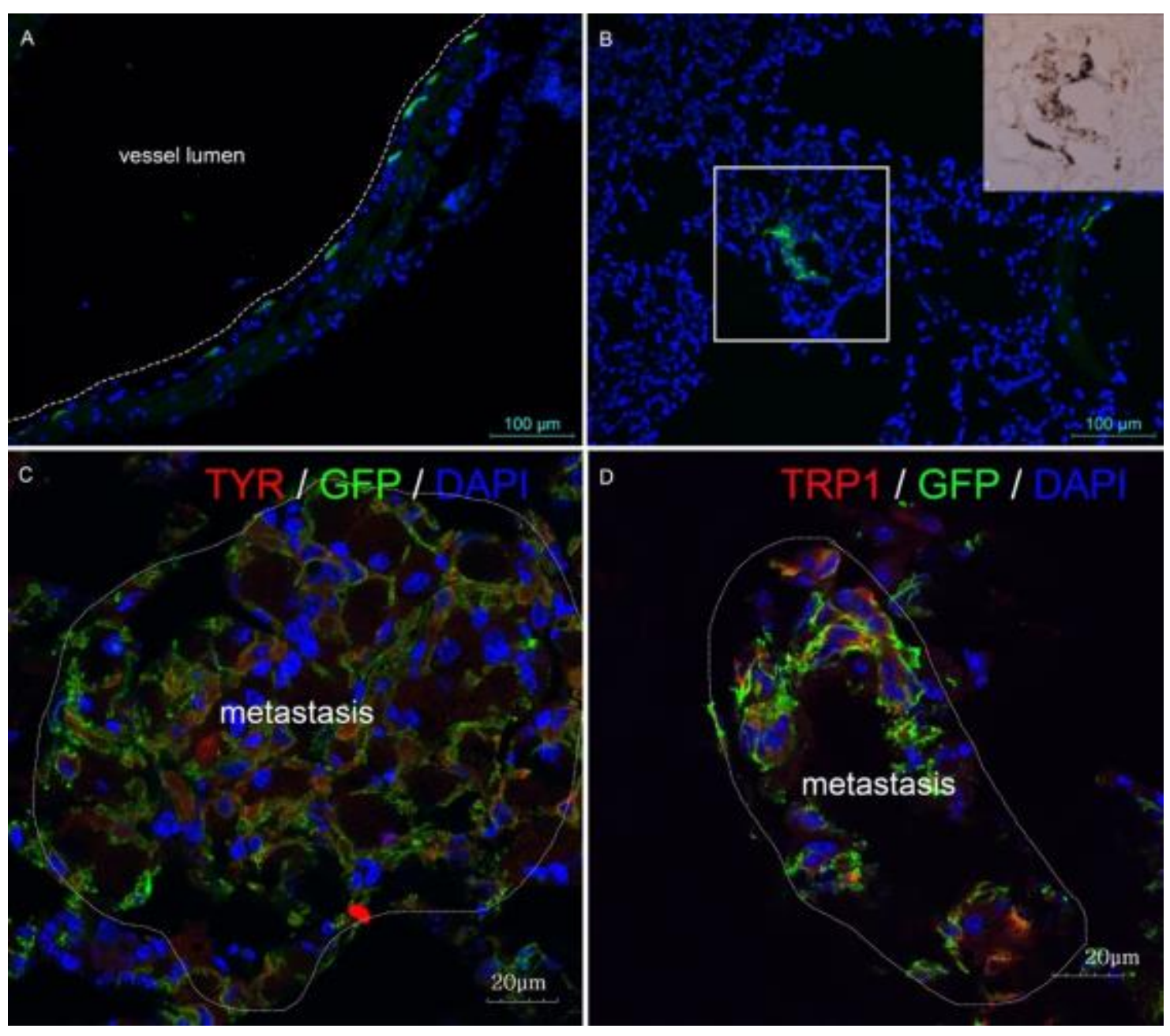

Figure 2.5 Lineage tracing of tumorigenic cells to the lung.

GFP+ cells were found in the lung, most of which were located at the inner wall of vasculature as single cells with an elongated, spindle shape (A), clusters of green cells were mainly seen in the lung metastatic foci (B, insert: bright field of the boxed area, showing green cells overlapped with pigment). GFP+ cell populated metastases in the lung were TYR and TRP1 positive showing the successful seeding of melanoma metastases (C, D). 


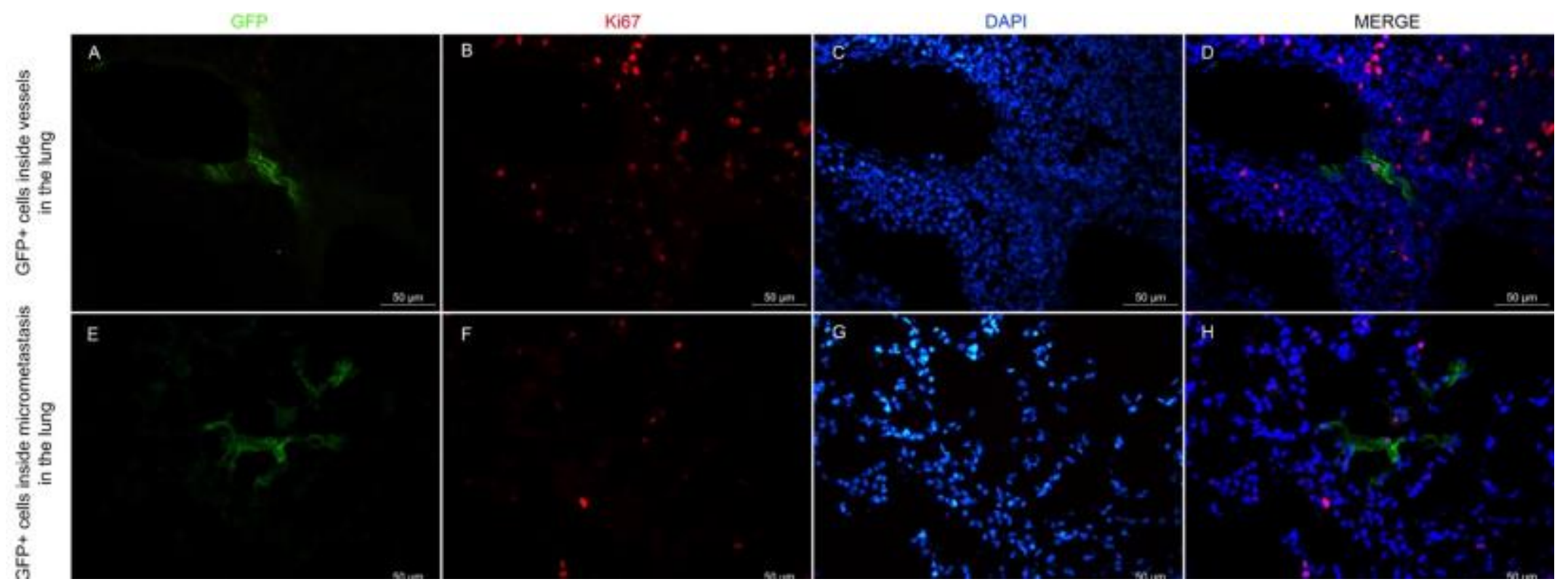

Figure 2.6 Primary tumor derived GFP+ cells proliferated in the lung.

Top panel (A-D) showed one GFP + cell located at the inner layer of the lung blood vessel (the green cell was located at the longitudinal section part of the vasculature) was positive for Ki67. Lower panel (E-H) showed one GFP cell inside the pigmented micro-metastasis expressed Ki67. Red, Ki67; green, GFP from the Cre induction or anti-GFP antibody used to amplify the signal for immunostaining; blue, DAPI. 


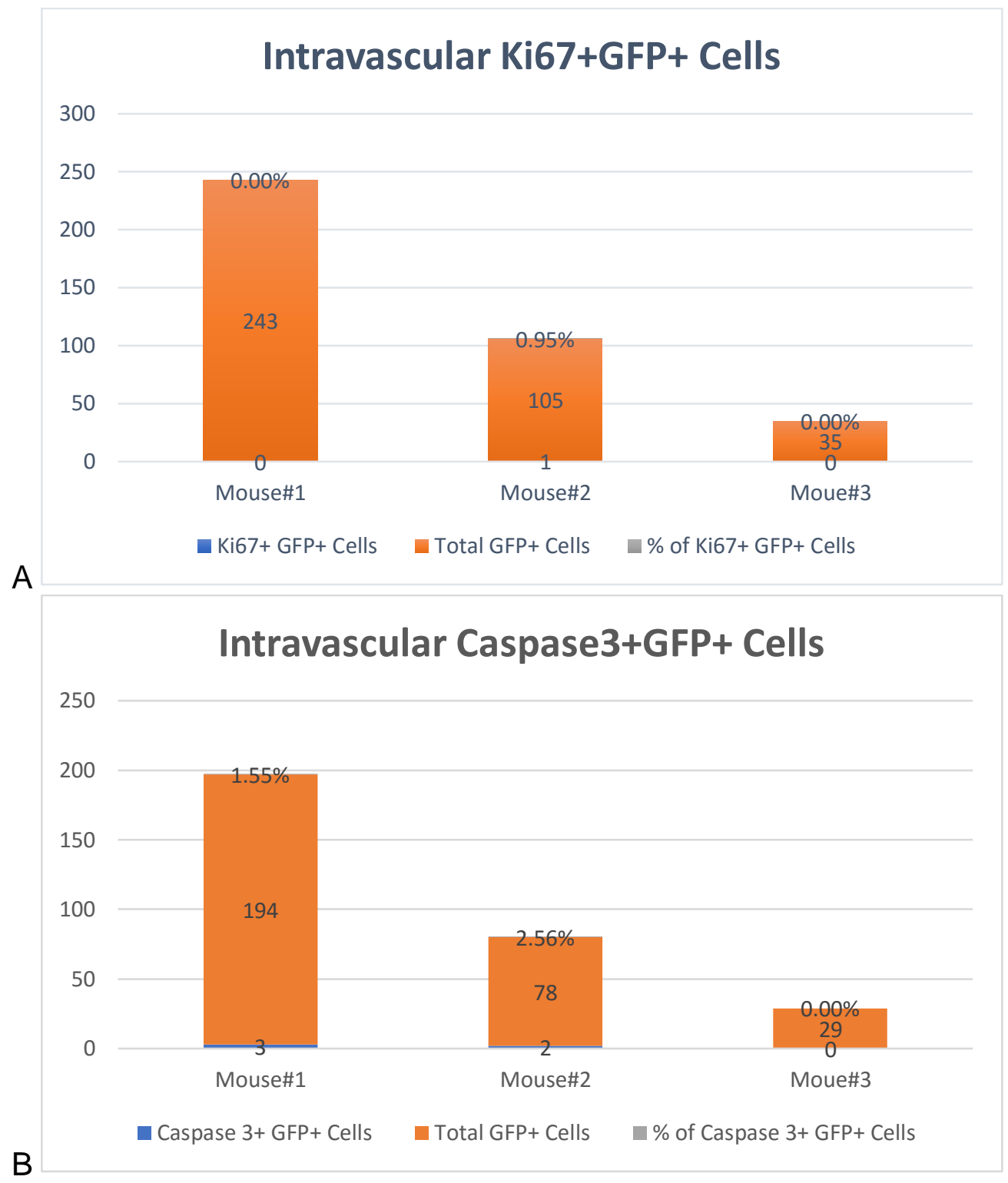

Figure 2.7 Numbers of Ki67 or Caspase3 staining of intravascular GFP+ cells in the lung.

Less than 1\% Ki67+ and less than 3\% Caspase3+ intravascular GFP+ cells were identified in the lung of Dct-Grm1/K5-Edn3/TYR-CreER ${ }^{T 2} / \mathrm{mT} / \mathrm{mG}$ mice. 

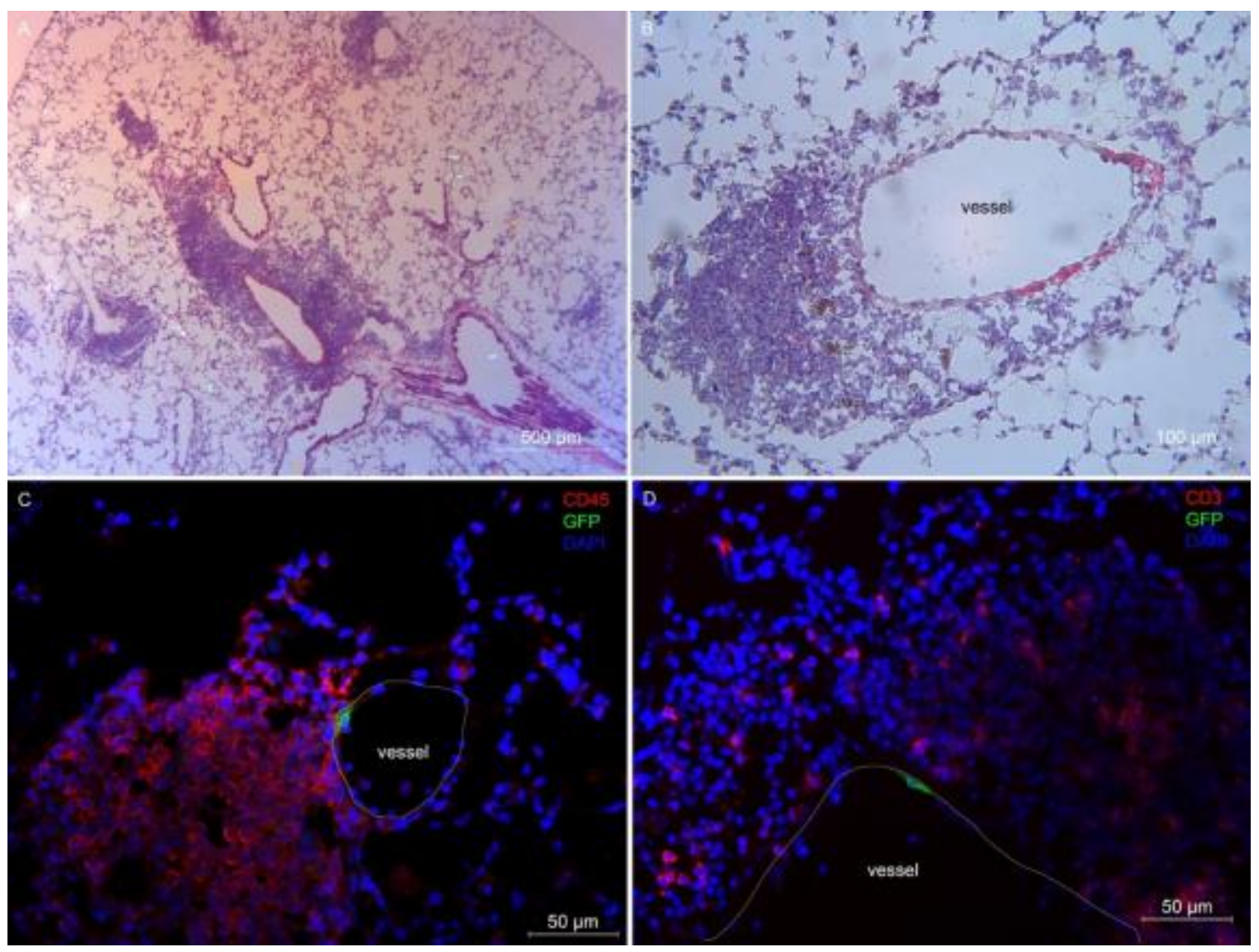

Figure 2.8 The presence of GFP+ cells in the lung was associated with perivascular infiltrates.

Hematoxylin-eosin (H\&E) staining (A, B) of lung cryosections from Dct-Grm1/ K5Edn3/TYR-CreERT2/ $\mathrm{mT} / \mathrm{mG}$ mice, of which primary tumor derived GFP+ cells were found. Perivascular cellular infiltrates were shown in the lung. $B$, a higher magnification of the cellular infiltrates, brown pigmented macrophages were seen inside the infiltrates. Immunostaining with indicated markers showed the perivascular infiltrates were mostly CD45 (lymphocyte common antigen) positive (C), and some were T cell marker CD3 positive (D). Note, one GFP+ cell was shown inside the vessels in $C$ and $D$. 


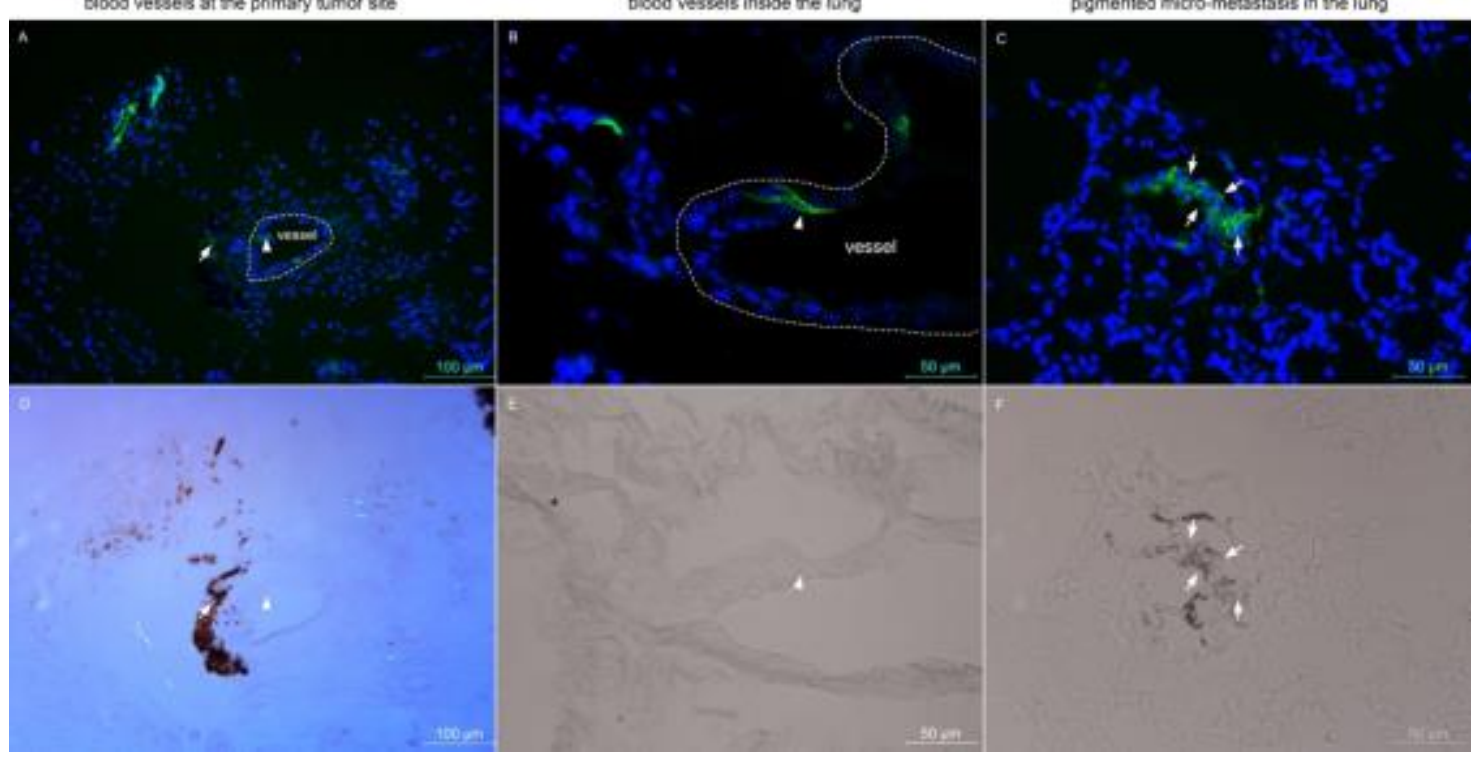

Figure 2.9 Pigmentation level of GFP+ cells during metastasis.

GFP + cells lost pigmentation while they were inside the vasculature at the tail tumor site (A, D, arrowhead) and in the lung (B, E, arrowhead), but produced pigmentation when they were outside the vessels $(A, D$, arrow) or within the metastatic foci (C, F, arrows). D-F are bright fields of $A-C$, respectively. Cryosections were counterstained with DAPI. 


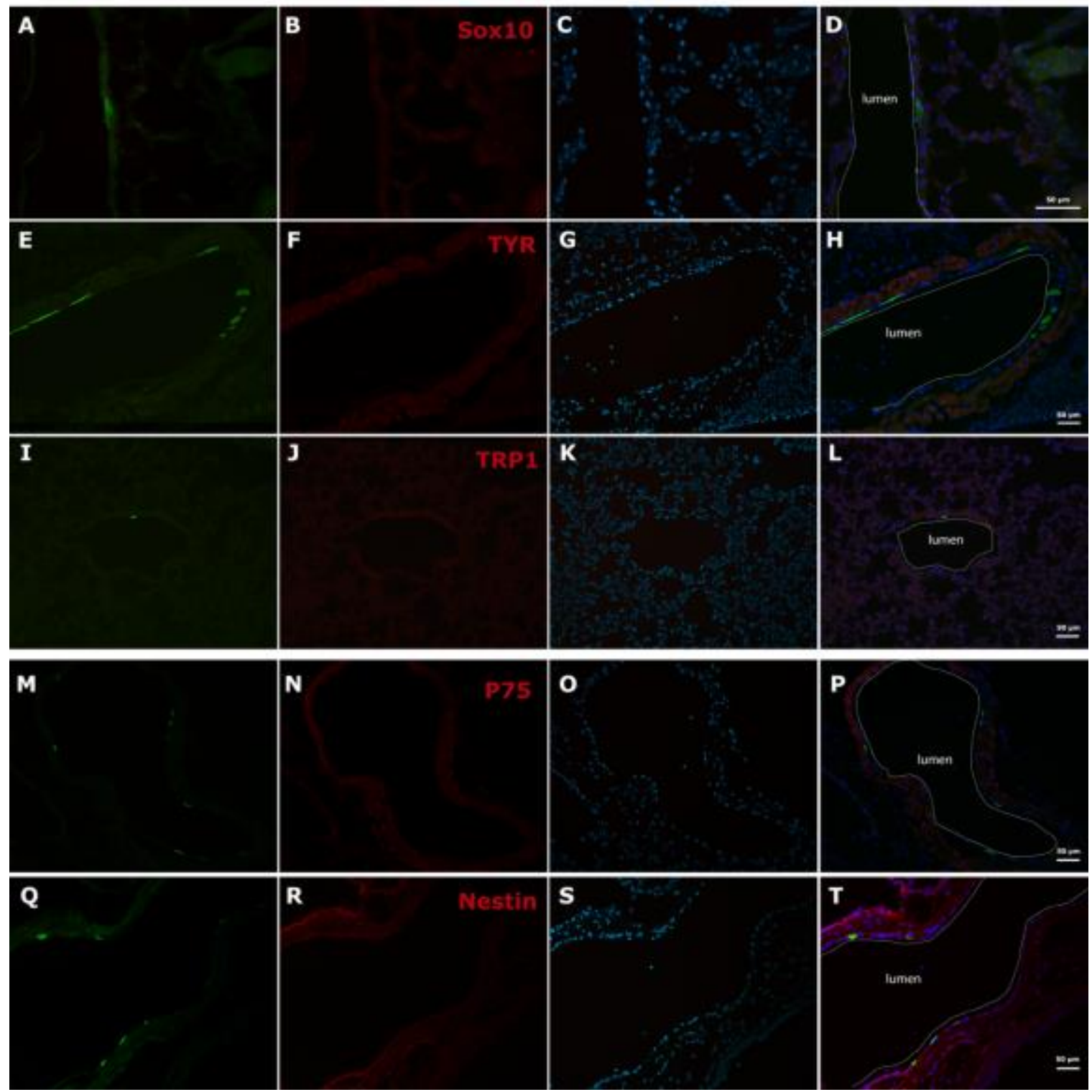

Figure 2.10 Immunostaining of GFP+ cells in the lung vasculature of Dct-Grm1/ $K 5$-Edn3/Tyr-CreER ${ }^{T 2} / m T / m G$ mice.

GFP+ cells in contact with lung vasculature (A, E, I, M, Q) did not express Sox10, TYR, TRP1 (B, F, J), P75, Nestin (N, R). Staining was performed on cryosections with appropriate positive controls to validate the indicated antibodies. 


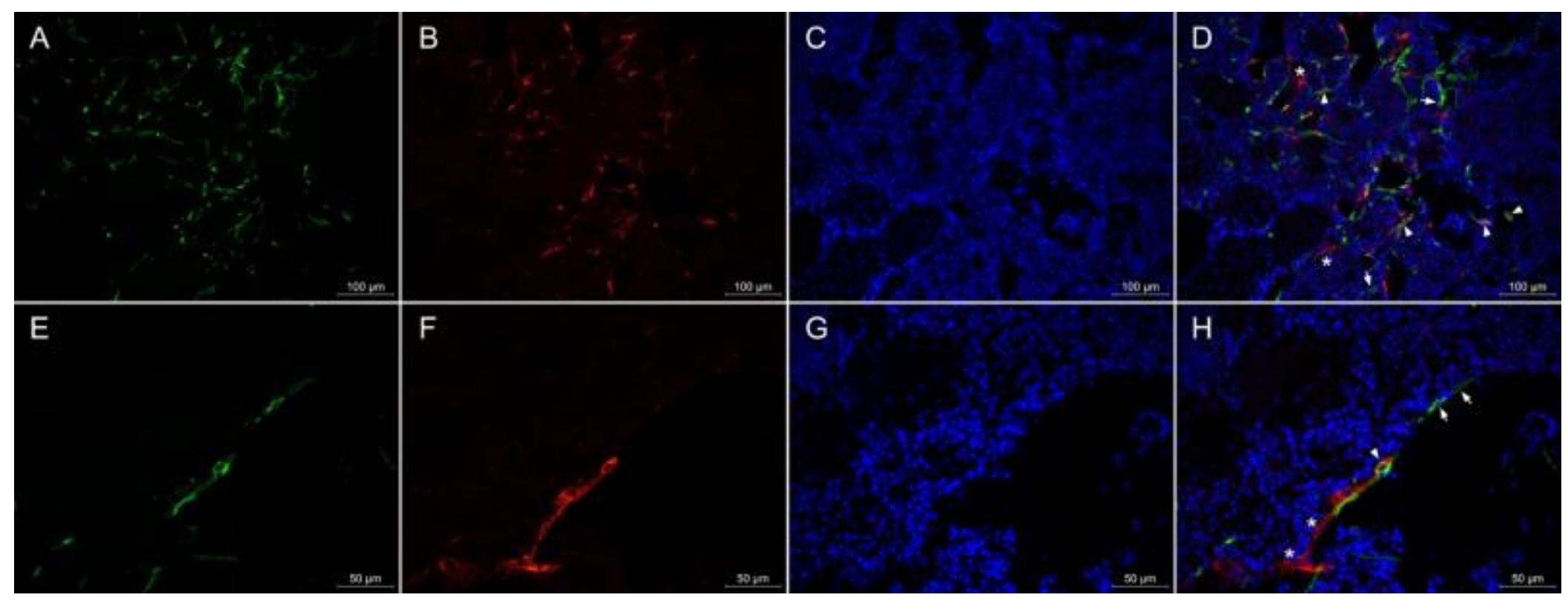

Figure 2.11 Characterization of GFP+ cells in lymph nodes.

TYR staining was done on the lymph node cryosections where GFP+ cells were found. Some GFP+ cells inside the lymph nodes expressed TYR (arrowhead), while some did not (arrow). A-D, a lower magnification; E-H, a higher magnification showed GFP+ cells inside the vasculature. Some TYR positive cells are not GFP+ (star). 


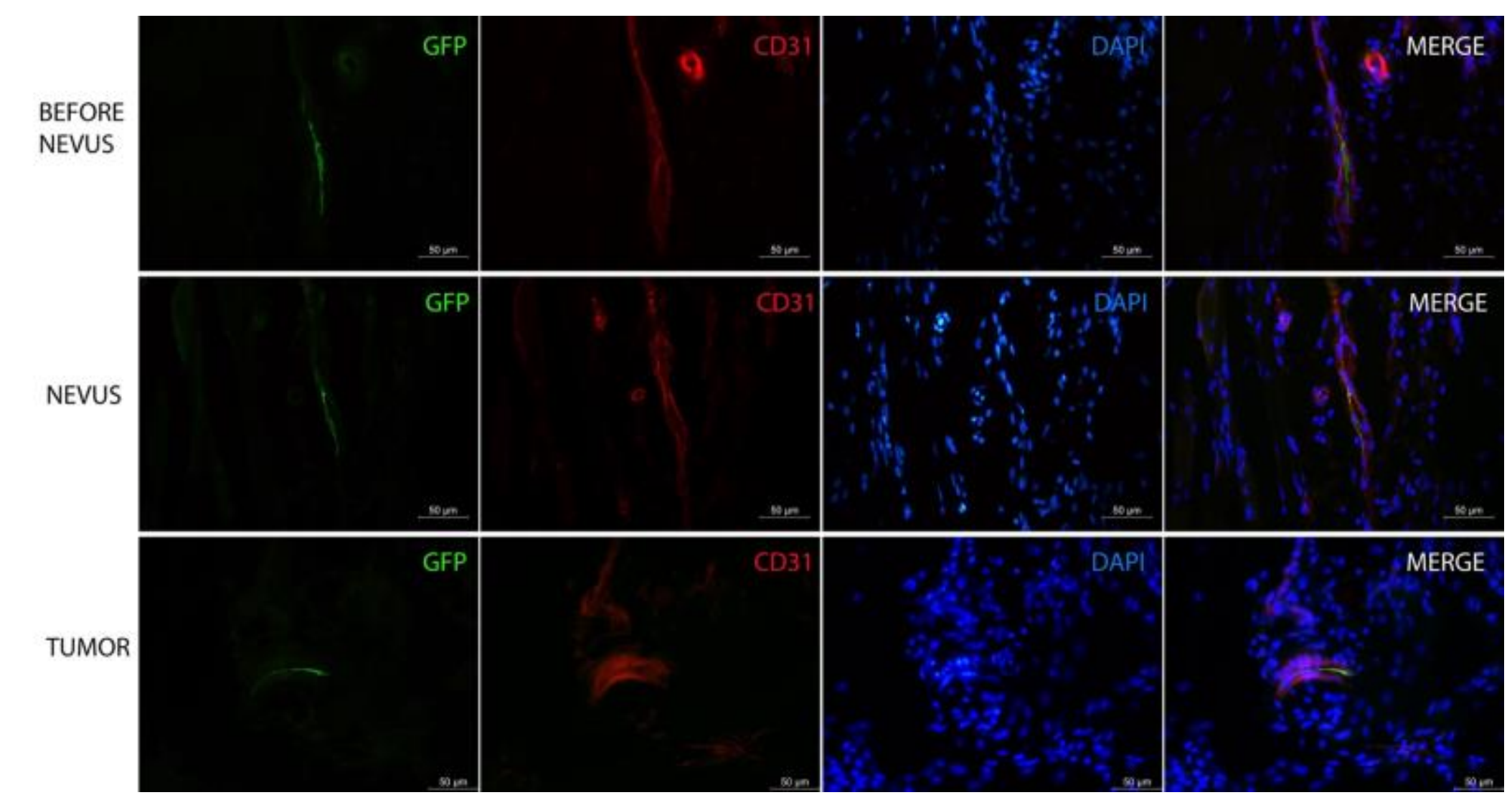

Figure 2.12 Timing of metastatic GFP+ cell dissemination.

4HT was painted on nevus or tumor or normal skin of the tail. Cryosections of the tail with the painted area were immunostained with CD31 to localize blood vessels underneath the tail skin. GFP+ cells were found inside the tail vasculature at all three stages. GFP, green; CD31, red; DAPI, blue. Only the vasculature underneath the painted area is shown, not the actual nevus/tumor/skin. 


\section{CHAPTER}

3.

PHENOTYPIC PLASTICITY OF METASTATIC MELANOMA CELLS 


\subsection{Introduction}

The vasculature plays an essential role in cancer progression. Most studies that have implicated the vasculature as a key factor in tumorigenesis have focused on the process of angiogenesis [1]. However, there is some evidence that angiogenesis may not be required for metastasis and other mechanisms such as vessel co-option have been suggested as an alternative [2]. In vessel co-option, tumor cells hijack and migrate along preexisting vessels of the host organs. Vessel co-option has been observed in human primary tumors and metastases and is most frequently described in highly vascularized tissues such as brain, lung, and liver [2]. Vessel co-option was detected in melanoma, and proposed to be the process employed by tumors to continue growing after antiangiogenic therapies $[3,4]$.

Another alternative pattern of tumorigenic functional microcirculation that has received special attention is VM where tumor cells acquire the capacity to form endothelial-like vessels recapitulating embryonic vasculogenesis. Vasculogenic mimicry is a striking example of tumor plasticity where tumor cells can transdifferentiate into an endothelial-like phenotype and express vascular related molecules. Numerous VM studies in distinct cancers have been published since the first introduction of this concept in $1999[5,6]$. Vasculogenic mimicry was first described in the context of human melanoma cells [6] and originally defined as the ability of aggressive melanoma cells to form CD31 negative but Periodic acid schiff positive vascular-like networks. Periodic acid schiff stains basement membranes including laminin, collage and glycogen and CD31 is an 
endothelial cell specific marker. Later, the same group provided the first direct evidence that another endothelial-associated molecule, vascular endothelial (VE)-cadherin, was exclusively expressed by highly aggressive melanoma cells and dispensable for VM [7]. Signaling pathways underlying VM with a focus on VE-cadherin expression were recently reviewed [8]. Although absence of CD31 is a characteristic of VM in melanoma, CD31 expression was reported in VM capable cell lines from ovarian cancer [9], prostatic cancer [10] and breast cancer [11]. Distinct contributions of VE-cadherin and CD31 in vessel formation [12] and embryonic origins of the tumor cell types may provide some clues to the selective expression of these two genes, but further investigations are needed to elucidate their specific roles in VM [13].

Tumor cells in various cancers, including melanoma, that are capable of VM share the "stemness" feature [14-19]. Gene-expression profiling of more than 45 human cutaneous and uveal melanoma-cell lines showed that, compared with the poorly aggressive melanoma cells, highly aggressive melanoma cells downregulated melanoma-specific markers including MITF, TYR, TRP1 and upregulated angiogenesis and vasculogenesis genes such as VE-cadherin, erythropoietin-producing hepatocellular carcinoma-A2 (EPHA2), and laminin 5 Y2-chain (LAMC2) [13]. The interplay between tumor cells acquiring endotheliallike and stem cell-like features may be what allows VM to participate in tumor metastasis or recurrence. The functional significance of VM is not well understood, but it may be involved in facilitating tumor perfusion and dissemination. Vasculogenic mimicry is positively related with tumor 
aggressiveness and an overall shorter survival time [20-22]. Vascular endothelial-cadherin positive melanoma cells co-expressing the stem cell marker CD133 engaged in VM creating a perivascular niche essential for primary tumor growth in mouse xenografts [19]. Another study by Wagenblast et al., linked VM in primary tumors with distant metastases in a breast cancer tumor mouse model. They provided evidence that Serpine2 and Slpi not only played essential roles for VM, but, as anticoagulants, also promoted metastatic cell intravasation and ultimate metastases by maintaining perfusion of the tumor cell-lined networks at the vascular/extravascular interface [23].

Another special pattern of vasculature in tumors is mosaic vessels, where vessels contain both authentic endothelial cells and tumor cells. Mosaic vessels in tumors were first observed in colon carcinoma, featured by discontinuous endothelial marker CD31 expression in tumors [24]. Mosaic vessels in hepatocellular carcinoma were also reported [25]. One of the proposed potential mechanisms of mosaic vessel formation [26] lies in the plasticity of highly malignant tumor cells, suggesting tumor cells can mimic the endothelial cells thus displace endothelial cells of the vessel lining. Whereas mosaic vessel features the endothelial-like behavior of cancer cells, those cancer cells being part of the vasculature do not express the typical endothelial cell marker CD31.

Vessel co-option differs from VM and mosaic vessels in that it is a nonangiogenesis mechanism. Tumorigenic cells take advantage of the preexisting vasculature for tumor growth or migration. While vessel co-option has not been associated to the process of angiogenesis, VM and mosaic vessels have been 
studied within its context. All studies about VM and mosaic vessels were carried out to demonstrate their relevance for primary tumor outgrowth and no correlation to the metastatic process has been established. Although some authors have hypothesized a functional role for VM and vessel co-option in facilitating tumor cell dissemination, no direct evidence is available. In the present study, I show a novel tumor-vasculature pattern observed in a spontaneous melanoma mouse model. In the new pattern, melanoma metastatic cells transdifferentiate into endothelial cells, hijack the existing vasculature at the metastatic sites and assemble an intravascular niche. I propose that in this niche metastatic cells are allowed to survive as dormant cells and re-acquire metastatic properties for latent spread.

\subsection{Results}

\subsubsection{Vascular Endothelium Associated GFP+ Cells Express Endothelial Cell Markers}

In the Dct-Grm1/ K5-Edn3/ TYR-CreER $R^{T 2} / \mathrm{mT} / m G$ mice, most metastatic GFP + cells in the lung were located inside the pulmonary vasculature. To establish the exact intravascular location of GFP+ cells in the lung, we labeled the lung cryosections where GFP+ cells were found with an antibody against CD31 to identify the vascular endothelial cells. To our surprise, the average of intravascular GFP+ cells was CD31 staining was also observed in approximately $70 \%$ of the GFP+ cells associated with the vascular endothelium (Figure 3.1, top panel), including solitary GFP + cells in alveolar capillaries (Figure S6). To further confirm the acquisition of an endothelial phenotype by the GFP+ cells, we used 
another endothelial cell marker, VE-cadherin, a similar percentage of intravascular GFP+ cells also labeled with VE-cadherin demonstrating their endothelial nature (Figure3.1, bottom panel).

Since CD31 and VE-cadherin are expressed in the membrane at the cellcell junction it is plausible that the staining detected was in fact associated with the vascular endothelial cells surrounding the GFP+ cells. In order to fully establish which cell type was immunolabeled with the antibodies against CD31 and VE-cadherin, small segments (2-3mm length) of pulmonary artery, pulmonary vein and aorta were obtained from $4 \mathrm{HT}$ painted mice and visualized directly by confocal microscopy. Since all cells in Dct-Grm1/ K5-Edn3/ TYRCreERT2/ $m T / m G$ mouse express tdTomato red fluorescence protein except GFP + Tyr expressing cells or their progeny, whole mount visualization of the vessels allowed us to detect the presence of GFP+ cells directly. As shown in Figure 3.2, primary tumor derived GFP+ cells were found in all three vessels. Of note, GFP+ cells were always located in association with or within the vascular endothelial layer, not the outer smooth muscle layer. The GFP+ cells embedded into the endothelium resembled the vascular endothelial cells morphologically. It is noteworthy that GFP+ cells changed their morphology according to the vascular endothelium where they were found (Figure 3.2, i.e., vein associated GFP+ cells showed a different shape compared with the artery associated ones), further indicating the plasticity of tumor cells. Whole mount staining of CD31 and VE-cadherin was carried out on the vessels and 3D reconstruction showed results consistent with the ones obtained from the lung cryosections. The GFP+ 
cells associated with the vasculature were clearly positive for CD31 and VEcadherin (Figure 3.3).

\subsubsection{Expression Pattern of Endothelial Cell Markers by GFP+ Cells is Dynamic}

The phenotypic plasticity of GFP + cells was demonstrated by characterizing the expression of endothelial cell markers during tumor progression. In the primary tumors, GFP+ cells did not present detectable CD31 expression (Figure 3.4A). In contrast, the majority of primary tumor resident GFP+ cells were VE-cadherin positive (Figure 3.4D), a feature of VM. In the lung vasculature, GFP+ cells associated with the vascular endothelium expressed both CD31 (Figure 3.4B) and VE-cadherin (Figure 3.4E). GFP+ cells populating the lung metastases lost the expression of both endothelial cell markers (Figure 3.4C, F). The fact that GFP+ cells lost CD31 expression when they seeded the metastases was expected given that they originally did not express it in the primary tumor. It was surprising that they lost VE-cadherin expression as well, in that they were VE-cadherin positive at the beginning of the metastatic journey.

As for what occurred in blood vessels, GFP+ cells also showed endothelial cell mimicry in lymphatic vessels. In the lymph nodes of Dct-Grm1/ K5-Edn3/ $T Y R-C r e E R^{T 2} / m T / m G$ mice, GFP+ cells were found associated with the lymphatic vessel endothelial hyaluronan receptor 1 (LYVE-1) positive lymphatic vessel cells. LYVE-1 is strongly expressed by endothelial cells of normal lymphatic vessels but not blood vessels [27]. 90\% of the intravascular (LYVE-1+ cell-lined vessels) GFP+ cells were also LYVE-1 positive (Figure 3.5A). GFP+ 
cells that were associated to the lymph node blood vessels (LYVE1-/CD31+) expressed CD31 (Figure 3.5B) consistent with the results obtained from lung blood vessels. Although LYVE-1 can be used as a lymphatic vessel marker to discriminate lymphatic vessels from blood vessels in most tissues, it has been demonstrated to label various blood vessels in the mouse lung [28-30]. Indeed, we performed double immunostaining of CD31 and LYVE-1 on lung cryosections and found them to overlap considerably. In contrast, LYVE-1 only labeled the lymphatic vessels in lymph nodes though weak CD31 staining on some lymphatic vessels was also observed (data not shown). We found LYVE-1+/CD31+ intravascular GFP+ cells in the lung, but we cannot confirm the type of vessels they were associated with. However, GFP+ cells within the metastatic foci in the lung did not express LYVE-1 (Figure 3.5C).

\subsubsection{EndMT as a Potential Mechanism Underlying Dormant Tumor Cell Awakening}

Since the intravascular GFP+ cells in the metastatic sites acquired an endothelial cell phenotype, we wanted to find out if they could undergo EndMT as a way to regain the capacity to establish successful metastases. Endothelialmesenchymal transition has been proposed as an important mechanism that underpins the role played by tumor-derived endothelial cells in tumor progression [31]. The hallmarks of EndMT are the acquisition of the mesenchymal markers VIMENTIN and $\alpha$-smooth muscle actin ( $\alpha$-SMA). We performed VIMENTIN and $\alpha$-SMA immunostaining on lung cryosections where GFP+ cells were found. VIMENTIN positive intravascular GFP+ cells were found in various areas of the 
lung (Figure 3.6, arrowhead), but heterogeneity existed even between cells in close proximity (Figure 3.6, arrow). $\alpha$-SMA+ GFP+ cells were also identified in the lung. Interestingly, some CD31+/ $\alpha-S M A+G F P+$ cells were found inside alveolar capillaries (Figure 3.7, arrowhead), indicating an intermediate state of EndMT. Figure 3.8 shows the heterogeneity and plasticity of a small cluster of GFP+ cells located in an alveolar capillary with both CD31-/ $\alpha-S M A+$ (Figure 3.8, arrow) and CD31+/ $\alpha-S M A+$ (Figure 3.8, arrowhead) GFP+ cells. It is noteworthy that $\alpha-S M A+G F P+$ cells were only found in smaller vessels (arterioles, capillaries). In contrast, GFP+ cells associated with larger vessels (pulmonary arteries) were always $\alpha$-SMA negative, and found wrapped around the $\alpha$-SMA+ smooth muscle cells and vascular endothelial cells (Figure 3.9)

\subsubsection{Plasticity and Heterogeneity of Metastatic GFP+ Cells}

The phenotypic change of GFP+ cells as they progressed from the primary tumor to the site of metastasis may require an initial process of dedifferentiation so they can acquire a novel fate. To evaluate if the intravascular GFP + cells may also have gone through a stem-cell phenotype, immunostaining with the stem cell markers SOX2 and OCT4 was performed on lung cryosections of Dct-Grm1/ K5-Edn3/ TYR-CreERT2/ mT/mG mice. SOX2 and OCT4 positive metastatic melanoma cells were identified, but as for all the other markers tested, the staining pattern was quite heterogeneous (Figure 3.10).

Connexin43 (Cx43) was shown to be involved in tumor/vascular endothelial cell communication in highly metastatic melanoma cells [32] and 
breast cancer cells [33]. Stoletov et al. showed that metastatic melanoma and breast cancer cells used $\mathrm{C} \times 43$ to initiate brain metastatic lesion formation in association with the vasculature [34]. Similarly to what they found, we detected a small population of GFP+ metastatic melanoma cells associated with the vascular endothelium that were $\mathrm{C} \times 43$ positive (Figure 3.10).

The heterogeneity and plasticity of primary tumor derived GFP+ cells were also observed in other metastatic organs. Immunostaining of VE-cadherin was performed on spleen and kidney cryosections from the Dct-Grm1/ K5-Edn3/ TYR-CreER $R^{T 2} / \mathrm{mT} / \mathrm{mG}$ mouse where visible metastases were found. It is intriguing that no detectable or weak signal of VE-cadherin immunoreactivity was found on GFP+ cells scattered in the spleen and kidney, whereas GFP+ cells within the metastatic foci in the spleen were positive for VE-cadherin (Figure 3.11A). S100 is used clinically for melanoma diagnosis, and we performed S100 immunostaining on the lymph node cryosections where GFP+ cells were found. S100 was highly expressed in the metastatic lymph node but intravascular and circulating GFP+ cells did not show S100 expression (Figure 3.11B).

\subsection{Discussion}

In our study, we found that primary tumor derived Tyr expressing cells or their progeny mimicked endothelial cells when in contact with blood or lymphatic vascular endothelium during metastasis but lost the endothelial phenotype in the lung metastatic foci. The strong association between vascular endothelial cells and GFP+ tumor cells observed in the spontaneous mouse melanoma model Dct-Grm1/ K5-Edn3/ TYR-CreER $R^{T 2 / ~} \mathrm{mT} / \mathrm{mG}$ is reminiscent of VM and mosaic 
vessels. However, it is obviously distinct from these two mechanisms in that 1) the association was observed in metastatic sites not primary tumors, 2) GFP+ cell associated with original vasculature of the circulatory system, not newly formed vessels, 3) the metastatic GFP + melanoma cells associated with the vascular endothelium were CD31 positive. Despite of these distinctions, similarity is evident because all these previously described mechanisms underlie the phenotypic plasticity of cancer cells by mimicking vascular endothelial cell properties. The possibility that metastatic GFP+ cells associated with the vasculature may achieve long-term survival because of the easy access to oxygen and nutrients also mirrors another tumor-vasculature pattern, vessel cooption. But then again, the intravascular location of the GFP+ cells is different from that where tumor derived cells are found in vessel co-option.

A recent review by Sun et al. suggested that a connection exists between VM and epithelial-to-endothelial transition (EET). They identified hypoxia, high interstitial fluid pressure and ECM remodeling as the likely factors that promote EET [35]. On the basis of the data provided in this study, we propose a melanoma (which is better characterized as a mesenchymal cell)-to-endothelial transition or transdifferentiation. This is not the first time that such a transition is suggested in the context of cancer. Tumor-derived endothelial cells were recognized decades ago in human B-cell lymphoma and human neuroblastoma when tumor specific chromosomal alterations were identified in tumor endothelial cells through fluorescence in situ hybridization [36, 37]. Notwithstanding, the transdifferentiation of tumorigenic cells into endothelial cells was only recently 
characterized in glioblastoma (GBM) using in vitro and in vivo evidence. In vitro, human glioma stem progenitor cells transdifferentiated into endothelial cells and formed tubular-like structures when cultured in endothelial differentiation medium. The expression of the endothelial markers CD31, CD34 and Von Willebrand factor (vWF) in glioma cells was induced by hypoxia or oxygen-glucose deprivation [38]. The in vivo evidence showing that GBM tumor cells transdifferentiated into CD31+ endothelial cells was first demonstrated through xenotransplantation. The authors found a GBM stem cell CD133+ subpopulation that had the capacity to differentiate along both tumor and endothelial cell lineages, and implicated VEGF and Notch pathways as important in this process [39]. These observations were corroborated by another group, who detected that a variable number (range 20-90\%) of endothelial cells in human glioblastoma carried the same genomic alteration as tumor cells [40]. Glioblastoma cell to endothelial transdifferentiation was also reported in a syngeneic C6 glioma rat model [41] and xenotransplantation assay by Shaifer's group [42]. Stronger evidence emerged from a study on a novel GBM mouse model using Cre/loxpcontrolled lentiviral vectors for tumor formation [43]. Tumor cells were labeled with GFP when lentiviral induced tumor formation happened and, notably, GFP+ tumor cells that associated with the vasculature expressed vWF, CD31, CD34 and CD144. Further in vitro differentiation experiments revealed that hypoxia and independence of VEGF underlie the mechanism responsible for the cancer cell into endothelial cell transdifferentiation [44]. The latter was also shown by Seno's group using miPS-LLCcm cells (a representative mouse induced pluripotent stem 
cells, miPS, converted with culture medium from Lewis lung carcinoma cells) both in vitro [45-47] and in vivo [18].

But why do tumor cells masquerade as endothelial cells? We showed in Chapter 2 that intravascular GFP+ cells in the lung of Dct-Grm1/K5-Edn3/TYRCreER $R^{T 2} / m T / m G$ mice lost melanocytic lineage markers and recapitulated the state of dormancy. If the transdifferentiation of melanoma cells into endothelial cells is the next step in the process, then endothelial cell mimicry may serve as a mechanism underlying metastatic dormancy to help tumor cell survival or escape immune surveillance.

Although endothelial cell markers CD31 and CD34 were detected in histological sections of uveal melanoma [48] and cutaneous melanoma [49], their presence was not connected to tube-like structures and the origin of the endothelial marker positive cells was not defined. Dudley's group described a CD31 positive cutaneous melanoma cell population that was also positive for the melanocytic marker Tyr. These CD31+/Tyr+ VM-competent tumor cells existed as stable, yet hidden subpopulations in heterogeneous melanomas [50]. The population of CD31+ cells described in this study is different in that they transitioned from expressing Tyr to expressing CD31 during the dissemination process and reverted back to expressing Tyr upon successful metastasis formation. VE-cadherin is a well-recognized marker for VM, GFP+ cells within the primary tumors of Dct-Grm1/K5-Edn3/TYR-CreER $R^{T 2} / \mathrm{mT} / \mathrm{mG}$ mice were positive for VE-cadherin and maintained VE-cadherin expression during the metastatic process. However, GFP+ cells lost VE-cadherin expression in the metastatic foci 
in the lung. Given the rich vasculature and gas exchange function of the lung tissue, this result could be interpreted with the assumption that VM is not necessary for the growth of metastases. Nonetheless, the internal or external factors required for triggering the dynamic gene expression changes of metastatic melanoma cells in Dct-Grm1/ K5-Edn3/TYR-CreERT2/ mT/mG mice are not clear. The study led by Kaessmeyer et al. demonstrated that the coculture of lung endothelial cells and squamous or adenocarcinoma lung cancer cells resulted in a contact dependent "CD31 staining switch", shown by the acquisition of CD31 expression of the tumor cells in direct contact with endothelial cells. This study suggested that tumor plasticity might be influenced by the endothelial microenvironment and by direct interactions with endothelial cells [51].

Endothelial-mesenchymal transition featured by the loss of endothelial marker expression, such as CD31, with the concomitant increase in mesenchymal marker expression, such as $\alpha$-SMA / VIMENTIN / FSP1, was originally observed during heart development where a population of endocardial cells differentiated into mesenchymal heart cushion cells forming cardiac septa and valves [52]. Later on, this phenotypic transition was shown to contribute to cardiac fibrosis [53] and carcinoma associated fibroblasts [54] in mouse models [55]. Transforming growth factor-beta (TGF- $\beta$ ) and bone morphogenetic protein (BMP) family of growth factors are key players in EndMT [56, 57]. Generation of mesenchymal cells from endothelium is a crucial step in the multipotent differentiation of endothelial cells and acquisition of a stem-like phenotype was 
observed in endothelium during EndMT $[57,58]$. The role of EndMT in cancer, especially during metastasis, has only recently been recognized. Endothelialmesenchymal transition was observed in endoglin-deficient vasculature and this process facilitated tumor cell intravasation in multiple mouse models [59]. The observation that cancer cells can acquire an endothelial-like phenotype and be incorporated into vessels suggested an extra role for EndMT in tumor progression. Selek et al. proposed that through EndMT, endothelial-like cancer cells can transdifferentiate into cancer associated fibroblasts or mesenchymal cancer stem cells (MCCs), and that either one can contribute to tumor progression. Additionally, disruption of tumor vasculature by antiangiogenic therapies may result in the dissemination of MCCs responsible for latent metastasis[31].

Despite of substantial evidence supporting the existence of tumor derived endothelial cells and the role played by EndMT in tumor progression, a robust connection between them and tumorigenesis is still missing, particularly in melanoma. The results presented here showed that in vivo metastatic melanoma cells can transdifferentiate into endothelial cells during metastasis and the subsequent transition into a mesenchymal phenotype may contribute to latent metastasis in the lung. We hope these findings will fill in the gaps in melanoma to endothelial transition, and offer a possible new mechanism underlying melanoma latent metastasis. 


\subsection{References}

1. Naumov, G.N., et al., Tumor-vascular interactions and tumor dormancy. APMIS, 2008. 116(7-8): p. 569-85.

2. Donnem, T., et al., Vessel co-option in primary human tumors and metastases: an obstacle to effective anti-angiogenic treatment? Cancer Med, 2013. 2(4): p. 427-36.

3. Dome, B., et al., Vascularization of cutaneous melanoma involves vessel co-option and has clinical significance. J Pathol, 2002. 197(3): p. 355-62.

4. Leenders, W.P., et al., Antiangiogenic therapy of cerebral melanoma metastases results in sustained tumor progression via vessel co-option. Clin Cancer Res, 2004. 10(18 Pt 1): p. 6222-30.

5. Bissell, M.J., Tumor plasticity allows vasculogenic mimicry, a novel form of angiogenic switch. A rose by any other name? Am J Pathol, 1999. 155(3): p. 675-9.

6. Maniotis, A.J., et al., Vascular channel formation by human melanoma cells in vivo and in vitro: vasculogenic mimicry. Am J Pathol, 1999. 155(3): p. 739-52.

7. Hendrix, M.J., et al., Expression and functional significance of VEcadherin in aggressive human melanoma cells: role in vasculogenic mimicry. Proc Natl Acad Sci U S A, 2001. 98(14): p. 8018-23.

8. Delgado-Bellido, D., et al., Vasculogenic mimicry signaling revisited: focus on non-vascular VE-cadherin. Mol Cancer, 2017. 16(1): p. 65.

9. Sood, A.K., et al., Molecular determinants of ovarian cancer plasticity. Am J Pathol, 2001. 158(4): p. 1279-88.

10. Sharma, N., et al., Prostatic tumor cell plasticity involves cooperative interactions of distinct phenotypic subpopulations: role in vasculogenic mimicry. Prostate, 2002. 50(3): p. 189-201.

11. Hendrix, M.J., et al., Molecular biology of breast cancer metastasis. Molecular expression of vascular markers by aggressive breast cancer cells. Breast Cancer Res, 2000. 2(6): p. 417-22.

12. Yang, S., et al., Functional roles for PECAM-1 (CD31) and VE-cadherin (CD144) in tube assembly and lumen formation in three-dimensional collagen gels. Am J Pathol, 1999. 155(3): p. 887-95. 
13. Hendrix, M.J., et al., Vasculogenic mimicry and tumour-cell plasticity: lessons from melanoma. Nat Rev Cancer, 2003. 3(6): p. 411-21.

14. Valyi-Nagy, K., et al., Stem cell marker CD271 is expressed by vasculogenic mimicry-forming uveal melanoma cells in three-dimensional cultures. Mol Vis, 2012. 18: p. 588-92.

15. Liu, T.J., et al., CD133+ cells with cancer stem cell characteristics associates with vasculogenic mimicry in triple-negative breast cancer. Oncogene, 2013. 32(5): p. 544-53.

16. Zhang, Y., et al., Clinical significances and prognostic value of cancer stem-like cells markers and vasculogenic mimicry in renal cell carcinoma. J Surg Oncol, 2013. 108(6): p. 414-9.

17. Liu, T., et al., USP44+ Cancer Stem Cell Subclones Contribute to Breast Cancer Aggressiveness by Promoting Vasculogenic Mimicry. Mol Cancer Ther, 2015. 14(9): p. 2121-31.

18. Prieto-Vila, M., et al., iPSC-derived cancer stem cells provide a model of tumor vasculature. Am J Cancer Res, 2016. 6(9): p. 1906-1921.

19. Lai, C.Y., B.E. Schwartz, and M.Y. Hsu, CD133+ melanoma subpopulations contribute to perivascular niche morphogenesis and tumorigenicity through vasculogenic mimicry. Cancer Res, 2012. 72(19): p. 5111-8.

20. Sun, B., et al., Vasculogenic mimicry is associated with poor survival in patients with mesothelial sarcomas and alveolar rhabdomyosarcomas. Int J Oncol, 2004. 25(6): p. 1609-14.

21. Sun, B., et al., Vasculogenic mimicry is associated with high tumor grade, invasion and metastasis, and short survival in patients with hepatocellular carcinoma. Oncol Rep, 2006. 16(4): p. 693-8.

22. Wang, S.Y., et al., Vasculogenic mimicry is a prognostic factor for postoperative survival in patients with glioblastoma. J Neurooncol, 2013. 112(3): p. 339-45.

23. Wagenblast, E., et al., $A$ model of breast cancer heterogeneity reveals vascular mimicry as a driver of metastasis. Nature, 2015. 520(7547): p. 358-62.

24. Chang, Y.S., et al., Mosaic blood vessels in tumors: frequency of cancer cells in contact with flowing blood. Proc Natl Acad Sci U S A, 2000. 97(26): p. 14608-13. 
25. Zhou, F., et al., Metronomic chemotherapy in combination with antiangiogenic treatment induces mosaic vascular reduction and tumor growth inhibition in hepatocellular carcinoma xenografts. J Cancer Res Clin Oncol, 2012. 138(11): p. 1879-90.

26. di Tomaso, E., et al., Mosaic tumor vessels: cellular basis and ultrastructure of focal regions lacking endothelial cell markers. Cancer Res, 2005. 65(13): p. 5740-9.

27. Jackson, D.G., et al., LYVE-1, the lymphatic system and tumor lymphangiogenesis. Trends Immunol, 2001. 22(6): p. 317-21.

28. Gordon, E.J., N.W. Gale, and N.L. Harvey, Expression of the hyaluronan receptor $L Y V E-1$ is not restricted to the lymphatic vasculature; $L Y V E-1$ is also expressed on embryonic blood vessels. Dev Dyn, 2008. 237(7): p. 1901-9.

29. Favre, C.J., et al., Expression of genes involved in vascular development and angiogenesis in endothelial cells of adult lung. Am J Physiol Heart Circ Physiol, 2003. 285(5): p. H1917-38.

30. Baluk, P. and D.M. McDonald, Markers for microscopic imaging of lymphangiogenesis and angiogenesis. Ann N Y Acad Sci, 2008. 1131: p. $1-12$.

31. Selek, L., et al., Existence of tumor-derived endothelial cells suggests an additional role for endothelial-to-mesenchymal transition in tumor progression. Int J Cancer, 2011. 128(6): p. 1502-3.

32. el-Sabban, M.E. and B.U. Pauli, Cytoplasmic dye transfer between metastatic tumor cells and vascular endothelium. J Cell Biol, 1991. 115(5): p. $1375-82$.

33. Pollmann, M.A., et al., Connexin 43 mediated gap junctional communication enhances breast tumor cell diapedesis in culture. Breast Cancer Res, 2005. 7(4): p. R522-34.

34. Stoletov, K., et al., Role of connexins in metastatic breast cancer and melanoma brain colonization. J Cell Sci, 2013. 126(Pt 4): p. 904-13.

35. Sun, B., et al., Epithelial-to-endothelial transition and cancer stem cells: two cornerstones of vasculogenic mimicry in malignant tumors. Oncotarget, 2016.

36. Streubel, B., et al., Lymphoma-specific genetic aberrations in microvascular endothelial cells in B-cell lymphomas. N Engl J Med, 2004. 351(3): p. 250-9. 
37. Pezzolo, A., et al., Tumor origin of endothelial cells in human neuroblastoma. J Clin Oncol, 2007. 25(4): p. 376-83.

38. Zhao, Y., et al., Endothelial cell transdifferentiation of human glioma stem progenitor cells in vitro. Brain Res Bull, 2010. 82(5-6): p. 308-12.

39. Wang, R., et al., Glioblastoma stem-like cells give rise to tumour endothelium. Nature, 2010. 468(7325): p. 829-33.

40. Ricci-Vitiani, L., et al., Tumour vascularization via endothelial differentiation of glioblastoma stem-like cells. Nature, 2010. 468(7325): $p$. 824-8.

41. Chen, X., et al., A new mosaic pattern in glioma vascularization: exogenous endothelial progenitor cells integrating into the vessels containing tumor-derived endothelial cells. Oncotarget, 2014. 5(7): p. 1955-68.

42. Shaifer, C.A., J. Huang, and P.C. Lin, Glioblastoma cells incorporate into tumor vasculature and contribute to vascular radioresistance. Int $\mathrm{J}$ Cancer, 2010. 127(9): p. 2063-75.

43. Marumoto, T., et al., Development of a novel mouse glioma model using lentiviral vectors. Nat Med, 2009. 15(1): p. 110-6.

44. Soda, Y., et al., Transdifferentiation of glioblastoma cells into vascular endothelial cells. Proc Natl Acad Sci U S A, 2011. 108(11): p. 4274-80.

45. Chen, L., et al., A model of cancer stem cells derived from mouse induced pluripotent stem cells. PLoS One, 2012. 7(4): p. e33544.

46. Chen, L., et al., Mouse induced pluripotent stem cell microenvironment generates epithelial-mesenchymal transition in mouse Lewis lung cancer cells. Am J Cancer Res, 2014. 4(1): p. 80-8.

47. Matsuda, S., et al., Cancer stem cells maintain a hierarchy of differentiation by creating their niche. Int J Cancer, 2014. 135(1): p. 27-36.

48. Folberg, R. and A.J. Maniotis, Vasculogenic mimicry. APMIS, 2004. 112(7-8): p. 508-25.

49. Pisacane, A.M., F. Picciotto, and M. Risio, CD31 and CD34 expression as immunohistochemical markers of endothelial transdifferentiation in human cutaneous melanoma. Cell Oncol, 2007. 29(1): p. 59-66.

50. Dunleavey, J.M., et al., Vascular channels formed by subpopulations of PECAM1 + melanoma cells. Nat Commun, 2014. 5: p. 5200. 
51. Kaessmeyer, S., et al., Lung cancer neovascularisation: Cellular and molecular interaction between endothelial and lung cancer cells. Immunobiology, 2014. 219(4): p. 308-14.

52. Eisenberg, L.M. and R.R. Markwald, Molecular regulation of atrioventricular valvuloseptal morphogenesis. Circ Res, 1995. 77(1): p. 1-6.

53. Zeisberg, E.M., et al., Endothelial-to-mesenchymal transition contributes to cardiac fibrosis. Nat Med, 2007. 13(8): p. 952-61.

54. Zeisberg, E.M., et al., Discovery of endothelial to mesenchymal transition as a source for carcinoma-associated fibroblasts. Cancer Res, 2007. 67(21): p. 10123-8.

55. Lin, F., N. Wang, and T.C. Zhang, The role of endothelial-mesenchymal transition in development and pathological process. IUBMB Life, 2012. 64(9): p. 717-23.

56. Xiao, L. and A.C. Dudley, Fine-tuning vascular fate during endothelialmesenchymal transition. J Pathol, 2017. 241(1): p. 25-35.

57. Medici, D. and R. Kalluri, Endothelial-mesenchymal transition and its contribution to the emergence of stem cell phenotype. Semin Cancer Biol, 2012. 22(5-6): p. 379-84.

58. Medici, D., et al., Conversion of vascular endothelial cells into multipotent stem-like cells. Nat Med, 2010. 16(12): p. 1400-6.

59. Anderberg, C., et al., Deficiency for endoglin in tumor vasculature weakens the endothelial barrier to metastatic dissemination. J Exp Med, 2013. 210(3): p. 563-79. 


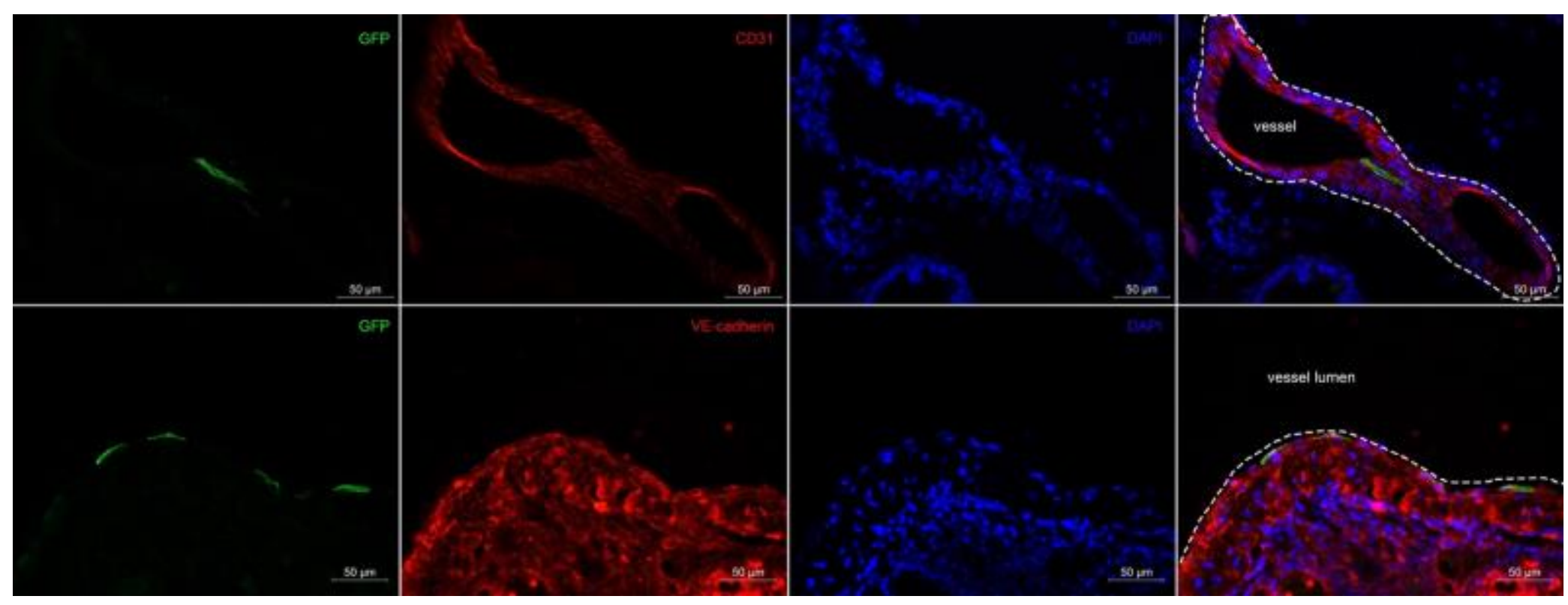

Figure 3.1 GFP+ cells inside the pulmonary vasculature expressed endothelial cell markers.

Immunostaining on lung cryosections indicated the primary tumor derived GFP+ cells were positive for endothelial cell specific markers CD31 (A-D) and VE-cadherin (E-H). 


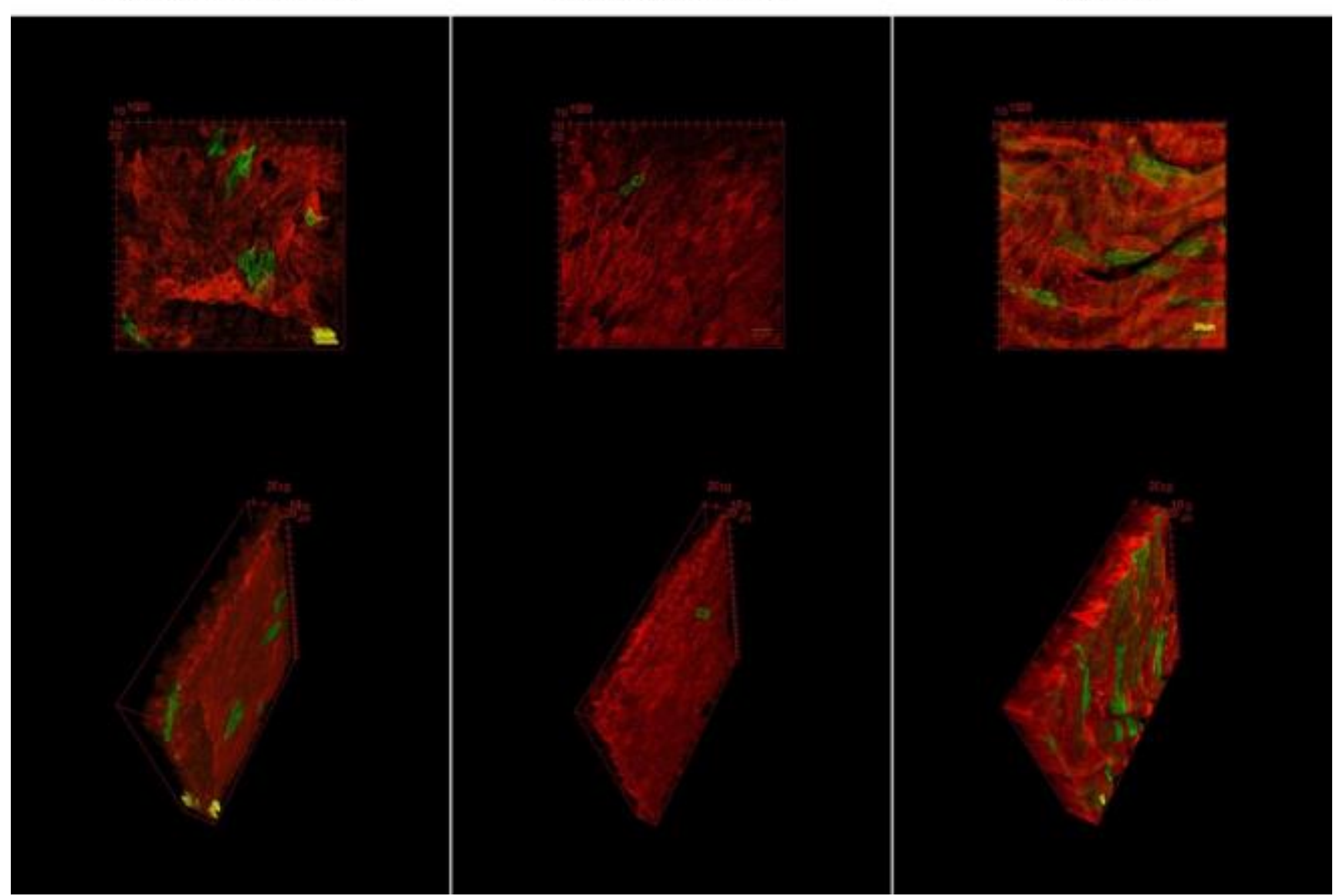

Figure 3.2 Confocal and 3D reconstruction of blood vessels.

2-3mm segments of pulmonary artery, pulmonary vein and aorta were dissected and directly visualized under the confocal microscope. GFP+ tumor cells were found within the endothelial layer of all three types of vessels. GFP+ cells exhibited different morphologies that corresponded to the type of blood vessel they were located. 

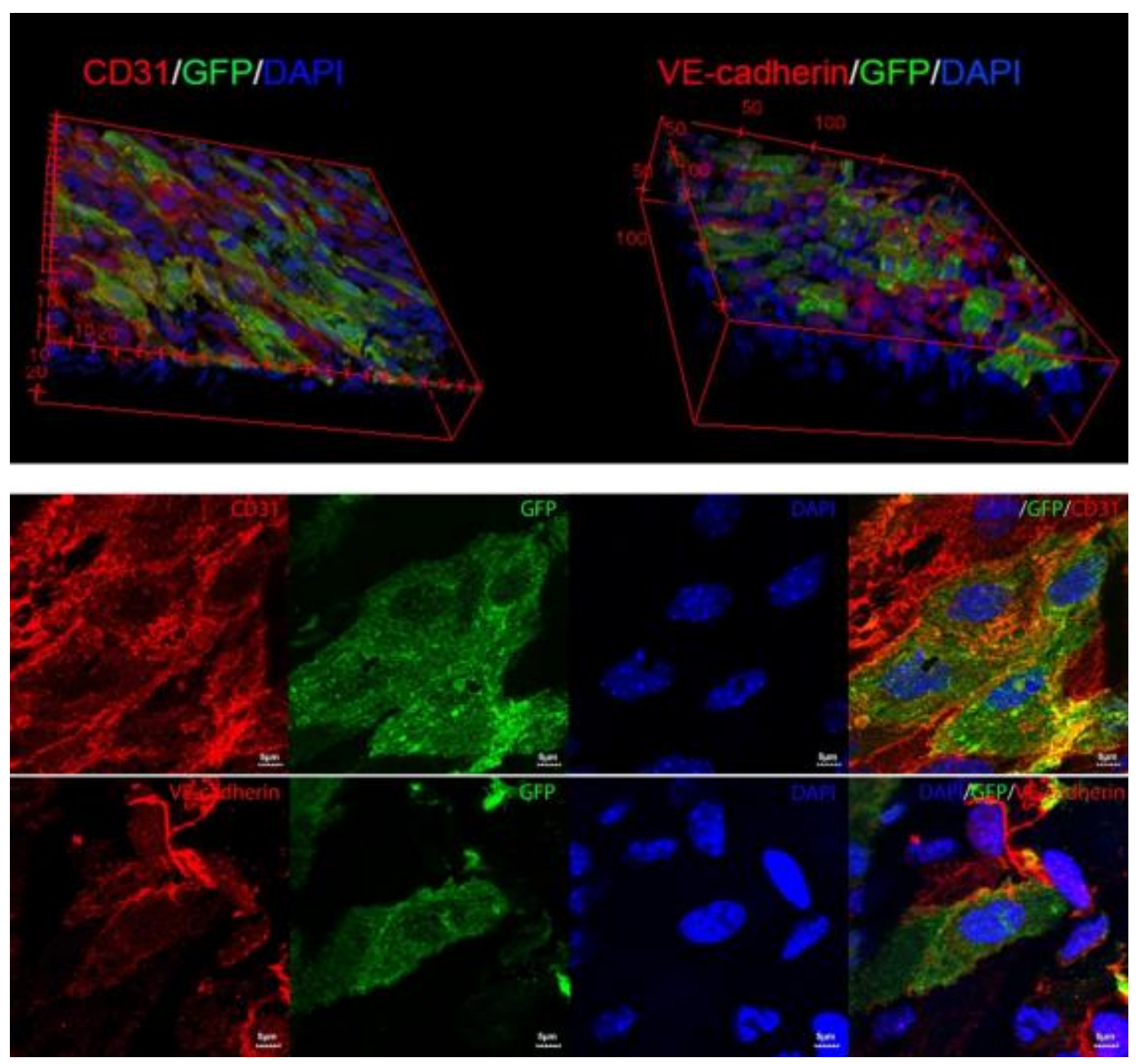

Figure 3.3 Whole mount staining and 3D confocal reconstruction of arteries where GFP+ cells were found.

Top panel 3D reconstruction of the whole mount staining showed that GFP+ cells integrated into the vascular endothelium and expressed CD31 and VE-cadherin (top surface is the endothelium of the vasculature, bottom is the smooth muscle cell layer negative for endothelial cell markers). Lower panel is one section from the $3 \mathrm{D}$ reconstruction confirming GFP + cells are positive for endothelial markers CD31 and VE-cadherin. 

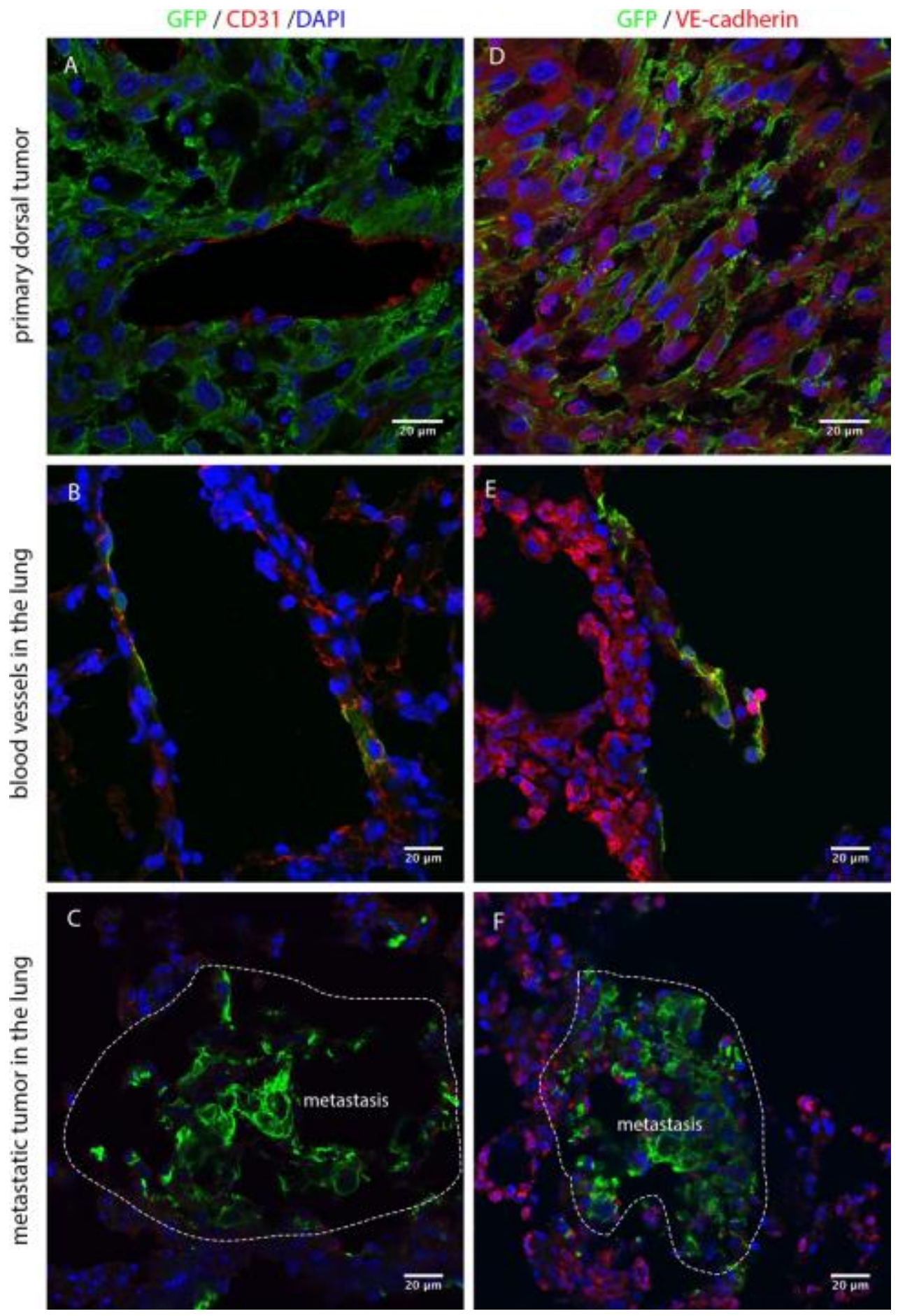

Figure 3.4 Plasticity of GFP+ cells from primary tumor sites to lung metastases.

GFP+ cells did not express endothelial cell marker CD31 in the primary tumors (A, only endothelial cells in the blood vessels were CD31+) but were VE-cadherin positive (D). GFP+ cells were positive for both CD31 and VE-cadherin in the lung vasculature $(B, E)$, but lost the endothelial cell markers in lung metastases $(C, F)$. 


\section{LYMPH NODE}
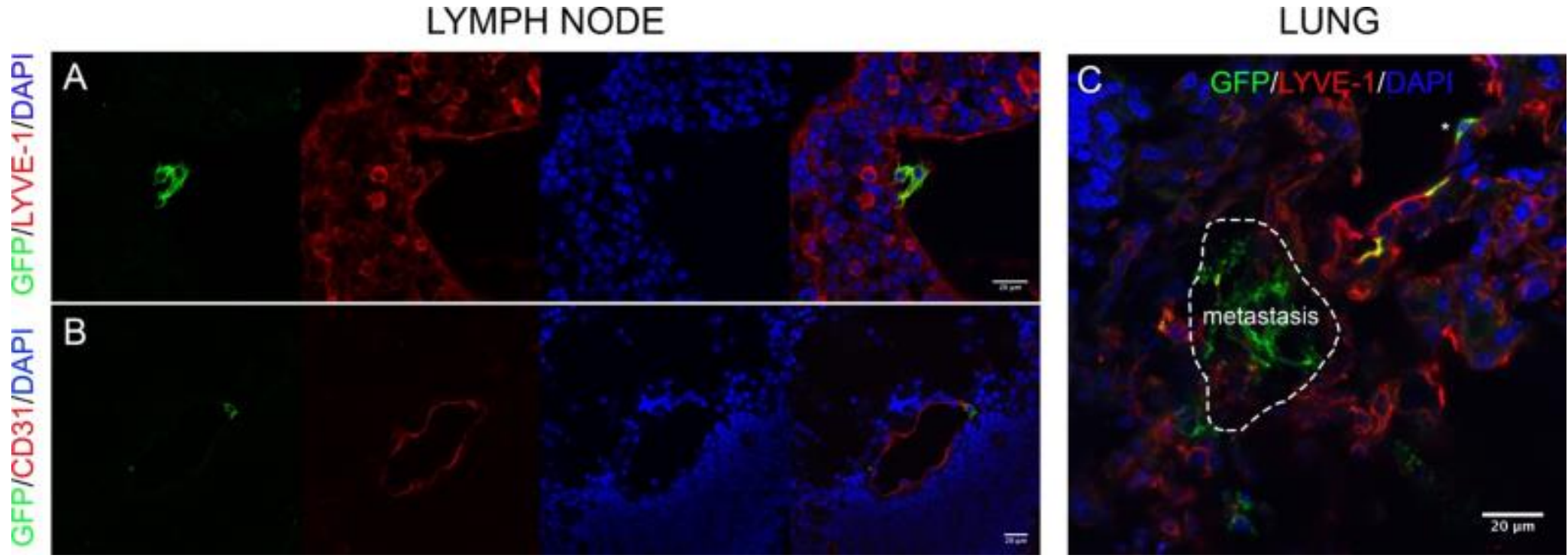

Figure 3.5 Endothelial cell mimicry in lymph nodes.

Primary tumor derived GPF+ cells in the lymph nodes expressed LYVE-1 inside lymphatic vessels $(A)$ and CD31 inside the blood vessels (B) and were strongly associated with the vascular endothelium no matter which type of vessels they were in. GFP+ cells lost the lymphatic endothelial marker LYVE-1 inside the lung metastatic foci (C). Note, one GFP+ cell outside the metastatic foci in the lung was LYVE-1 positive (C, star), although we cannot identify whether this is a lymphatic vessel or blood vessel. 

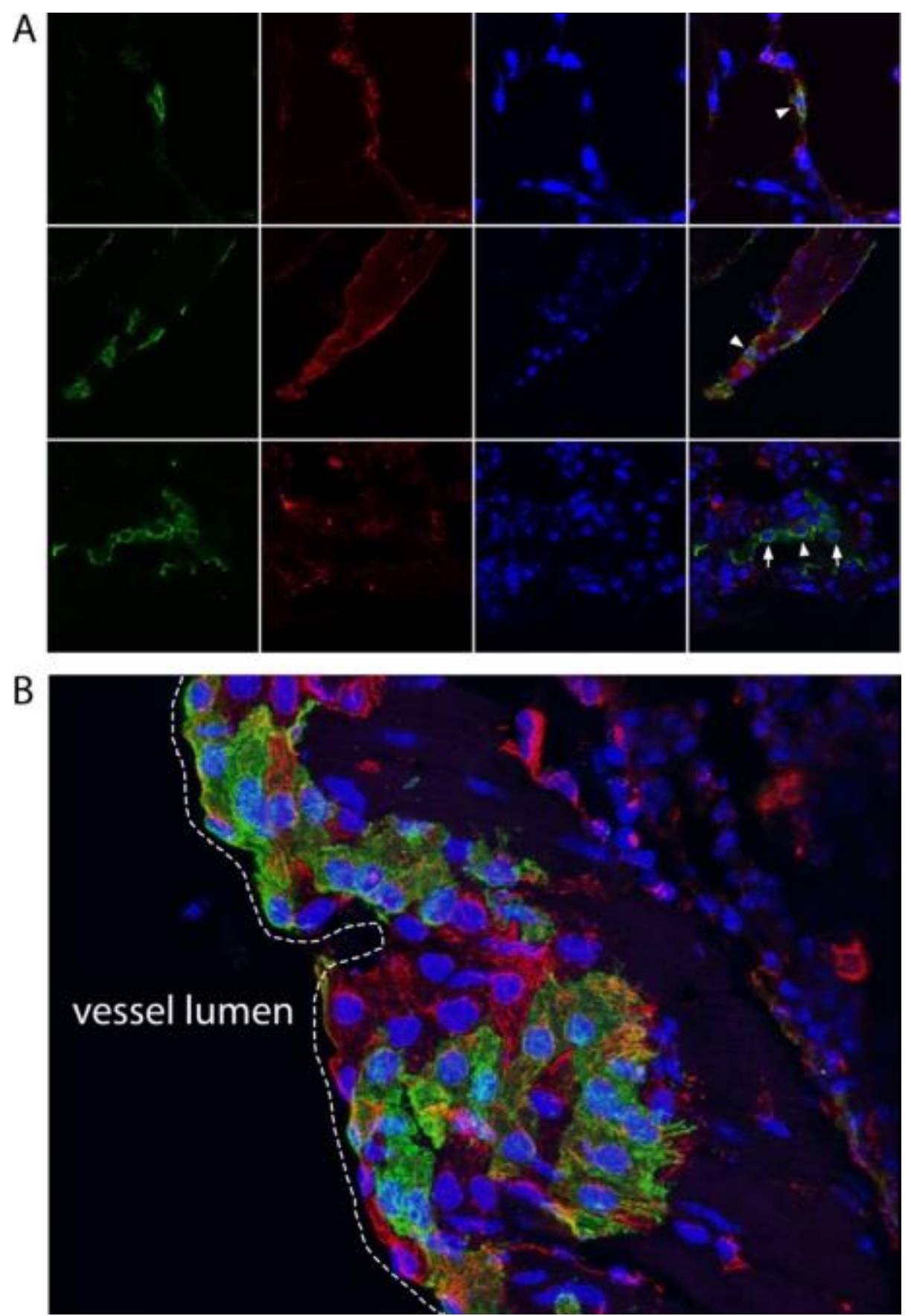

Figure 3.6 Immunostaining of VIMENTIN on lung cryosections.

VIMENTIN positive (arrowhead) and negative (arrow) GFP+ cells were identified at various locations in the lung $(A), 3 D$ projection from confocal z-stack images (B) confirmed that primary tumor derived GFP + metastatic melanoma cells expressed mesenchymal cell marker VIMENTIN. Green, GFP; red, VIMENTIN; blue, DAPI. 


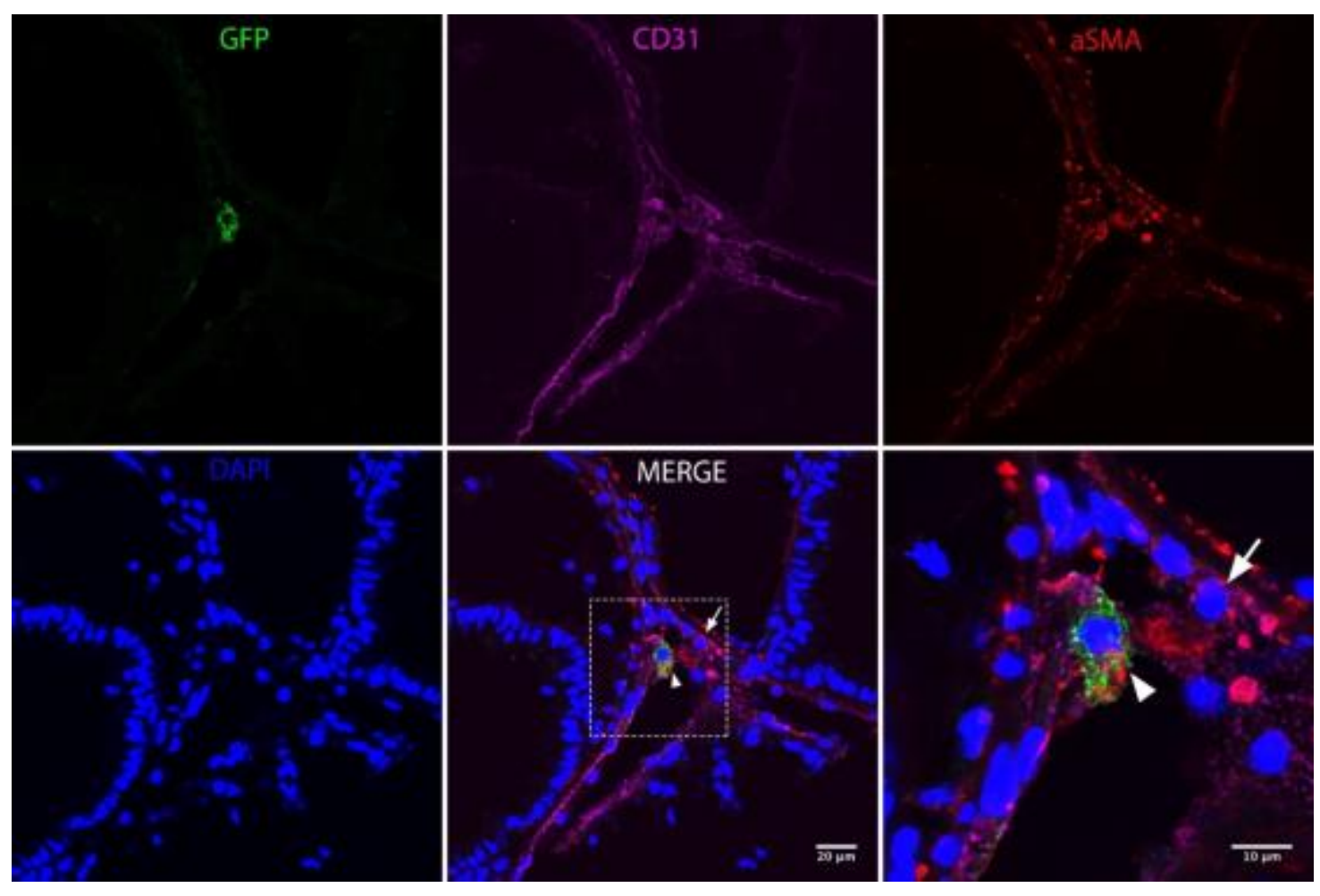

Figure 3.7 GFP+ metastatic tumor cell acquired mesenchymal marker $\alpha$-SMA expression in the lung.

GFP + cell (arrowhead) maintained endothelial cell marker CD31 and acquired the expression of mesenchymal cell marker $\alpha$-SMA, indicating an intermediate state of EndMT. A CD31+/ $\alpha$-SMA+/ GFP- cell (arrow) in close proximity to the GFP+ cell shows the same phenotype. It is possible that this is an authentic vascular endothelial cell undergoing EndMT, or a metastatic cell that was not labeled with GFP. Lower right picture shows a higher magnification of the boxed area. Green, GFP; red, $\alpha$-SMA; blue, DAPI; magenta, CD31. 

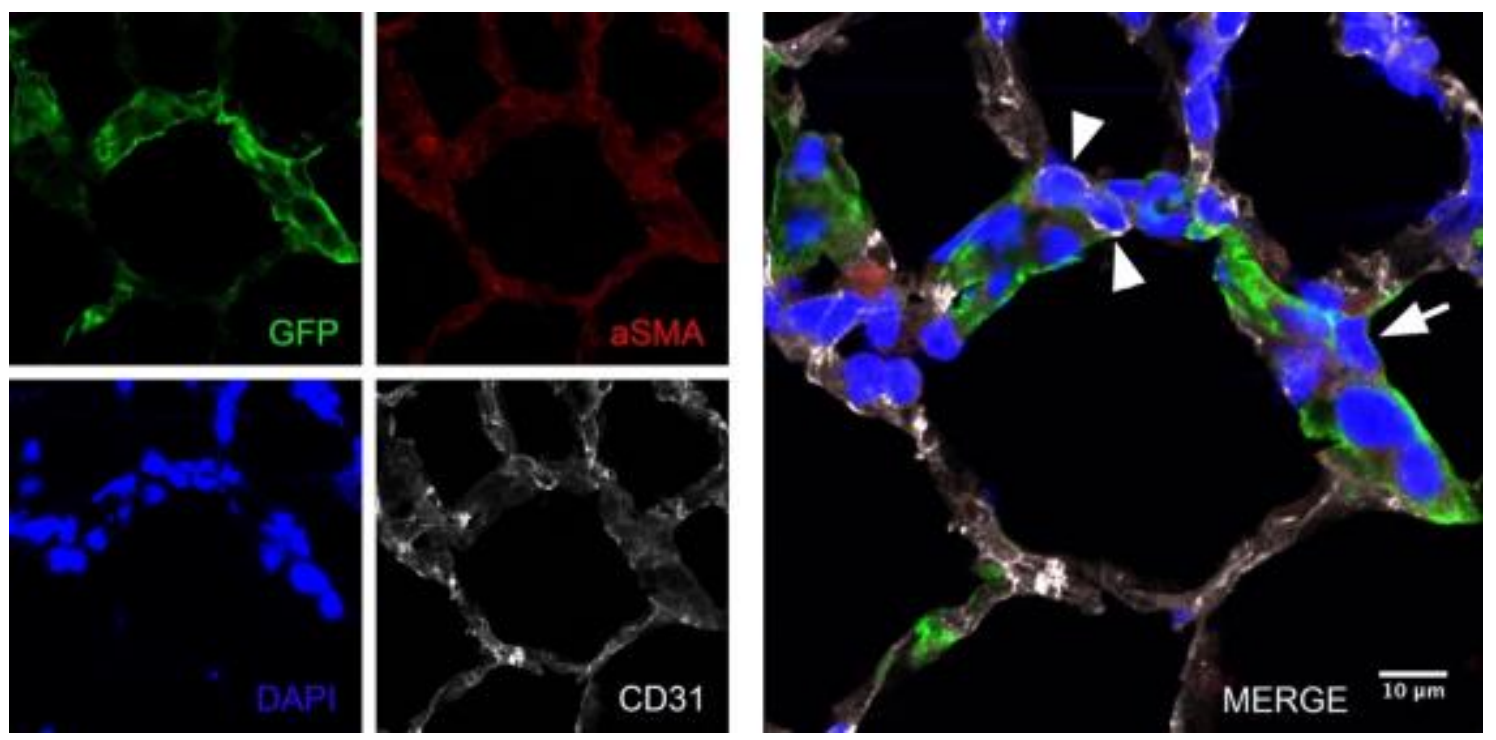

Figure $3.8 \alpha-S M A$ and CD31 immunostaining on lung sections.

A cluster of GFP+ cells located at the alveolar capillary. Both CD31-/ $\alpha-S M A+$ (arrow) and CD31+/ $\alpha-S M A+$ (arrowhead) GFP+ cells were found. No cell with strong CD31+/ $\alpha$-SMA- immunoreactivity was found in this view. Green, GFP; red, $\alpha$-SMA; blue, DAPI; gray, CD31. 


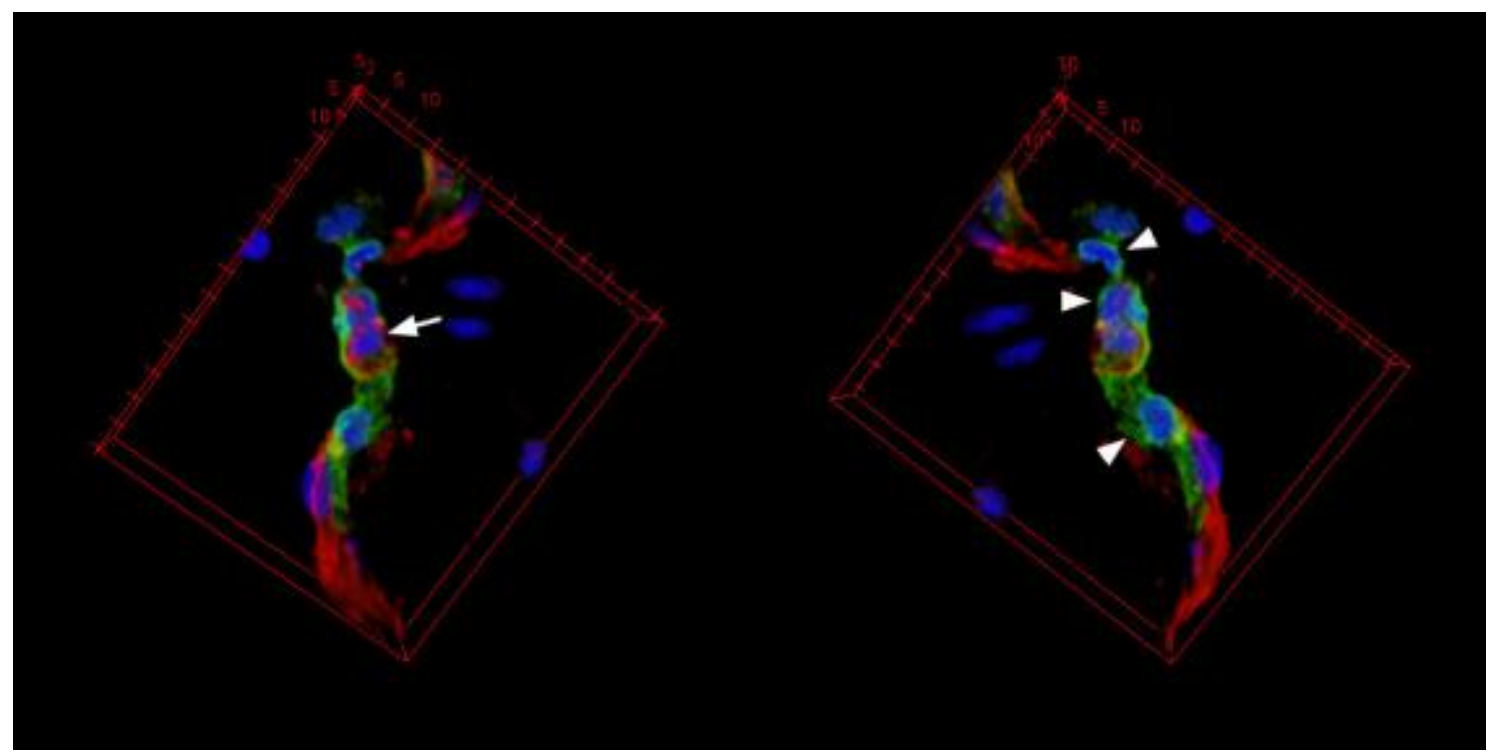

Figure 3.9 3D reconstruction of GFP+ cells located in the pulmonary artery.

$3 \mathrm{D}$ reconstruction of GFP + cells in lung cryosection showed three $\alpha$-SMA negative GFP + cells (arrowhead) wrapped around one $\alpha$-SMA positive smooth muscle cell (arrow). GFP, green; red, $\alpha$-SMA; blue, DAPI. 


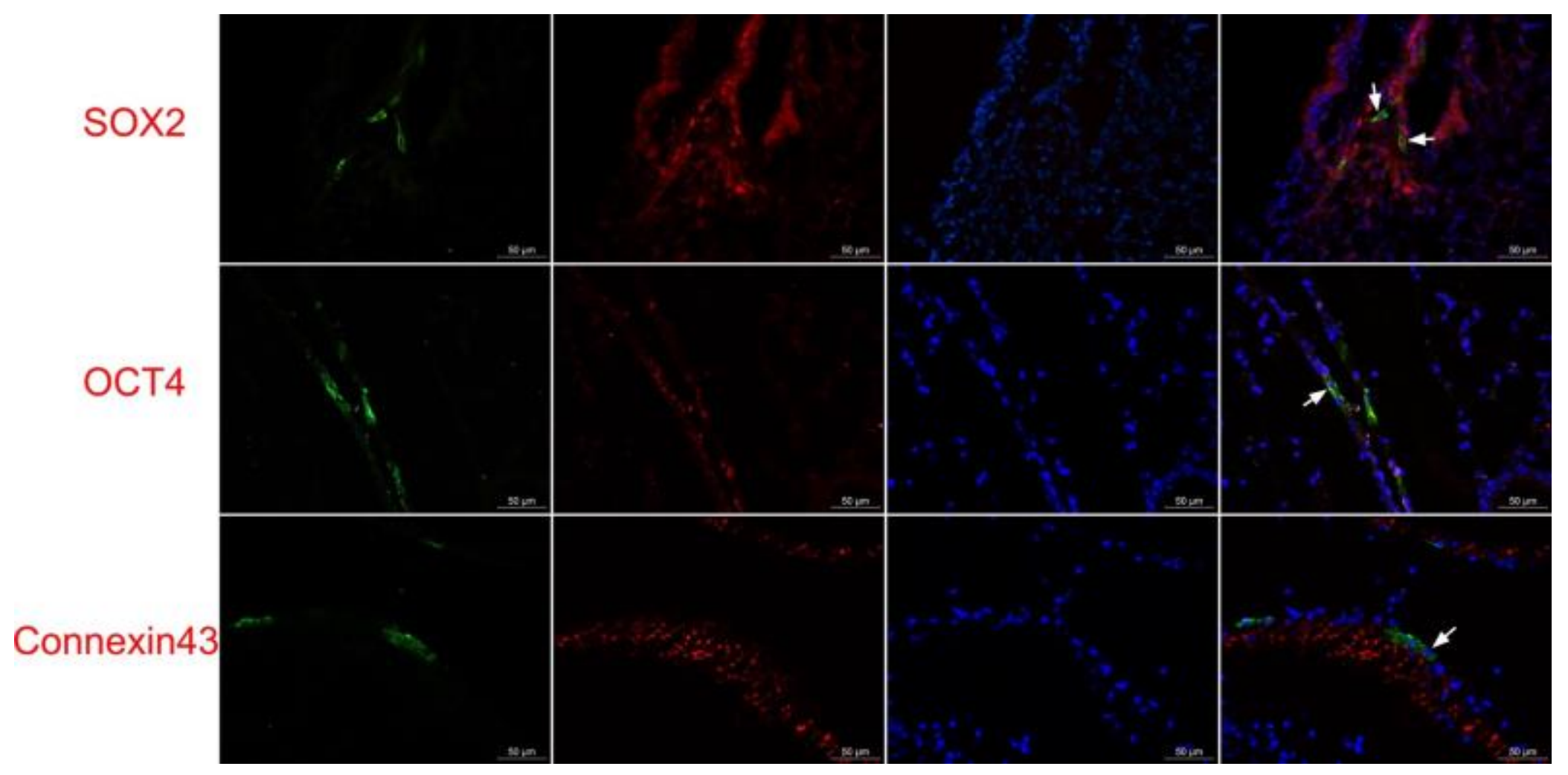

Figure 3.10 Plasticity of GFP+ cells associated with the lung vasculature.

Immunostaining on lung cryosections was performed. Intravascular GFP+ cells showed stem cell marker SOX2 and OCT4 immunoreactivity. A subpopulation of GFP+ cells expressed gap junction protein connexin43. Arrows indicate the immunoreactive GFP+ cells. 

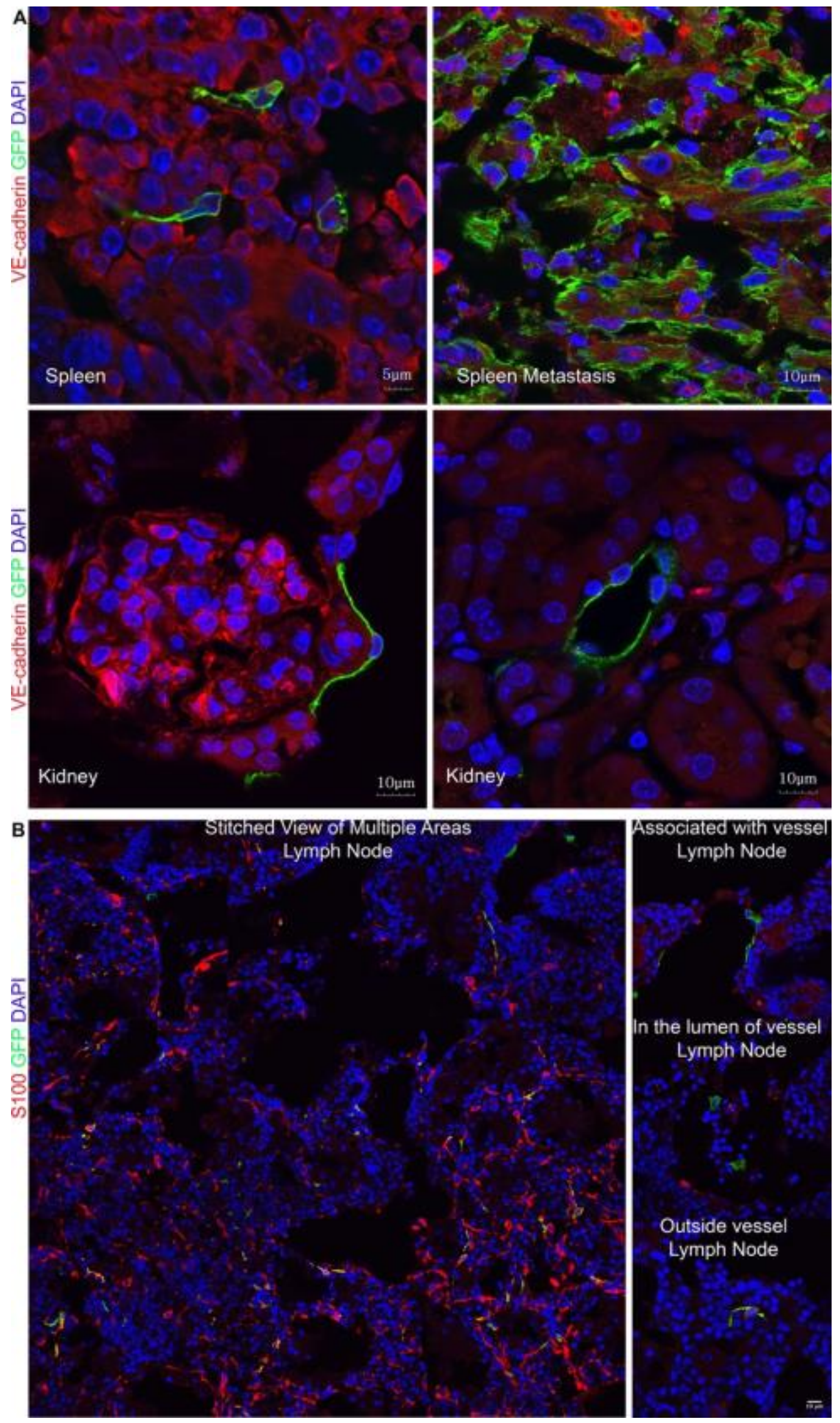
Figure 3.11 Plasticity and heterogeneity of melanoma metastatic cells in other organs.

Immunostaining of various markers in spleen, kidney and lymph nodes from DctGrm1/K5-Edn3/TYR-CreER ${ }^{T 2} / m T / m G$ mice. Primary tumor derived GFP+ cells scattered in the spleen had undetectable VE-cadherin expression while GFP+ cells inside the metastatic foci in the spleen showed strong VE-cadherin expression (A, top panel). In the kidneys, no detectable or weak signal was detected on GFP + cell (A, lower panel). S100 staining was performed on lymph node cryosections where GFP + cells were found. GFP + cells associated with the vascular endothelium or within the lumen were negative for $S 100$ (B). 


\section{CHAPTER}

4. CONCLUSIONS AND FUTURE DIRECTIONS 


\subsection{Conclusions}

Melanoma is not the most common type of skin cancer, but it causes the most deaths. It is notorious for the high propensity to metastasize and poor response to therapies. Numerous questions remain unanswered regarding the process of melanoma metastasis, which is partially due to the lack of proper melanoma metastasis mouse models. The Dct-Grm1/ K5-Edn3 mice not only spontaneously develop melanoma tumors on the ear, tail and dorsal skin, but also show metastases in the lung, providing an ideal system to identify the intrinsic tumor initiating capacity of specific cell subpopulations within an unperturbed tumor environment.

Using Cre/loxp system, I was able to label the primary tumor resident Tyr expressing cells with GFP and perform lineage tracing of the GFP+ cells during metastasis in the Dct-Grm1/ K5-Edn3 mice. I showed that the primary tumorderived differentiated Tyr expressing cell subpopulation or their progeny possessed metastasis-initiating capacity and exhibited phenotypic plasticity during the metastatic process. The GFP+ metastatic melanoma cells could reach the distant organs and seed metastases successfully. Numerous GFP+ cells were detected inside the vasculature and established strong association with the vascular endothelium in the organs where metastases were identified. Interestingly, GFP + cells lost the pigmentation as well as melanocytic lineage

markers upon contact with the vascular endothelium was established. Vasculature-associated GFP+ cells did not express melanoma stem cell markers, 
however, they mimicked vascular endothelial cells by expressing CD31 and VEcadherin. Three-dimensional reconstruction by confocal microscopy further identified the endothelial cell mimicry of GFP+ cells. The phenomenon was also observed in the lymphatic vessels of lymph nodes. The phenotypic plasticity of metastatic GFP+ cells was also corroborated by the fact that GFP+ cells lost the endothelial cell marker expression and resumed pigment production when populating the metastatic foci. Furthermore, the morphology and distinct phenotypic entities of GFP+ cells in different metastatic organs substantiated the plasticity of metastatic melanoma cells.

GFP + cells in the lung vasculature were found positive for mesenchymal markers $\alpha$-SMA or VIMENTIN. Assuming that the intravascular GFP+ cells were the potential metastasis-initiating cells in the lung of Dct-Grm1/ K5-Edn3/ TYRCreER $R^{T 2} / \mathrm{mT} / \mathrm{mG}$ mice, I propose a two-step mechanism underlying melanoma metastasis that involves melanoma-endothelial cell transition at the primary tumor site and EndMT at the metastatic site. The proposed model based on the experimental observations and implied suggestions for the process of melanoma metastasis in the Dct-Grm1/ K5-Edn3/ TYR-CreERT2/ $\mathrm{mT} / \mathrm{mG}$ mouse is summarized in Figure 4.1.

In conclusion, I have provided direct evidence that a specific cell subpopulation within the primary tumor possesses tumor initiating capacity in the context of metastasis. Lineage tracing of the metastatic melanoma cells in vivo indicated the phenotypic plasticity of cancer cells. My results will not only enhance our understanding of melanoma metastasis, but also provide insights 
for the diagnostics and re-examination of melanoma patients aiming at the detection of "vascular hidden" metastatic melanoma cells.

\subsection{Future Directions}

The heterogeneity of tumors including melanoma has been recognized for decades addressing the varied tumor initiating capacities of cell subpopulations within the same solid tumors [1]. Although the cancer stem cell model has been proposed for melanoma [2], it remains controversial and several questions are still unanswered. In this study, I have shown that the more differentiated Tyr expressing cells or their progeny (GFP+) possessed metastasis-initiating capacities and seeded successful metastases in various distant organs of the Dct-Grm1/ K5-Edn3/ TYR-CreERT2/ $m T / m G$ mice. However, the exact subpopulation of the primary tumor derived GFP+ cells that initiated the distant metastasis is not clear. Considering this, it would be of great interest to isolate the circulating GFP+ cells and the lung vasculature-associated GFP+ cells in the Dct-Grm1/ K5-Edn3/ TYR-CreER ${ }^{T 2 / ~} \mathrm{mT} / \mathrm{mG}$ mice and characterize the tumorigenic capacities of these two populations. High deformability of Sox2expressing melanoma cells grown in 3D soft fibrin gels has recently been shown to facilitate the extravasation of metastatic cells [3]. Given the morphological plasticity of metastatic GFP+ cells I observed in the established lineage tracing system, it is worthwhile to test the mechanical stiffness of the two GFP+ cell subpopulations. RNA-sequencing would be another approach to further identify the mechanism underlying the distinct tumorigenic capacities, if any, between the circulating GFP+ cells and the lung vasculature-associated GFP+ cells. 
I proposed the melanoma-endothelial cell transition as the first step for Tyr expressing cells to successfully metastasize based on the finding that CD31+ GFP + cells were identified inside the vasculature at the primary tumor site. Most of the studies focusing on characterizing tumor derived endothelial cells have been carried out in the context of glioma. Hypoxia has been suggested as a promoter of glioma cell transdifferentiation [4, 5]. Although melanoma tumors from the Dct-Grm1/ K5-Edn3/ TYR-CreER T2/ $m T / m G$ mice were suggested to display hypoxic areas [6], I did not observe sufficient CD31+ GFP+ cells within the primary tumor mass. One possibility to explain this finding is that it was very difficult to detect single cells due to the extensive amount of pigmentation in the tumor sections. However, alternative factors other than hypoxia may be the trigger of melanoma to endothelial cell transdifferentiation. For example, lung carcinoma cells co-cultured with human microvascular lung endothelial cells became strongly positive for CD31 as a non-angiogenic process for blood supply [7]. To characterize the potential effects of tumor-endothelial cell contact in melanoma, it would be interesting to perform similar co-culture of human microvascular lung endothelial cells with human melanoma cells. To better replicate the context of my in vivo experiments, human melanoma cells overexpressing Grm1 would be the ideal cells to employ.

Furthermore, in the Dct-Grm1/ K5-Edn3/ TYR-CreERT2/ mT/mG mice, primary tumor derived GFP+ cells associated with lung vasculature were not proliferating or dying and the number of those intravascular cells far exceeded the number of metastatic foci in the lung. The above observations imply the 
features of metastatic dormancy. The presence of lung infiltrates surrounding the GFP + cell-containing vessels raises the question of why GFP+ cells were found embedded in the vascular endothelium. Suppression of the immune system in Dct-Grm1/K5-Edn3/TYR-CreERT2/ mT/mG mice will allow us to identify whether lymphocyte infiltrates are the main suppressor of extravasation or EndMT of GFP+ cells. Alternatively, the immune response observed is possibly a general phenomenon of metastasis, and the intravascular GFP+ cells are intrinsically programmed for remaining in a dormant state and can only be re-awaken upon exposure to as yet unidentified environmental factors. Further studies to determine both the intrinsic and extrinsic cues underlying entry into and exit from dormancy state would be very valuable.

Late recurrence has been observed in human melanoma patients [8], indicating the presence of residual cancer cells that escape the detection of available techniques. Based on my observations in the mouse model, it is highly possible that metastatic melanoma cells cease to express most, if not all, melanocytic features and masquerade themselves as other cell types and become clinically invisible. Labeling of primary tumor cells is impossible in human patients and the loss of pigmentation of the intravascular metastatic melanoma cells challenges their detection in metastatic organs. Other than the genetic tracing of tumor cells in mouse models, analysis of tumor specific chromosomal alterations[9-11] was used to identify the tumor derived endothelial cells in human samples. BRAF mutations are found in approximately $60 \%$ of somatic melanoma cases [12]. An antibody against BRAF V600E, the mutated form of 
BRAF, is commercially available. One possible alternative for detecting these "invisible" metastatic cells in human melanoma samples is to use immunostaining or flow cytometry with Anti-BRAF V600E and endothelial cell specific markers. If a population of double positive cells in the primary or metastasis melanoma samples can in fact be revealed, current strategies for melanoma metastasis diagnostics and metastasis-targeted therapies need to be enhanced taking the existence of these cells into consideration.

\subsection{References}

1. Reya, T., et al., Stem cells, cancer, and cancer stem cells. Nature, 2001. 414(6859): p. 105-111.

2. Regenbrecht, C., et al., Cancer stem cells in melanoma. Ecancermedicalscience, 2008. 2: p. 114.

3. Chen, J., et al., Efficient extravasation of tumor-repopulating cells depends on cell deformability. Sci Rep, 2016. 6: p. 19304.

4. Zhao, Y., et al., Endothelial cell transdifferentiation of human glioma stem progenitor cells in vitro. Brain Res Bull, 2010. 82(5-6): p. 308-12.

5. Soda, Y., et al., Transdifferentiation of glioblastoma cells into vascular endothelial cells. Proc Natl Acad Sci U S A, 2011. 108(11): p. 4274-80.

6. Chin, N., The Role of Endothelin 3 in Melanoma Progression and Metastasis. FIU Electronic Theses and Dissertations, 2015. 2286.

7. Kaessmeyer, S., et al., Lung cancer neovascularisation: Cellular and molecular interaction between endothelial and lung cancer cells. Immunobiology, 2014. 219(4): p. 308-14.

8. Ossowski, L. and J.A. Aguirre-Ghiso, Dormancy of metastatic melanoma. Pigment Cell Melanoma Res, 2010. 23(1): p. 41-56.

9. Streubel, B., et al., Lymphoma-specific genetic aberrations in microvascular endothelial cells in B-cell lymphomas. N Engl J Med, 2004. 351(3): p. 250-9. 
10. Pezzolo, A., et al., Tumor origin of endothelial cells in human neuroblastoma. J Clin Oncol, 2007. 25(4): p. 376-83.

11. Ricci-Vitiani, L., et al., Tumour vascularization via endothelial differentiation of glioblastoma stem-like cells. Nature, 2010. 468(7325): $p$. 824-8.

12. Davies, $\mathrm{H}$., et al., Mutations of the BRAF gene in human cancer. Nature, 2002. 417(6892): p. 949-54. 


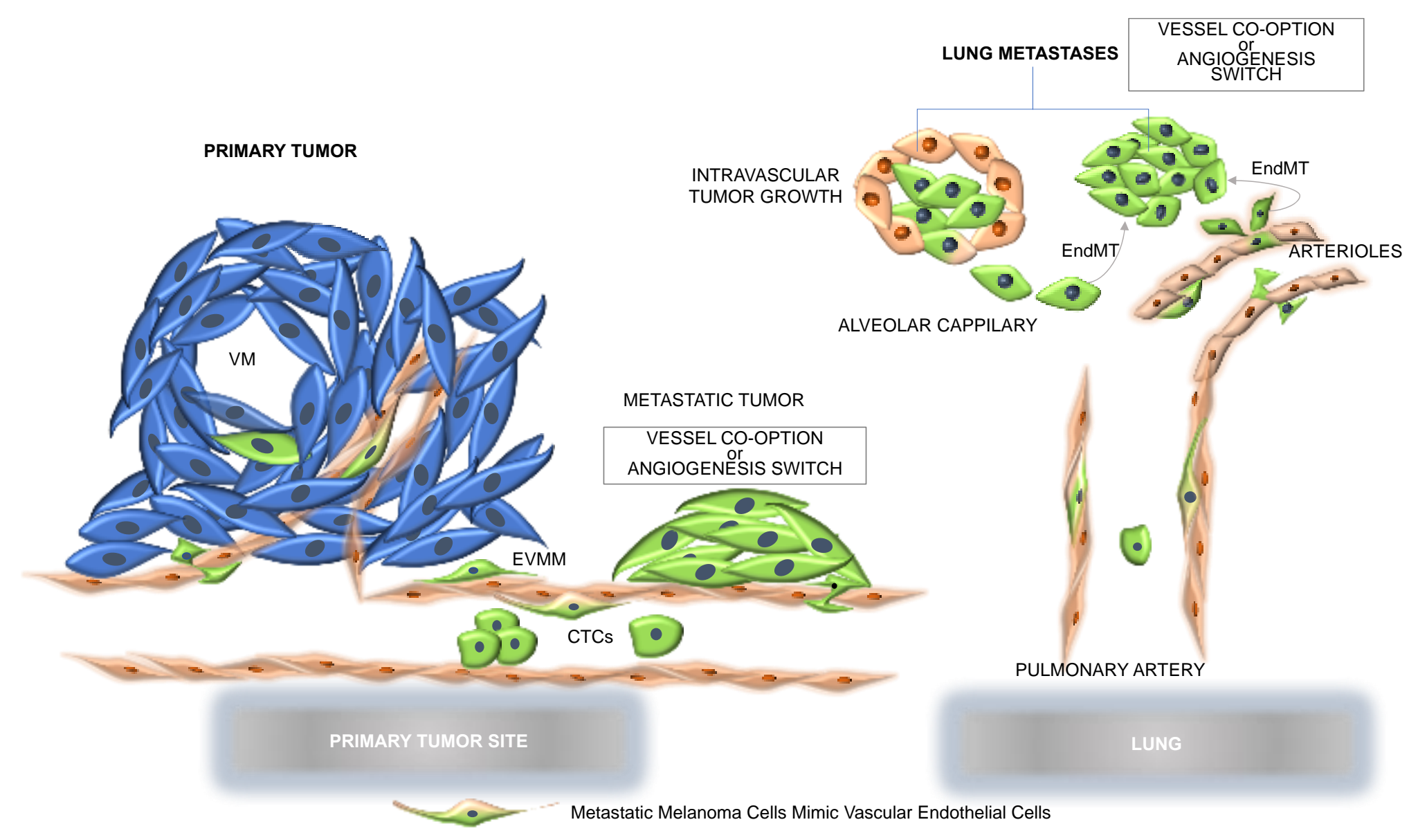


Figure 4.1 Diagram of melanoma metastasis in the Dct-Grm1/ K5-Edn3/ TYRCreER $R^{T 2} / \mathrm{mT} / \mathrm{mG}$ mice.

Primary tumor resident Tyr expressing cells express VE-cadherin, indicating VM. Metastatic Tyr expressing cells or their progeny (GFP+, green color cells in diagram) enter the vasculature through extravasation or transdifferentiate into CD31+ endothelial cells establishing associations with the vascular endothelium. Intravascular GFP+ cells move towards the metastatic site as circulating tumor cells (CTCs) or may roll over the vascular endothelium during endothelial mimicry. EVMM was only observed in metastatic tumor at the primary tumor site, not distant organs in the Dct-Grm1/ K5-Edn3/TYR-CreER ${ }^{T 2} / \mathrm{mT} / \mathrm{mG}$ mice. In the lung, intravascular GFP+ cells form metastases through extravasation and grow using angiogenesis or vessel co-option. A subset of CD31+ GFP+ cells in smaller pulmonary vessels went through EndMT, suggesting a potential mechanism for the metastasis-initiating capability of vasculature-associated metastatic cells. Intravascular growth of GFP+ cells in the pulmonary capillaries with subsequent extravasation when intravascular micro-metastatic foci outgrow the vessels they are in can be another source for metastases formation. 
MATERIALS AND METHODS 


\section{Mice and Genotyping}

The K5-tTA;TRE-Edn3-lacZ (K5-Edn3, for simplicity) mice, which overexpress Edn3 under the keratinocyte promoter Keratin 5 resulting in a hyperpigmentation phenotype due to the accumulation of melanocytes at the dermal-epidermal junction, were generated in our laboratory[1]. The $\operatorname{Tg}(G r m 1)$ Epv (E) mice (Dct-Grm1, for simplicity, a gift from Dr. William Pavan, NIH) [2]express the metabotropic glutamate receptor 1 under the regulation of the melanocyte specific Dopachrome tautomerase promoter and develop spontaneous melanocytic tumors on the ear and tail, but rarely metastasize. The progeny from the K5-Edn3 mice and Dct-Grm1 mice mating carrying all transgenes, Dct-Grm1/K5-Edn3, were used in this study as a melanoma mouse model. The Dct-Grm1/ K5-Edn3 mice not only spontaneously develop melanoma on the ear, tail and dorsal skin, but also metastasize to the lung with $80 \%$ penetrance.

To genetically label Tyrosinase expressing cells in the Dct-Grm1/ K5-Edn3 mice and establish an in vivo lineage tracing system, Cre/loxp system was used in this study. TYR-CreER $R^{T 2}$ mice are widely used for melanoma or melanocyte related studies. These mice have expression of CreER ${ }^{T 2}$ fusion protein directed by mouse Tyr promoter/enhancer regions. When bred with mice containing loxpflanked sequences, tamoxifen/4HT-inducible Cre-mediated recombination results in the deletion of the floxed sequences in the Tyr-expressing cells of the offspring. For the Cre-reporter mice, the bifluorescent mice $m T / m G$ [3] was selected due to the following reasons. First, it not only labels cells after Cre-mediated 
recombination, but also labels non-recombined cells. Second, the double fluorescent reporter genes in these mice simplify the visualization of recombined and non-recombined cells without the addition of an exogenous enzymatic substrate like $\beta$-Galactosidase used in LacZ reporter mice. Third, the membrane targeted tdTomato and GFP fluorescent proteins in $\mathrm{mT} / \mathrm{mG}$ mice allows the labeling to be visualized at single cell resolution which is important for lineage tracing. The Cre/loxp system in this study using $T Y R-C r e E R^{T 2}$ and $m T / m G$ mice will be established through the mating of those two mouse strains resulting in the offspring TYR-CreERT2/mT/mG mice.

The genotyping of the Dct-Grm1/K5-Edn3/TYR-CreER $R^{T 2} / m T / m G$ mice was carried out by DNA extraction from a small piece of the tail using standard procedures and followed by PCR using the appropriate primers (Table S2) for each transgene $([1,2]$, The Jackson Laboratory). Mice were housed in the University Animal Care Facility at Florida International University. The animal protocol was approved by the Committee on Animal Care and Use and Office of Sponsored Research at Florida International University and all Institutional Animal Care and Use Committee regulations were followed.

\section{HT Topical Painting on Tumors}

Topical administration of $4 \mathrm{HT}$ was performed by preparing a $50 \mathrm{mg} / \mathrm{ml}$ solution of 4HT (Sigma, H6278) in DMSO and applying enough solution to wet the tumors with a small paint brush. Dct-Grm1/ K5-Edn3/TYR-CreER ${ }^{T 2} / \mathrm{mT} / \mathrm{mG}$ mice were monitored for tumor appearance on the tail and dorsum. As soon as the first tumor appeared, we topically painted $4 \mathrm{HT}$ on the primary tumors twice a 
day for three consecutive days during $3 \sim 4$ weeks to ensure the labeling of most Tyr expressing cells within the primary tumors. Mice were monitored for primary tumor growth until 30 weeks, unless euthanasia was necessary due to poor health. As such, mice were euthanized at different times after the first painting that varied from 2 weeks to 30 weeks. After euthanasia, tumor burdened mice were examined for the presence of metastases in the lungs as well as other organs under the dissecting microscope. Pigmented lesions in the lung ranged from large macro-metastatic tumors ( $>1 \mathrm{~mm}$ in diameter) to smaller pigmented lesions that were clearly visible with the naked eye (pepper-like micrometastases) or much smaller micro-metastases that were only visible under a dissecting microscope.

\section{Immunofluorescence Staining}

Harvested organs were fixed in $4 \%$ paraformaldehyde (PFA) overnight at $4^{\circ} \mathrm{C}$ and washed in $1 \mathrm{X}$ PBS. Organs were cryo-protected by sequential immersion in $15 \%$ and $30 \%$ sucrose and then embedded with OCT. $10 \mu \mathrm{m}$ sections were obtained for immunofluorescence staining. Sections were incubated in blocking buffer (10\% normal serum, $0.3 \%$ Triton $\mathrm{X}-100,1 \% \mathrm{BSA}$ power) at room temperature for 1 hour and followed by primary antibody incubation at room temperature for 1 hour or at $4^{\circ} \mathrm{C}$ overnight. Primary antibodies were diluted in dilution buffer (1\% BSA, $1 \%$ normal serum, $0.3 \%$ Triton $X-100)$. Sections were thoroughly washed before incubation in secondary antibodies for 1 hour at room temperature. Sections were mounted with fluoroshield mounting medium with DAPI (Abcam, ab104139) and visualized on a 
Leica Leitz DMRB fluorescent microscope or Olympus Confocal BX61 microscope. For pigment bleaching on primary tumor sections, slides were incubated in $10 \% \mathrm{H}_{2} \mathrm{O}_{2}$ in PBS at room temperature for about 16 hours followed by regular immunostaining. Where necessary, tissue GFP and tdTomato fluorescence from the $\mathrm{mT} / \mathrm{mG}$ allele were photobleached by treatment with $3 \%$ $\mathrm{H}_{2} \mathrm{O}_{2}$ in methanol and illumination on a fluorescent light box for 4 hours to overnight at $4^{\circ} \mathrm{C}$. GFP signal was amplified by anti-GFP antibody if necessary.

Primary antibodies used: GFP (1:500, Aves Labs, GFP-1020), Ki67 (1:200, Abcam, ab15580), Cleaved Caspase 3 (1:200, CST, 9664s), Rat CD31 (1:200, eBioscience, 14-0311-82), Rabbit CD31 (1:200, Abcam, ab28364), CD45 (1:200, Biolegend, 103101), CD3 (1:200, Novusbio, NB600-1441), P75 (1:200, Millipore, ab1554), Nestin (1:50, Millipore, MAB353), SOX10 (1:50, Santa cruz, sc17342), TYR/TRP1 (1:200, gift from Dr. Vincent Hearing), LYVE-1 (1:200, eBioscience, 14-0443-80), VE-cadherin (1:200, Abcam, ab33168), SOX2 (1:200, Abcam, ab97959), OCT4 (1:200, Abcam, ab18976), Connexin43 (1:200, CST, 3512), S100 (1:200, Sigma, S2644). Secondary antibodies used: anti-chicken 488 (1:500, Abcam, ab150169), anti-rabbit 594 (1:400, Invitrogen, A11012), antirabbit 647 (1:400, Abcam, ab150075), anti-rat 647 (1:400, Abcam, ab150159).

\section{H\&E Staining of Lung Cryosections}

Cardiac perfusion with PBS was performed immediately after euthanasia. After the PBS perfusion, lungs were infiltrated with OCT through the trachea by a 18G needle. Sections were subjected to $\mathrm{H} \& \mathrm{E}$ staining as follows: $\mathrm{dH} 2 \mathrm{O}$ for 30 secs; Gill's Hematoxylin 3 (VWR, 87001-924) for 5 mins; running tap water for 1 
min; Clarifier (VWR, 89237-218) for 15 secs; $\mathrm{dH} 2 \mathrm{O}$ for 30 secs; Bluing Agent (VWR, 95057-852) for 45 secs; $\mathrm{dH} 2 \mathrm{O}$ for 30 secs; $95 \%$ ethanol for 15 secs; Eosin (poly scientific R\&D Crop, s2186) for 45 secs; $95 \%$ ethanol for 30 secs; $100 \%$ ethanol for 10 secs; Xylene for 15 secs; Xylene for 1 min; dry slides and mount with cytoseal (xylene-based medium).

\section{Counting of Ki67+ or Caspase 3+ Intravascular GFP+ Cells in the Lung}

15 non-parallel lung cryosections per Dct-Grm1/ K5-Edn3/ TYR-CreERT2/ $m T / m G$ mouse $(\mathrm{n}=3)$ were immunostained for Ki67 or Caspase 3 together with GFP. Total intravascular GFP+ cells were counted for each mouse. Among the intravascular GFP+ cells counted, double positive (Ki67+GFP+ or Caspase $3+G F P+)$ cells were counted. Total number of intravascular GFP+ cells varied from 29 to 243 per mouse. Percentage of Ki67+ or Caspase 3+ intravascular cells was obtained through double positive intravascular cells/total intravascular GFP+ cells.

\section{Timing of Metastatic Cell Dissemination}

Adult Dct-Grm1/ K5-Edn3/ TYR-CreER ${ }^{T 2} / \mathrm{mT} / m G$ mice were separated into three groups based on the stage of tumor development on the tail: 1) before nevus stage, where no noticeable tumor or nevus was observed;2) nevus stage, where the lesion was less than $1 \mathrm{~mm}$ in height; 3 ) tumor stage, where a clearly detectable tumor had formed. 4-HT was topically applied to the nevus/tumor site by a small painting brush twice a day for three consecutive days. For the before nevus stage, 4-HT was applied to the tail of Dct-Grm1/ K5-Edn3/ TYR-CreERT2/ $m T / m G$ mice that were 8-month-old yet without detectable tumor or nevus. The 
proximal $3-4 \mathrm{~cm}$ of the tail where lesions generally develop was $4 \mathrm{HT}$ painted twice a day for three consecutive days.

Whole Mount Confocal Imagining and Immunofluorescence Staining of Blood Vessels

A small segment (2-3mm length) of pulmonary artery, pulmonary vein, thoracic aorta or abdominal aorta was used for whole mount imaging or staining. The vessel segments were dissected and fixed in fresh $4 \%$ PFA in PBS at $4^{\circ} \mathrm{C}$ overnight. For confocal imaging, the vessels were cut open and mounted flat on glass slides with fluoroshield mounting medium with DAPI (Abcam, ab104139). For immunofluorescence staining, vessels were cut open and washed in $1 \%$ Triton X-100 in PBS for 40 minutes and blocked in 1\% Triton X-100, 10\% FBS in PBS for 90 minutes at room temperature. Primary antibodies were diluted in blocking buffer as described previously; vessels were incubated with primary antibodies in $0.5 \mathrm{~mL}$ PCR tube at $4^{\circ} \mathrm{C}$ for 20 hours with shaking. After PBS washing for 30 minutes twice, secondary antibodies were applied in blocking buffer for 2 hours. Vessels were washed in PBS thoroughly and mounted with fluoroshield mounting medium with DAPI. Z-stack images were taken from the top layer (endothelial layer) to the bottom layer (smooth muscle layer) at a step size 0.5 to $1 \mu \mathrm{m}, 30$ to $60 \mathrm{z}$-slice images were taken with Olympus Confocal BX61 microscope. 3D reconstruction or 3D projection of the z-stack images was performed with Fiji-ImageJ software. 


\section{References}

1. Garcia, R.J., et al., Endothelin 3 induces skin pigmentation in a keratindriven inducible mouse model. J Invest Dermatol, 2008. 128(1): p. 131-42.

2. Pollock, P.M., et al., Melanoma mouse model implicates metabotropic glutamate signaling in melanocytic neoplasia. Nat Genet, 2003. 34(1): p. 108-12.

3. Muzumdar, M.D., et al., A global double-fluorescent Cre reporter mouse. Genesis, 2007. 45(9): p. 593-605. 
SUPPLEMENTARY FIGURES AND TABLES 


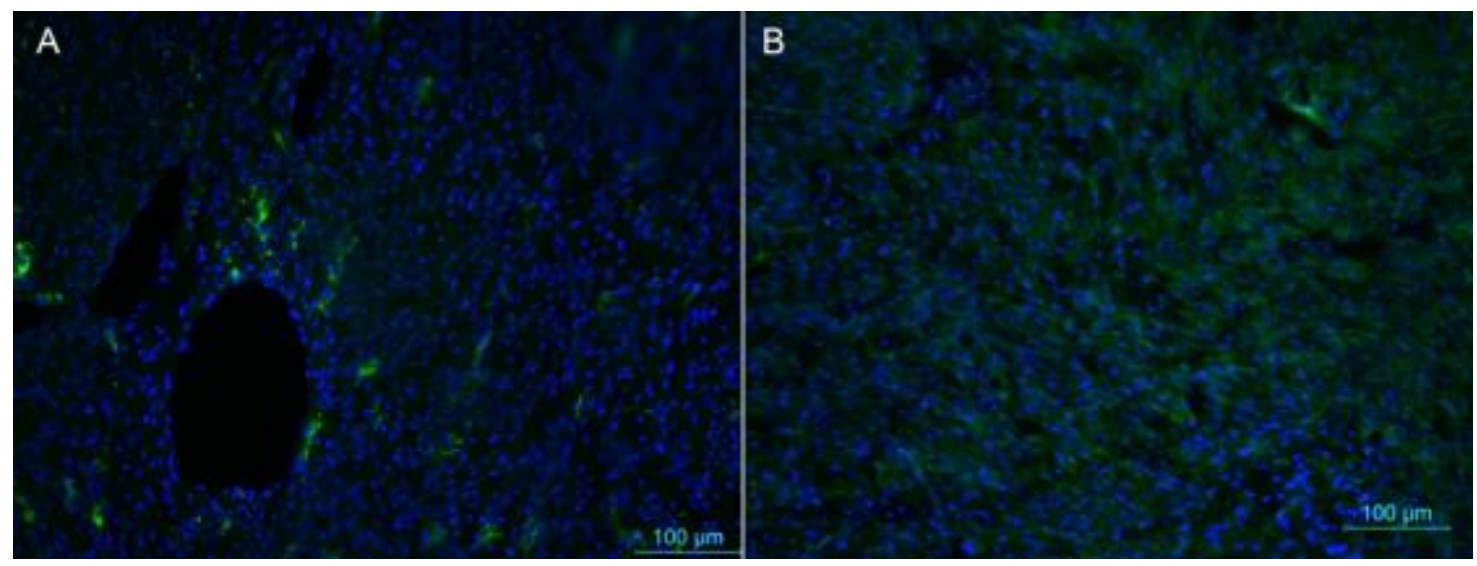

Figure S 1. GFP+ cells in the tail tumors after $4 \mathrm{HT}$ induction.

Primary tumor cryosections 7 months after the first $4 \mathrm{HT}$ painting. $4 \mathrm{HT}$ topical painting was performed once (twice a day for three consecutive days) when the tail tumor was at the nevus stage. Few GFP+ cells were identified in the tumor (A). 4HT topical painting was performed for 4 weeks since the nevus stage. Numerous GFP+ cells were found in the tumor (B). Sections were counterstained with DAPI (blue). 


\begin{tabular}{|c|c|c|c|c|c|c|}
\hline $\begin{array}{l}\text { Ear Tag\# } \\
\text { \&Genotype }\end{array}$ & $\begin{array}{l}\text { 4HT Painting } \\
\text { Site }\end{array}$ & $\begin{array}{l}\text { Painting } \\
\text { Times }\end{array}$ & $\begin{array}{l}\text { Lung } \\
\text { Metastasis }\end{array}$ & $\begin{array}{l}\text { GFP+ } \\
\text { Cells } \\
\text { in } \\
\text { Lung }\end{array}$ & $\begin{array}{l}\text { GFP+ } \\
\text { Cells in } \\
\text { Lymph } \\
\text { Nodes }\end{array}$ & $\begin{array}{l}\text { GFP+ } \\
\text { cells in } \\
\text { Other } \\
\text { Organs }\end{array}$ \\
\hline \#298* & tail tumor & 2 & $\begin{array}{l}\text { micro- } \\
\text { metastasis }\end{array}$ & no & no & $\mathrm{NA}$ \\
\hline$\# 875^{\star}$ & tail tumor & 5 & $\begin{array}{l}\text { micro- } \\
\text { metastasis }\end{array}$ & no & no & $\mathrm{NA}$ \\
\hline$\# 300^{*}$ & tail tumor & 5 & $\begin{array}{l}\text { micro- } \\
\text { metastasis }\end{array}$ & yes & no & $\mathrm{NA}$ \\
\hline$\# 396^{*}$ & $\begin{array}{l}\text { dorsal tumor } \\
\text { with } 2-3 \mathrm{~mm} \\
\text { in height }\end{array}$ & 3 & $\begin{array}{l}\text { micro- } \\
\text { metastasis }\end{array}$ & yes & no & NA \\
\hline$\# 471^{*}$ & tail tumor & 4 & no & no & NA & NA \\
\hline \#231* & tail tumor & 8 & $\begin{array}{l}\text { micro- } \\
\text { metastasis }\end{array}$ & no & yes & NA \\
\hline$\# 365^{\star}$ & tail tumor & 5 & $\begin{array}{l}\text { micro- } \\
\text { metastasis }\end{array}$ & no & no & NA \\
\hline$\# 946^{*}$ & $\begin{array}{l}\text { tail \& dorsal } \\
\text { tumor with 2- } \\
3 \mathrm{~mm} \text { in } \\
\text { height }\end{array}$ & $\begin{array}{l}\text { tail } 4, \\
\text { dorsal } 1\end{array}$ & $\begin{array}{l}\text { micro- } \\
\text { metastasis }\end{array}$ & yes & yes & $\mathrm{NA}$ \\
\hline \#997* & $\begin{array}{l}\text { tail \& dorsal } \\
\text { tumor }\end{array}$ & $\begin{array}{l}\text { tail } 1, \\
\text { dorsal } 5\end{array}$ & $\begin{array}{l}\text { micro- } \\
\text { metastasis }\end{array}$ & yes & yes & $\mathrm{NA}$ \\
\hline \#369* & $\begin{array}{l}\text { tail \& dorsal } \\
\text { tumor }\end{array}$ & $\begin{array}{l}\text { tail } 4 \text {, } \\
\text { dorsal } 7\end{array}$ & $\begin{array}{l}\text { pepper like } \\
\text { micro- } \\
\text { metastasis }\end{array}$ & yes & yes & $\mathrm{NA}$ \\
\hline \#443* & dorsal tumor & 4 & no & yes & yes & NA \\
\hline \#476* & dorsal tumor & 1 & $\begin{array}{l}\text { micro- } \\
\text { metastasis }\end{array}$ & no & yes & NA \\
\hline$\# 451^{*}$ & $\begin{array}{l}\text { tail \& dorsal } \\
\text { tumor }\end{array}$ & $\begin{array}{l}\text { tail } 3 \text {, } \\
\text { dorsal } 5\end{array}$ & $\begin{array}{l}\text { micro- } \\
\text { metastasis }\end{array}$ & yes & $\mathrm{NA}$ & $\mathrm{NA}$ \\
\hline \#479* & dorsal tumor & 10 & $\begin{array}{l}\text { macro- } \\
\text { metastasis }\end{array}$ & yes & yes & $\begin{array}{l}\text { spleen, } \\
\text { kidney }\end{array}$ \\
\hline$\# 425^{*}$ & tail tumor & 8 & $\begin{array}{l}\text { micro- } \\
\text { metastasis }\end{array}$ & no & NA & \\
\hline $\begin{array}{l}\text { Control }(\mathrm{n}=10) \\
\text { Dct-Grm1/K5- } \\
\text { Edn3/mT/mG }\end{array}$ & & $1 \sim 8$ & yes & no & NA & $\mathrm{NA}$ \\
\hline $\begin{array}{l}\text { Control }(\mathrm{n}=3) \\
\text { Dct-Grm1/ K5- } \\
\text { Edn3/ TYR- } \\
\text { CreER }{ }^{T 2 /} \\
m T / m G\end{array}$ & $\begin{array}{l}\text { dorsum } \\
\text { (before } \\
\text { nevus) }\end{array}$ & 1 & no & no & NA & $\mathrm{NA}$ \\
\hline
\end{tabular}


Table S 1. 4HT induction of GFP expression and lung metastasis.

Macroscopic metastases in other organs were only observed in mouse\#479, and GFP+ cells were found in those organs. When macroscopic metastases were not found, organs were not checked for GFP+ cells (NA), except brains (no GFP+ cells in any of the mice). Painting time " 1 " means $4 \mathrm{HT}$ topical application twice a day for three consecutive days. Every painting was performed for a duration of three or four weeks. All paintings started from nevus stage, unless specified, and lasted until the mouse was euthanized. Painting of dorsal tumors may have started post nevus stage because of the difficulty in detecting the nevi under the coat. For genotype, "*” indicates Dct-Grm1/ K5-Edn3/TYR-CreER ${ }^{T 2} / \mathrm{mT} / \mathrm{mG}$ experimental mice, genotypes of control mice were specified in table. 


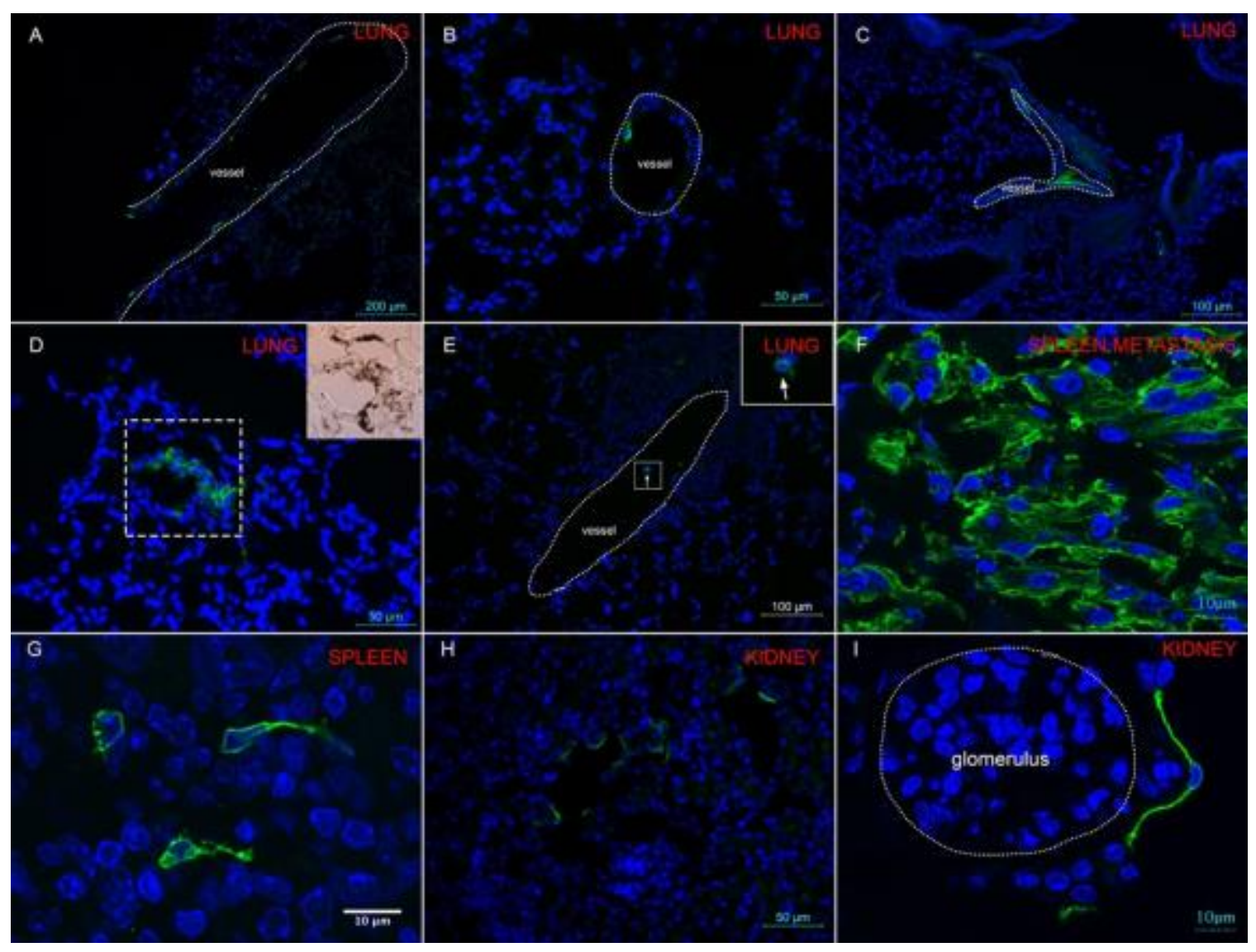

Figure S 2.Primary tumor derived GFP+ green cells were found in different organs.

A-E, lung; F-G, spleen; H-I, kidney. Note, most of the green cells were single cells with an elongated shape; clusters of cells were mostly confined to micrometastasis (D) or macro-metastasis ( $F$, pigmented lesion in the spleen). Most $\mathrm{GFP}+$ cells found in the lung vasculature were in close association with the vascular endothelium $(A-C)$ with rare cases in the lumen of the vasculature corresponding to the circulating cells (E). Scattered single GFP+ cells were detected in the spleen $(\mathrm{G})$, between the renal tubules $(\mathrm{H})$ and adjacent to glomeruli (I). 


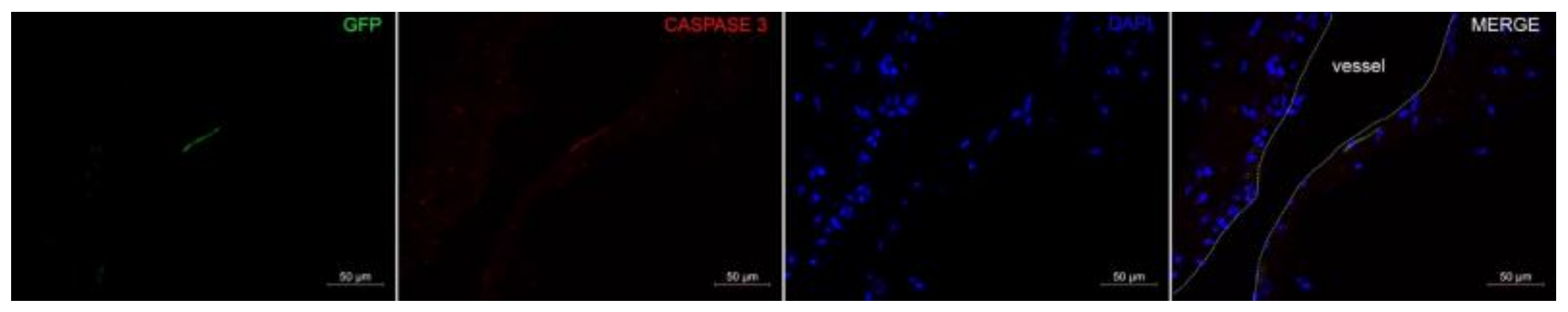

Figure S 3. Cleaved Caspase 3 staining on the lung.

One GFP+ cell in contact with the pulmonary vascular endothelium was positive for Caspase 3, indicating this cell underwent apoptosis. 


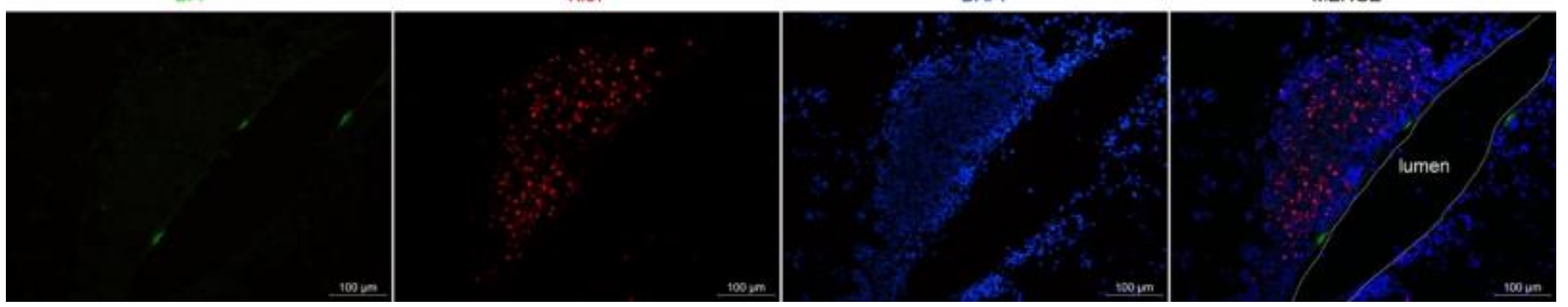

Figure S 4. Ki67 staining on lung perivascular infiltrates.

Most lymphocytes inside the infiltrates were Ki67 positive indicating the activation of immune response towards the emergence of GFP+ cells inside the vessels. 


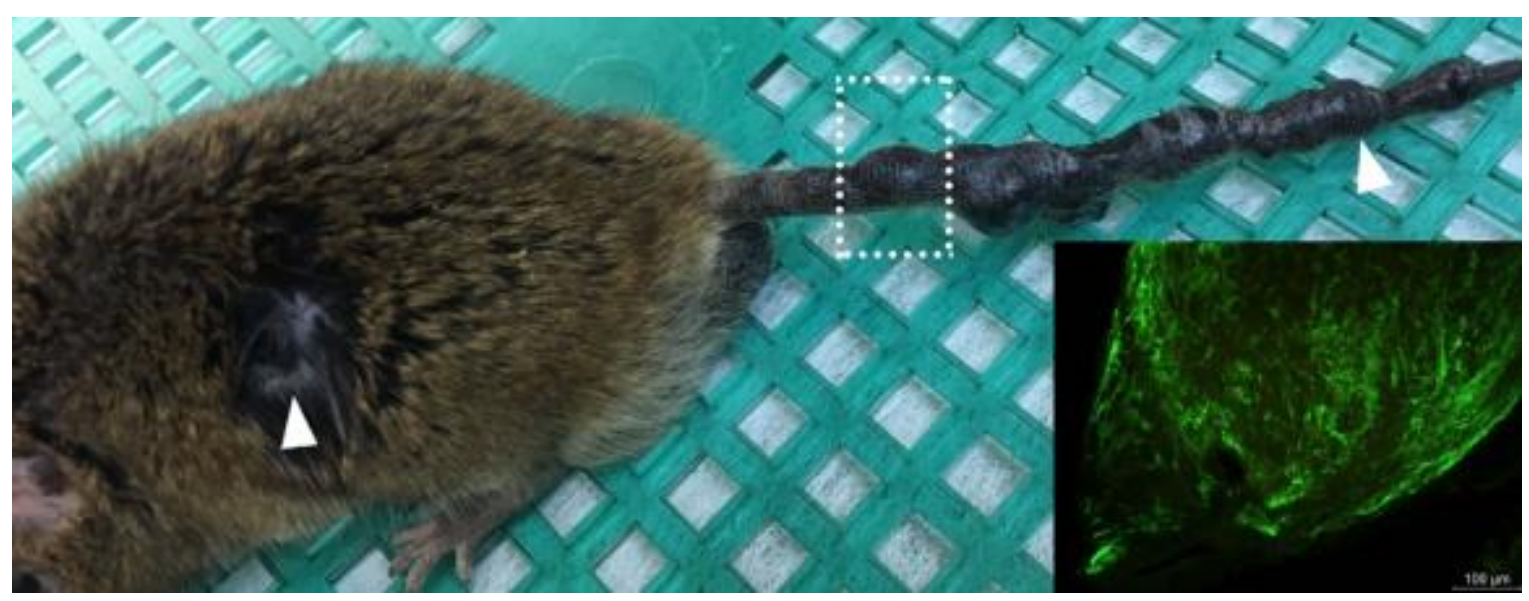

Figure S 5. Metastatic tumors on the skin.

4HT was applied to the dorsal tumor and distal tail tumor (arrowhead) of the DctGrm1/K5-Edn3/TYR-CreERT2/mT/mG mouse shown here. Proximal tail tumor (boxed area) was mostly constituted by GFP+ cells indicating it was a metastasis derived from the Tyr+ cells from the distal tail or dorsal tumor. 


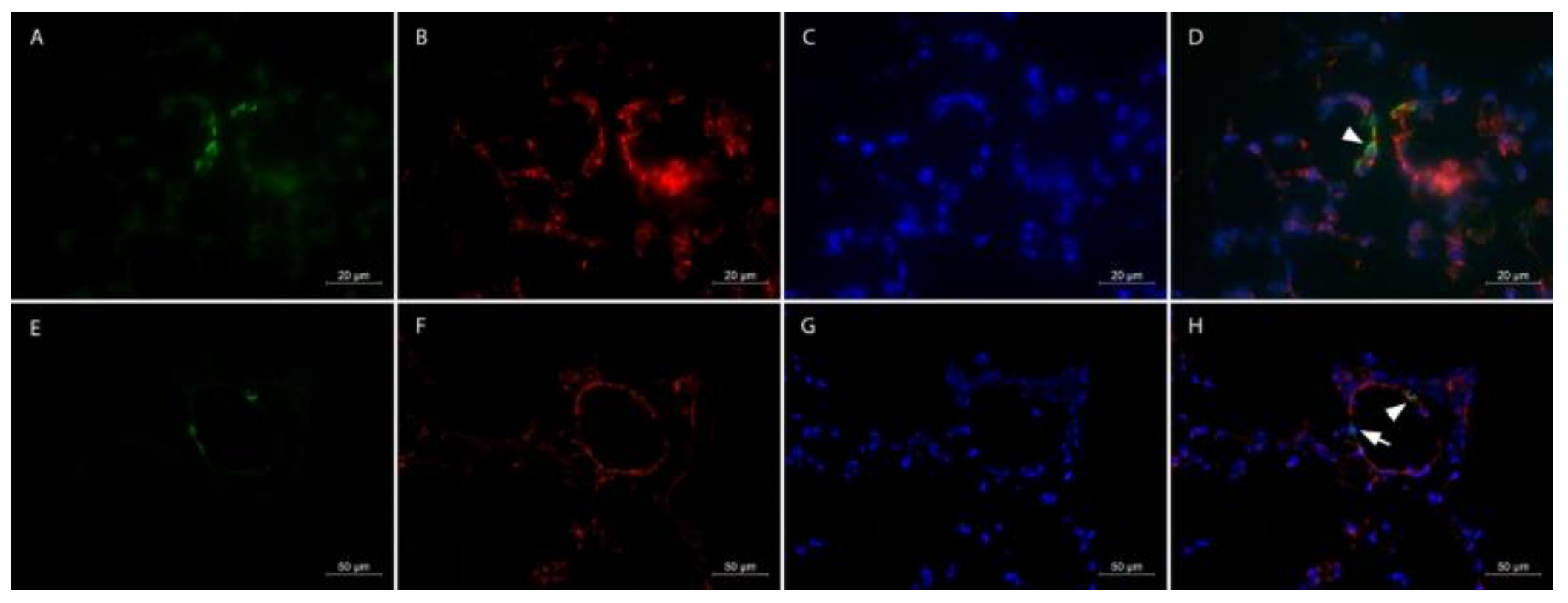

Figure S 6. GFP+ cells inside the alveolar capillaries were CD31 positive.

Lung cryosections $(A-H)$ depicting GFP + cells $(A, E)$ inside alveolar capillaries, were labeled with CD31 antibody (B, F) and counterstained with DAPI (C, D). Some GFP+ cells were CD31 positive (D, H, arrowhead) and some were not $(\mathrm{H}$, arrow) indicating the heterogeneity of metastatic tumor cells. 


\begin{tabular}{|c|c|}
\hline Gene & Sequence 5' --> 3' \\
\hline \multirow{3}{*}{$\begin{array}{l}\text { TYR- } \\
\text { CreER }{ }^{\top 2}\end{array}$} & CTC TGC TGC CTC CTG GCT TCT \\
\hline & CGA GGC GGA TCA CAA GCA ATA \\
\hline & TCA ATG GGC GGG GGT CGT T \\
\hline \multirow[t]{4}{*}{$\mathrm{mT} / \mathrm{mG}$} & GCG GTC TGG CAG TAA AAA CTA TC \\
\hline & GTG AAA CAG CAT TGC TGT CAC TT \\
\hline & CTA GGC CAC AGA ATT GAA AGA TCT \\
\hline & GTA GGT GGA AAT TCT AGC ATC ATC C \\
\hline \multirow[t]{2}{*}{ Dct-Grm1 } & CCGGGTCCGCATTAATCTTATCTA \\
\hline & GGTAGCATACGGTTCCACGCA \\
\hline \multirow[t]{4}{*}{ K5-Edn3 } & CCAGGTGGAGTCACAGGATT \\
\hline & ACAGAGACTGTGGACCACCC \\
\hline & GGCCTGTGCACACTTCTGT \\
\hline & TCCTTGTGAAACTGGAGCCT \\
\hline
\end{tabular}

Table S 2. Primers for mouse genotyping. 
VITA

XIAOSHUANG LI

2006-2010

2009

2010-2011

2011-2015

2015-2017

$2011-2017$

2014

2015

2016

2017
Bachelor's Degree

Biology Science-Animal \& Developmental Biology

Shandong University, Jinan, Shandong, China

Research Trainee

Institute of Development and Molecular Medicine

Fudan University, Shanghai, China

Research Assistant

Laboratory Animal Research Center

Institute of Biophysics, Chinese Academy of Science (CAS),

Beijing, China

Graduate Teaching Assistant

Department of Biological Sciences

Florida International University, Miami, FL, USA

Graduate Research Assistant

Department of Biological Sciences

Florida International University, Miami, FL, USA

PhD candidate

Department of Biological Sciences

Florida International University, Miami, FL, USA

BRI Summer Research Award

Florida International University, Miami, FL, USA

BRI Summer Research Award

Florida International University, Miami, FL, USA

BRI Summer Research Award

Florida International University, Miami, FL, USA

AACR WICR Scholar Award, Women in Cancer Research American Association for Cancer Research (AACR) Annual Meeting 2017, Washington, D.C., USA

SELECTED PUBLICATIONS AND PRESENTATIONS 
$\mathrm{Li}, \mathrm{X}$., Kos L (2015). Cellular origin of melanoma metastasis. $17^{\text {th }}$ Biomedical \& Comparative Immunology Symposium, Florida International University, Miami, FL, USA (Oral Presentation)

$\mathrm{Li}, \mathrm{X}$., Kos L (2015). Identification of the metastatic cell populations in a mouse model of melanoma. Society for Melanoma Research 2015 Congress, San Francisco, California, USA (Poster Presentation)

$\mathrm{Li}, \mathrm{X}$., Torres, R., Kos L (2016). Identification of the metastatic cell populations in a mouse model of melanoma. $18^{\text {th }}$ Biomedical \& Comparative Immunology Symposium, Florida International University, Miami, FL (Oral Presentation)

$\mathrm{Li}, \mathrm{X}$., Torres, R., Kos L (2017). Identification of the metastatic cell populations in a mouse model of melanoma. AACR Annual Meeting 2017, Washington, D.C., USA (Poster Presentation) 